\title{
Recent progress in instrumental techniques for architectural heritage materials
}

\author{
Chen Zhao ${ }^{1}$, Yiwen Zhang ${ }^{1}$, Chong-Chen Wang ${ }^{1,2^{*}}$, Miaole Hou ${ }^{2}$ and Aiqun Li ${ }^{1} 2^{*}$
}

\begin{abstract}
Both conservation and intervention methods must be compatible with each other and appropriate for the original building materials. Therefore, the characterization of historic building materials is indispensable for investigating chemical composition, micro-structure and morphological features to study the current condition, environmental influence and change mechanism due to natural aging or man-made decay processes. Given the great variety of chemicals which can be analyzed, complex problems related to architectural heritage materials are investigated via optimized methodologies. Among the existing techniques, optical microscopy (OM) is an inexpensive and dominating tool to obtain preliminary information on complex samples. Atomic force microscopy (AFM) can provide real three-dimensional topographies showing sample surface properties. Electron microscopes combined with energy dispersion X-ray analysis (EM-EDX) are the instruments specifically developed to acquire images of target materials at high magnification. Infrared and Raman spectroscopies are frequently used to characterize inorganic and organic compounds. Thermal analysis can rapidly and accurately measure changes in crystalline structure, dehydration and decomposition. X-ray based technologies have a wide range of applications as follows. X-ray fluorescence (XRF) is one of the most frequently used techniques for elemental analysis. X-ray diffraction (XRD) is a fast and inexpensive technique for the characterization of man-made and natural materials. X-ray photoelectron spectroscopy (XPS) is applied to quantify the valence and electronic levels of specific elements. X-ray absorption spectroscopy (XAS) is a powerful technique for detecting the electronic structure of matter. UV-visible (UV-vis) spectroscopy is also of great importance in architectural heritage, which can reveal different physicochemical mechanisms causing color. Laserinduced breakdown spectroscopy (LIBS) can effectively eliminate the pollution on the surface and detect the internal elements of the target material. Ion beam analysis can quantify trace elements with high sensitivity. Mass-based techniques are mainly applied to identify unknown organic substances at the molecular level. This review describes some classical applications of individual techniques and provides scientific support for scientists and engineers to make decisions in the context of architectural heritage.
\end{abstract}

Keywords: Architectural heritage, Materials, Characterization, Diagnostic survey, Conservation

\section{Introduction}

Historic architecture which includes numerous kinds of monuments/sites and ancient buildings has witnessed the creativeness and aesthetics of different nationalities in different regions. More importantly, the restoration and conservation of the historic architecture which is as an integral constituent of human civilization turn out to be a

\footnotetext{
*Correspondence: chongchenwang@126.com; liaiqun@bucea.edu.cn ${ }^{1}$ Beijing Key Laboratory of Functional Materials for Building Structure and Environment Remediation, Beijing University of Civil Engineering and Architecture, Beijing 100044, China

Full list of author information is available at the end of the article
}

global and worldwide issue [1-4]. As for the architectural heritage preservation, what must be taken into account are the factors which deal with issues of extending the life and preserving the authenticity and integrity of building characteristics such as design style and the constituent materials including sandstone [5-8], brick [9-11], glass [12-15], wood [16, 17], painting layer [18-20], mortar [21-24], wall material $[25,26]$, etc. Furthermore, in addition to the original material itself, ancient building materials have been suffering from decay and intervention in different processes [27]. Firstly, environmental conditions (e.g. pollutants in the immediate environment) [28-30]
Springer Open

(c) The Author(s) 2019. This article is distributed under the terms of the Creative Commons Attribution 4.0 International License (http://creativecommons.org/licenses/by/4.0/), which permits unrestricted use, distribution, and reproduction in any medium, provided you give appropriate credit to the original author(s) and the source, provide a link to the Creative Commons license, and indicate if changes were made. The Creative Commons Public Domain Dedication waiver (http://creativecommons.org/ publicdomain/zero/1.0/) applies to the data made available in this article, unless otherwise stated. 
can significantly change the composition and structure of building materials. Secondly, bio-deterioration can destroy the structural materials via mechanical interaction (e.g. plant root growth, formation of bio-films) and disassimilation (metabolites produced by microorganisms), and thus dramatically influences the aesthetic appearance and increases the cost of cleaning, conservation and maintenance for architectural heritage [31, 32]. Thirdly, some contaminants in the atmosphere, underground water, surface water and soil can damage the ancient building materials irreversibly. Natural pollutants are mainly inorganic salts and particulate matters (PM) $[33,34]$, whereas the anthropocentric pollutants include heavy metals, sulfur oxides, nitrogen oxides [26, 35], volatile organic compounds (VOCs), persistent organic pollutants (POPs) and many other organic and inorganic components [36-38] probably formed by multiple human activities such as energy production, transportation and agricultural activities [31,39]. The above-mentioned pollutants can interact with the building materials, influence their original properties or even play the role as catalysts to accelerate the damage of materials via physical, chemical or biological effects. As the conservation must make sure about the physical, chemical and structural aspects of the materials, environmental impact and deterioration processes, characterization of ancient building materials is beneficial for scientists or engineers to understand the chemical evolution in the past, predict the various trends in the future, choose the suitable restoration methods to preserve their present state, and even for them to describe the alteration process of materials and modification through time [40].

Years ago, both excessive interventions and a large number of applications of mismatched materials had given rise to damage effect and accelerated the decay process of architectural heritage [41]. However, a more scientific way in safeguard of the architectural heritage is to put into consideration: the existing technical specifications, mature criteria and credible methodology to reserve their authenticity and integrity. In essence, the decision-making should ensure the authenticity of materials and structures, employ the reliable techniques, remain the principal part of structures and surrounding environment, and estimate their social-economic influence $[42,43]$. In summary, scientific and efficient architectural heritage conservation requires practitioners to have deep understanding of building materials, to be qualified to diagnose existing problems precisely, and to assess the feasibility of protective materials and corresponding intervention methods.

With the spirit of International Charter for the Conservation and Restoration of Monuments and Sites (Venice Charter) adopted in 1964 [44], the conservation and restoration of monuments must have recourse to all sciences and techniques, which contributes a lot to the study and safeguard the architectural heritage. An increasing number of researchers apply modern high precision instruments to characterize the architectural heritage materials $[14,18,45,46]$. In this review, an overview of different types of characterization techniques used for historic building materials was presented (the major characteristics and the typical applications of each technique were summarized in Table 1), which included the optical microscopy (OM), atomic force microscopy (AFM), infrared spectroscopy (IR), Raman spectroscopy (RS), microscopy both in SEM and TEM, environmental scanning electron microscopy (ESEM), energy dispersion X-ray analysis (EDX), thermogravimetric analysis (TG), differential thermal analysis (DTA), differential scanning calorimetry (DSC), X-ray diffraction (XRD), X-ray fluorescence (XRF), X-ray photo-electron spectroscopy (XPS), $\mathrm{X}$-ray absorption spectroscopy (XAS), ultraviolet-visible spectroscopy (UV-vis), laser-induced breakdown spectroscopy (LIBS), ion beam analysis and mass-based molecular techniques. It is certain that any technique selected for the micro-analysis of architectural heritage materials will produce useful, precise and accurate results, and hence this paper will also provide successful characterization cases to help scientists, archaeologists and conservators to choose the most suitable approach for their study.

This section focuses on the frequently used analytical techniques for architectural heritage conservation, with an emphasis on chemical composition of the material, anthropocentric/natural environmental influence and deterioration mechanism. It is noteworthy that the listed techniques can be known as its applicability and specialty. For example, the OM/AFM/SEM/TEM/ESEM provide morphology and topography images; the UVvis/LIBS/FTIR/Raman/PIXE/PIGE/XRF give information both at elemental and molecular levels; the TG/DTA/ DSC measure the weight loss curves versus the temperatures and provide the corresponding thermal properties; the XRD/XPS/XANES/EXAFS identify the crystalline substances, chemical state and local environmental of all the targeted atoms in those samples. Furthermore, the MS-based techniques can provide molecular formula for it and identify the molecular structures. Moreover, many of them can offer higher spatial and spectral resolution because they can be combined with other techniques, such as microscopes and synchrotron radiation sources. In all, each sub-heading dedicates to the explanation of the results obtained by the individual technique concerning the architectural heritage (the structure and the technical route of this review were shown in Scheme 1). 
Table 1 The characteristics and major applications of each technique used in the field of architectural heritage conservation

\begin{tabular}{|c|c|c|c|c|}
\hline Analytical technique & Destructiveness & Portability & $\begin{array}{l}\text { Compatibility } \\
\text { with synchrotron } \\
\text { radiation sources }\end{array}$ & Typical applications \\
\hline $\mathrm{OM}$ & Micro-destructive/non-destructive & Portable & No & $\begin{array}{l}\text { Morphology characterization of mortar, black } \\
\text { crust, brick, ceramic, glass and the corre- } \\
\text { sponding decay processes }\end{array}$ \\
\hline AFM & Micro-destructive & Not portable & No & $\begin{array}{l}\text { Surface analysis (roughness, symmetry and } \\
\text { gloss level) of materials before and after } \\
\text { physical and chemical treatments }\end{array}$ \\
\hline SEM & Destructive & Not portable & No & $\begin{array}{l}\text { Surface characterization of mortar, pigment, } \\
\text { stone, etc. Equipped with EDX, it can provide } \\
\text { elemental analysis }\end{array}$ \\
\hline ESEM & Destructive & Not portable & No & $\begin{array}{l}\text { Morphology characterization of biological } \\
\text { deposition and biofilm }\end{array}$ \\
\hline TEM & Destructive & Not portable & No & $\begin{array}{l}\text { Cross-section characterization of formation } \\
\text { mechanism of inorganic and organic com- } \\
\text { pounds present in the interface of different } \\
\text { materials }\end{array}$ \\
\hline UV-vis & Destructive & Portable & No & $\begin{array}{l}\text { Characterization of pigment and stained glass } \\
\text { collected from ancient buildings. }\end{array}$ \\
\hline LIBS & Micro-destructive & Not portable & No & $\begin{array}{l}\text { Elemental and cross-section analysis for pig- } \\
\text { ment, stone, brick, etc }\end{array}$ \\
\hline FTIR & Destructive/non-destructive & Portable & No & $\begin{array}{l}\text { Identification of organic functional groups in } \\
\text { mortar, pigment, black crust, etc }\end{array}$ \\
\hline Raman & Destructive/non-destructive & Portable & No & $\begin{array}{l}\text { Characterization of pigment and dye used in } \\
\text { architectural heritage }\end{array}$ \\
\hline TG/DTA/DSC & Destructive & Not portable & No & $\begin{array}{l}\text { Identification of the degree of carbonation and } \\
\text { hydration reactions of mortars }\end{array}$ \\
\hline XRF & Destructive/non-destructive & Portable & Yes & $\begin{array}{l}\text { Major and trace elemental analysis for pig- } \\
\text { ment, stone, mortar, etc. Assessment of bio- } \\
\text { logical and pollution impact on architectural } \\
\text { materials }\end{array}$ \\
\hline $\mathrm{XRD}$ & Destructive & Portable & Yes & $\begin{array}{l}\text { Identification of crystalline phases of mortar, } \\
\text { brick, pigment, stone, additive, etc }\end{array}$ \\
\hline XPS & Destructive & Not portable & No & $\begin{array}{l}\text { Characterization of surface contamination or } \\
\text { corrosion products }\end{array}$ \\
\hline XAS (XANES/EXAFS) & Non-destructive & Not portable & Yes & $\begin{array}{l}\text { Detection of specific elements presented in } \\
\text { glass, pigment, stone, ceramic, metal, mortar, } \\
\text { wood, etc }\end{array}$ \\
\hline PIXE/PIGE & Non-destructive & Not portable & No & $\begin{array}{l}\text { Identification of elements at trace level pre- } \\
\text { sented in pigment, glass, mortar, etc }\end{array}$ \\
\hline MS-based techniques & Destructive & Not portable & No & $\begin{array}{l}\text { Identification and quantification of unknown } \\
\text { organic compounds at molecular level }\end{array}$ \\
\hline
\end{tabular}

\section{Results and discussion}

Imaging techniques at different scales

Optical and atomic force microscopy analysis

The optical microscopy $(\mathrm{OM})$ with polarized light is one of the most frequently-applied tool in the mineralogical and petrographic investigation of minerals and rocks of ancient buildings [40]. The visible light must pass through a thin section of the specimen (transmitted-light TL-OM, or polarized-light PL-OM), or it will be reflected by the polished surface of a thick sample (reflected-light RL-OM). The OM technique is always micro-destructive due to that it requires a polished surface of the sample, which can offer rapid access to the desired information such as phase information, grain size, defects, textural relationships and amorphous components.

The destructive force of the salt corrosion is tremendous on natural and artificial porous materials like bricks, ceramic, mortars used in architectural heritage [47-50]. Cardell et al. [51] applied OM technique to characterize the micro-structure changes, corrosion products and destructive forms of weathered limestones interacting with single and mixed sulfate solutions in South Spain. 


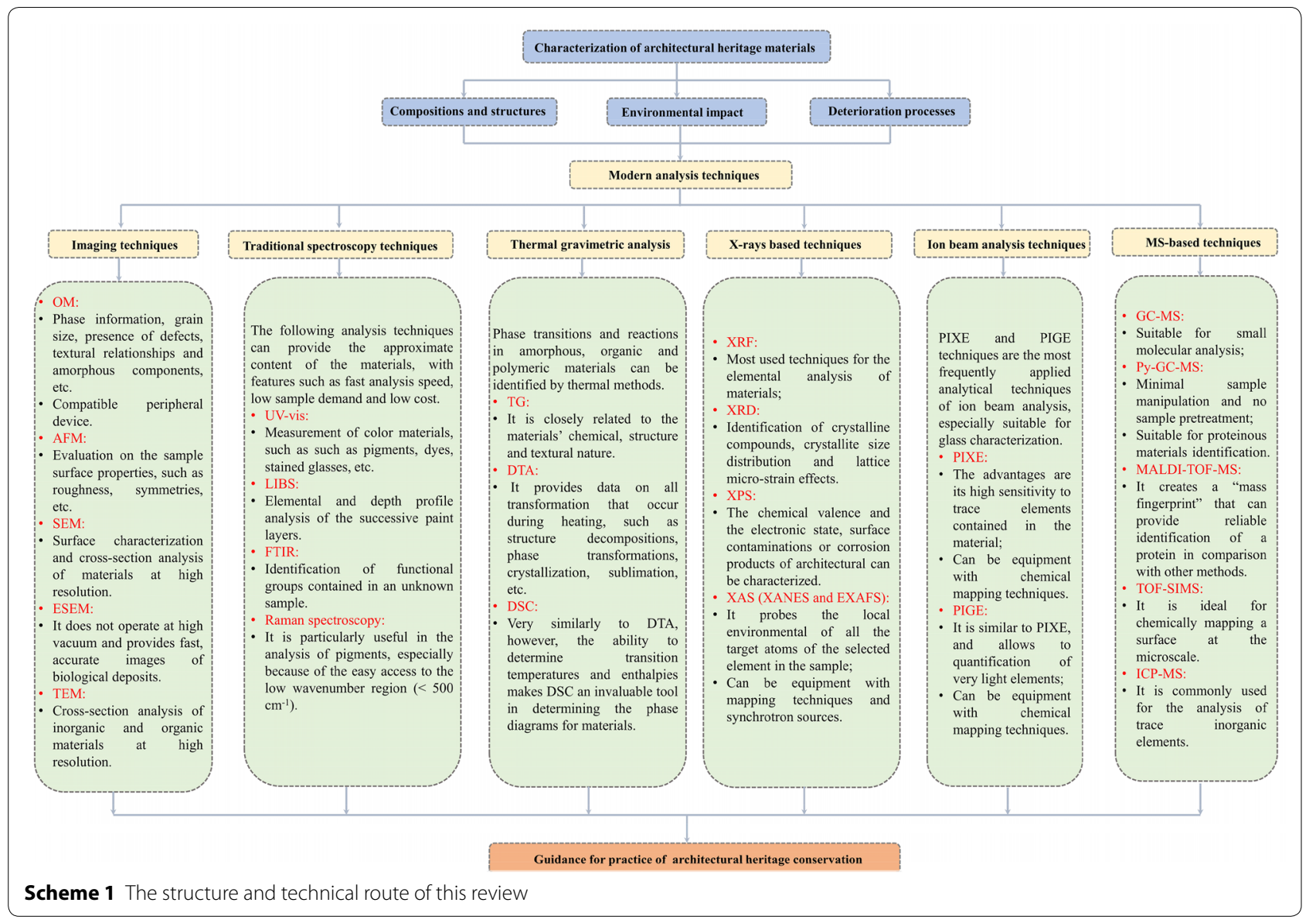

The salt crystallization measurement demonstrated that the sulfate solutions facilitate the coexisting $\mathrm{Mg}$-sulfates and $\mathrm{Ca}$-sulfates to be precipitated near the stone surface, leading to dissolution of the carbonate cement (as shown in Fig. 1a, b). However, when the stone materials reacted with the single solution of $\mathrm{Ca}$-sulfates or $\mathrm{K}$-sulfates (Fig. 1c), the salt crystallization, cement dissolution and the degree of fracture were less intense. The solutions containing $\mathrm{Na}^{+}$were labile to induce plentiful salt deposition. It was also found that lots of tiny needles-like $\mathrm{Na}$-sulfate crystals deposited in dendrites of both large and small pores (Fig. 1d) due to slightly higher supersaturating ratios. Rodruguez-Navarro et al. [52] investigated the microscopic behavior of $\mathrm{Na}$-sulfate crystallization at different relative humidity $(\mathrm{RH})$ by means of $\mathrm{OM}$ technique. The results revealed that thenardite $\left(\mathrm{Na}_{2} \mathrm{SO}_{4}\right)$ was inclined to develop as tiny needles grouped in dendrites under $>40 \% \mathrm{RH}$ condition, while in prismatic shape under 13\% RH condition (as illustrated in Fig. 1e, f), thus explaining the reasons of different crystalline morphology of thenardite in previous studies. Considering that the pigments applied in conventional lime-washing paintings are inorganic materials, Gil et al. [53] applied OM to detect the major compounds of pigments in Alentejo urban heritage, which indicated that OM techniques can identify quartz, feldspars, phyllosilicates and carbonate minerals associated with the ferric oxides or hydroxides. Moreover, the clay minerals were often utilized as the finishing layers to overlap the surface of ancient buildings. Calia et al. reported that they used OM to verify the chemical composition and the provenance of external clay minerals of several ancient buildings located in Apulia region of Italy [54], and the results demonstrated that ochre pigments were the dominant compounds which were widely used in the treatment of wall surface in the past. It is interesting that Mazzeo et al. [16] applied $\mathrm{OM}$ techniques to the study of the traditional decorative materials in Ming-Dynasty wooden structures of the Drum Tower in Xi'an Province of China. The photomicrographs suggested that the painted decorations mainly included five layers, i.e., cotton fabric, plaster, organicred/brown layer, varnish layer and red layer, respectively, and the thickness of the layers ranged from 1 to $40 \mu \mathrm{m}$.

Besides the mentioned applications, the OM techniques are usually used to conduct mineralogical/chemical characterization of ancient mortars $[24,55-59]$ and 

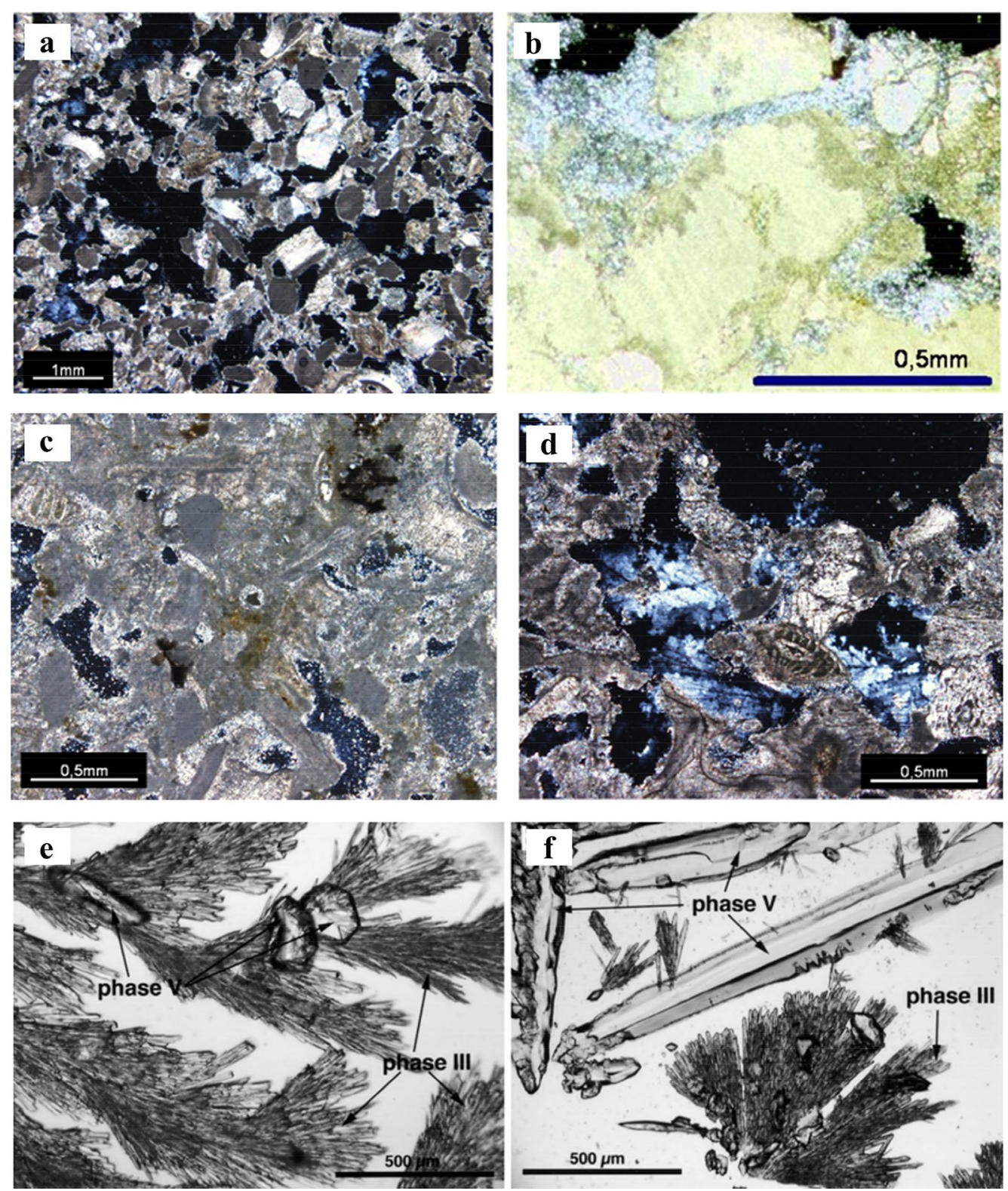

Fig. $1 \mathrm{TL}$ and PL-OM photographs of the calcarenites reacted with high concentration of salt solutions and thenardite crystals. a carbonate cement dissolved in $\mathrm{MgSO}_{4} \cdot 7 \mathrm{H}_{2} \mathrm{O}$ and $\mathrm{CaSO}_{4} \cdot 2 \mathrm{H}_{2} \mathrm{O}$ aqueous solution; $\mathbf{b}$ the surface of calcarenite was split after the action of $\mathrm{Mg}$-rich salts; $\mathbf{c} \mathrm{K}_{2} \mathrm{SO}$, simple solution had no effect on the surface topography of calcarenites; $\mathbf{d}$ after reaction with $\mathrm{NaSO}_{4} \cdot 10 \mathrm{H}_{2} \mathrm{O}$ aqueous solution, the thenardite crystals displayed non-equilibrium needle shapes; $\mathbf{e}$ the acicular shape (phase III) of thenardite crystals is easy to generate under conditions of $20^{\circ} \mathrm{C}$ and $\mathrm{RH}>40 \%$; $\mathbf{f}$ massive amounts of bipyramidal prisms crystals (phase V) formed at $20^{\circ} \mathrm{C}$ and $13 \% \mathrm{RH}[51,52]$, copyright $(2000,2008)$ Elsevier

building crusts resulted from environmental contamination, which is one of the most prominent problems in the field of architectural heritage conservation over the past few decades [60, 61]. In Silva and co-workers' study [55], the ancient mortars from 16 to 17th century military forts located at the estuary of the Tagus River in Lisbon were characterized by PL-OM. In the collected samples, ceramic fragments (Fig. 2a), neoformation pozzolanic products (Fig. 2b) and aragonite shell fragments (Fig. 2d) were widespread, demonstrating that hydraulic compounds were deliberately added by the fort constructors to enhance the mechanical strength and resistance. The shrinkage cracks in mortars due to dehydration-driven contraction and secondary recrystallized calcite were also detected by PL-OM (Fig. 2c). In addition, Bonazza et al. [61] used OM to interpret the patterns, surface 

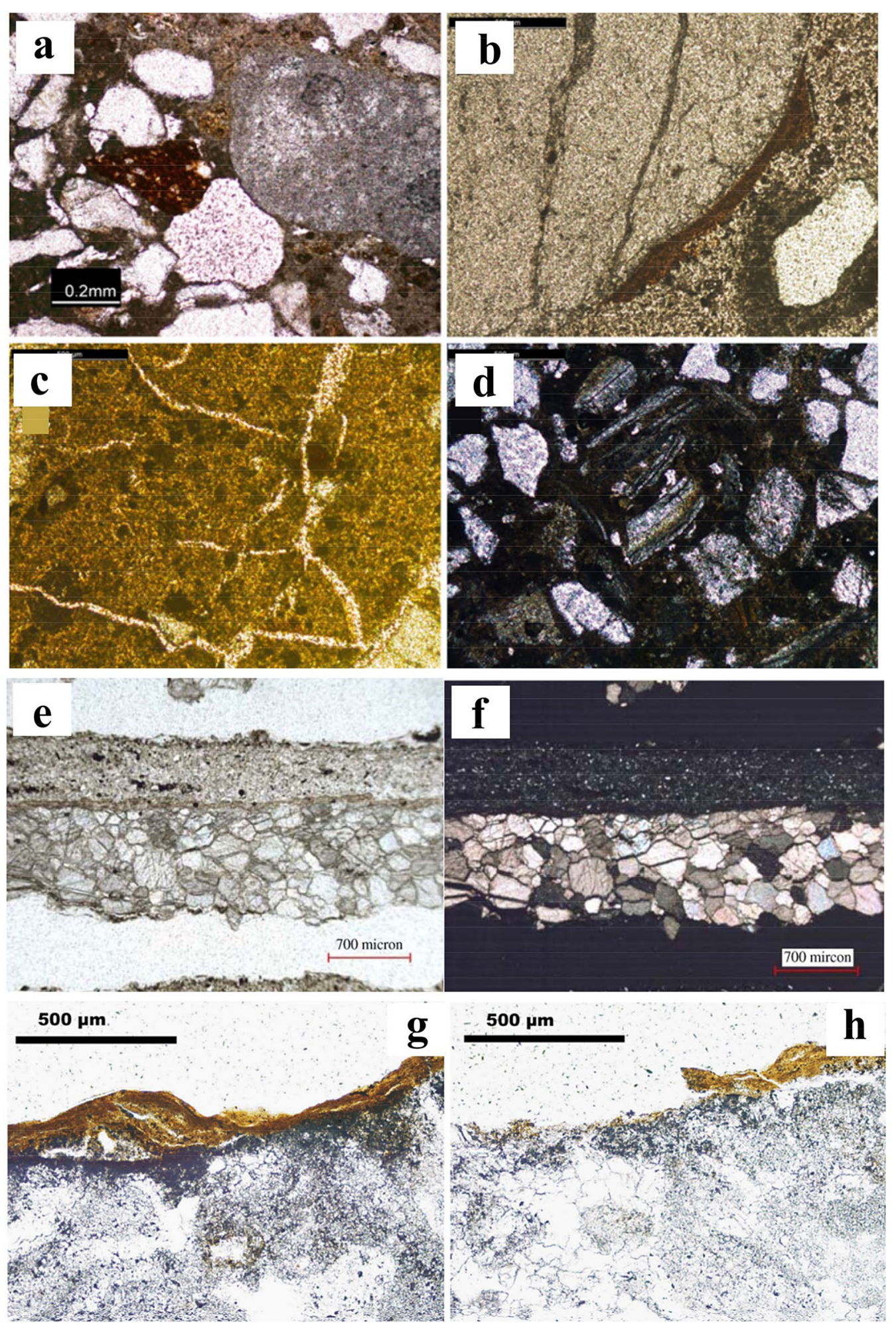

Fig. 2 OM photographs. a Quartz aggregates and a ceramic fragment; b newly formed volcanic ash material at a quartz grain/binder interface; c shrinkage cracks caused by dehydration within the binder groundmass; $\mathbf{d}$ shell materials as important substances of the aggregate particles; $\mathbf{e}$ plane-polarized light micrography of dendritic black crust; $\mathbf{f}$ cross-polarized light micrography of dendritic black crust; $\mathbf{g}$ external form of the patina in plane-polarized light mode; $\mathbf{h}$ discontinuous patina in plane-polarized light mode [55, 61, 62], copyright $(2005,2007)$ Elsevier and (2011) Springer Link 
distribution and composition of black crusts and soiled area on European building heritage. As illustrated in Fig. 2e, f, an obvious dendritic black crust with thickness of ca. $1 \mathrm{~mm}$ was observed, which mainly consisted of gypsum, quartz and silicate (soil dust) with microcrystalline structures. Similarly, numerous stone-made ancient architectures have a yellowish layer called "patina" on their external surface. Vazquez-Calvo et al. [62] used OM to obtain the information about the status of the patinas by observing the homogeneity, thickness and continuity of the film (Fig. $2 \mathrm{~g}$, h) to further determine if the patina was always presented on the stone and to offer corresponding conservation methods.

Different from OM, the atomic force microscopy (AFM) can provide high resolution topographies, which are acquired as real three-dimensional datasets allowing statistical evaluation on the sample surface properties (roughness, symmetries, size etc.). The AFM is generally regarded as micro-destructive technique due to the fact that it was carried out on very small samples (a few $\mathrm{mm}^{2}$ ). For instance, Pflugfelder et al. [63] used AFM to investigate the gloss levels of alkyd resin layer in wall paintings before and after plasma treatment, and to obtain the optimal parameters of plasma cleaning. Taglieri et al. [64] applied eco-compatible hydro-alcoholic nanoparticles (called nanolime) to repair Italian historic lime-based mortars, the AFM analysis showed the diameter and height of the nanoparticle were less than 50 and $5 \mathrm{~nm}$, respectively. Furthermore, in the Falcão and co-workers' study [65], the pigments used in pre-class (300BC-300AD) architecture of the ancient pre-Columbian city in Calakmul were characterized, revealing that the sizes of the crystal were $0.5-1 \mu \mathrm{m}$ and the fiber structures were $30-60 \mu \mathrm{m}$. It was representative of palygorskite with corrugated texture, suggesting that the samples were mainly associated with Maya Blue.

Except for the mentioned applications, how to protect and restore the metal structure of ancient building remains one of the most complex problems. In Kiele and co-workers' study, [66], the changes of surface morphologies of both uncoated and coated samples were studied by AFM. They used sol-gel technique to prepare methylmodified silica coatings to protect copper structures. The silica coatings treated with hexamethyldisilozane (HMDS) were extremely smooth (Fig. 3a, b). However, the surface treated with trimethylchlorosilane (TMCS) was rough and consisted of submicron particles of different shapes (Fig. 3c, d). Therefore, the HMDS modified silica protective coatings on copper substrate were applied for the conservation of copper at local ambient conditions.

\section{Electron microscopy and energy dispersion X ray (EDX) analysis}

Although OM can effectively avoid the preprocessing procedure which may cause irreversibly damage to
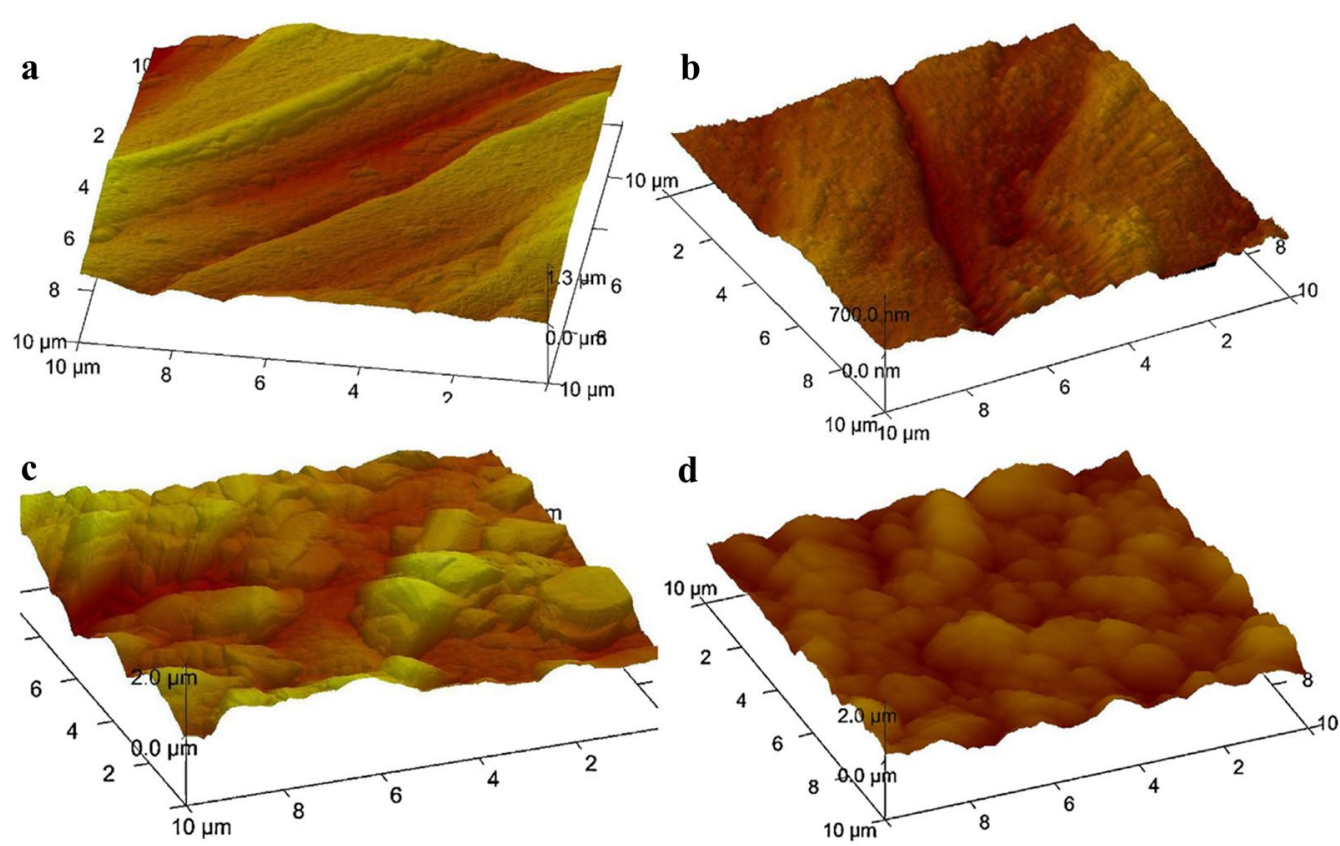

Fig. 3 AFM micrographs of coatings on copper. $\mathbf{a}$, b Treated with $8 \%$ HMDS before and after photochemical aging; $\mathbf{c}$, d treated with 10\% TMCS before and after photochemical aging [66], copyright (2014) Elsevier 
samples, such as metal or carbon coatings, they can only detect the morphology of samples. The electron microscopes coupled with energy-disperse X-ray spectroscopy (EDX) are both imaging and chemical techniques. They can not only provide higher resolution and magnified images, but also analyze the elements on surface or crosssections of materials. Typically, the scanning electron microscopes (SEM) employ electron beams accelerated in the range $10^{2}-10^{4} \mathrm{eV}$, corresponding to wavelengths of the order of $0.123-0.012 \mathrm{~nm}$, and therefore may reach magnifications over 100,000 times, compared with the magnification factors for the best optical microscopes of about 1000 times. Transmission electron microscopes (TEM) employ the electron beams accelerated in the range $10^{4}-10^{5} \mathrm{eV}$, and they can reach the magnification factors over $10^{7}$ times [40]. The best TEM instruments have a resolving power, which is sufficient to discriminate atoms. However, preparation of the samples for SEM is comparatively trivial, and usually only a metal coating (for imaging) or a graphite coating (for chemical analysis) is required. Moreover, the preparation of samples for TEM is a little more laborious, which requires preparation of very thin layers of materials usually produced by grinding or ion thinning and deposited on copper/graphite nets. In all instances, the samples should be measured in a vacuum, as the air molecules $\left(\mathrm{N}_{2}, \mathrm{O}_{2}, \mathrm{H}_{2} \mathrm{O}, \mathrm{Ar}, \mathrm{CO}_{2}\right.$ in order of relative abundance) would scatter and absorb the electrons. The measurement in a vacuum is generally not a problem for anhydrous materials whereas the major problem is usually the perturbation of the sample by the energy deposited although it may cause changes in hydrous systems. In the actual applications, the sample may be partially kept under a low pressure of water (up to $2.5 \mathrm{kPa}$ ) in modern environmental scanning electron microscopes (ESEM), which allows hydrated samples to be measured in a wet atmosphere [40].

Being compared to the OM techniques, SEM can be utilized to analyze the morphology of inorganic and organic materials of architectural heritage (like mortars $[23,58,67]$, binders/pigments of mural paintings [16, $18,68]$, and sandstones $[6,7,51,69,70]$ etc.) at a higher resolution. The reason is that the thermo-ions emitted by electron beam sputter the samples directly to obtain the information of crystal array, elemental composition and magnetic structure. For example, in Ruffolo and coworkers' study [25], most black crust samples collected from Seville Cathedral in the southern part of Spain were analyzed by SEM-EDX. The objective was to obtain the topography of the black crusts, their interaction with the stone substrates, and characterization of elemental composition of damaged layers. The microscopic images obtained by the backscattered electron mode (BSE) showed that the stone substrates of all sampling locations were degraded, and the thickness of crust samples varied from $20 \mu \mathrm{m}$ to $3 \mathrm{~mm}$ (as illustrated in Fig. $4 \mathrm{a}-\mathrm{c}$ ). Furthermore, the crusts of CS-BG (the abbreviation of sampling location) were made up of acicular gypsum, along with lots of spherical and subspherical combustion particles with smooth or porous surfaces (Fig. 4d). Finally, EDX analysis demonstrated that the main components of black crusts were $\mathrm{CaO}$ and $\mathrm{SO}_{3}, \mathrm{SiO}_{2}, \mathrm{Al}_{2} \mathrm{O}_{3}, \mathrm{Fe}_{2} \mathrm{O}_{3}$ were the secondary substances, and $\mathrm{K}_{2} \mathrm{O}, \mathrm{Na}_{2} \mathrm{O}$ and $\mathrm{MgO}$ were the least abundant substances. The high contents of $\mathrm{CaO}$ and $\mathrm{SO}_{3}$ were mainly attributed to the gypsum formed on surface, and the elements such as aluminum, silicon and iron may be due to the adsorption of atmospheric particulates on the stone substrates.

As the composition of historic mortars is largely influenced by both temporal and spatial variation, the study of composition and microstructure of ancient mortars can supply information about the ages of architectural heritage and their manufacturing process. Xiao et al. [71] applied SEM-EDX to the investigation of mineral phase composition and the characterization of the pore structure of sticky rice-lime mortars sampled from the Wugang Ming dynasty city wall in China. As shown in Fig. 5a, undecayed mortar was still in good condition of dense microstructure characterized by homogenously distributed fine particles. In contrast, as shown in Fig. 5b, decayed mortar showed loose microstructure and obvious large cracks can be observed. In addition, this study showed that the component and microstructure of Chinese mortars were significantly different from those of ancient Roman mortars in which brick fragments were used as hydraulic components. Larger added ceramic particles played a dominant role in interactions with air, interfering with the pore structures, thus ultimately improving the carbonation efficiency of mortars [72]. Usually, lime can react with water to generate hydrated lime with emission of a lot of heat and simultaneously create alkaline environment that can effectively inhibit bacteria. When slaked lime $\left(\mathrm{Ca}(\mathrm{OH})_{2}\right)$ is contacted to moist ambient environment, calcium hydroxide reacts with $\mathrm{CO}_{2}$ in the air and converts into $\mathrm{CaCO}_{3}$. The strength and durability of mortar were gradually improved when mortar gradually solidified until lime was completely converted to calcium carbonate. Furthermore, composition of undecayed and decayed mortars analyzed by EDX was revealed in Fig. 6c, d, respectively. Except for a small amount of silicon, aluminum, magnesium and iron, the main composition of undecayed mortar only included calcium, oxygen and carbon. However, a significant amount of sulfur and chlorine were observed in decayed mortar. The high sulfur concentration in decayed mortar revealed the presence of sulfate with very high mean concentration, proving that the external 

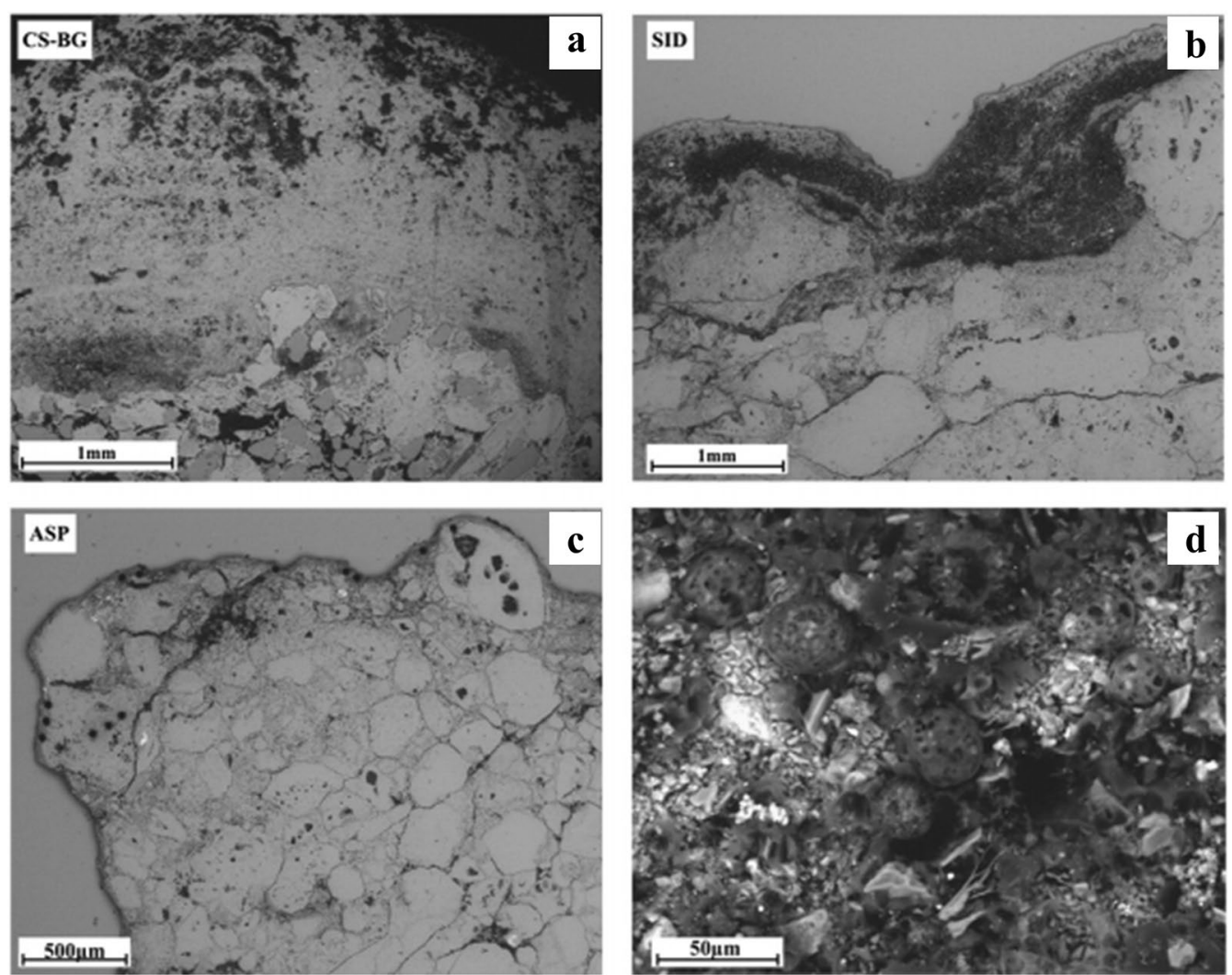

Fig. 4 BSE-SEM images of the tested samples. a CS-BG, b SID, c ASP are the abbreviations of sampling locations. Images (d) showed the particles from combustion with different shapes in the crusts of sample CS-BG [25], copyright (2015) Elsevier

masonry structures were critically eroded by sulfate and calcium carbonates were converted into gypsum at different levels.

The SEM-EDX technique can also be applied to the survey of the additives or by-products produced in damage process in architectural heritage samples. In Wei and co-workers' work [23], SEM-EDX technique was carried out to characterize rice-lime mortar used in the stone tower located in Xiangji Temple. According to the SEM micrographs, when the rice-lime mortar was treated without any additives, the particles exhibited cross-linking tiny sheets with relatively loose structures; when the sticky rice-lime mortar treated with aluminum sulfate and dihydrate gypsum, the tiny particles were closely interlaced. Therefore, the compact structure of sticky rice-lime mortar obtained by the treatment of aluminum sulfate and dihydrate gypsum was the key to improve the physical properties, such as comprehensive strength, surface hardness and freezing resistance, etc. González et al. [70] adopted SEM-EDX to investigate the iron corrosion on the stone decay of the Royal Palace, Madrid in 18th century monuments. The results implied that the corrosion processes gave rise to the increase of iron hydroxide components (lepidocrocite and geothite), resulting into $83 \%$ volume expansion. Because of high capacity of water adsorption of lepidocrocite $(\gamma-\mathrm{FeOOH})$, rosettelike lumps with higher oxygen content can be detected by SEM-EDX. But geothite $(\alpha-\mathrm{FeOOH})$ showed more crystallized acicular shapes with lower oxygen content. Furthermore, Doherty et al. [73] proposed the use of artificial calcium oxalate to treat marble architecture in Florence so as not to be affected by environmental pollutants. The SEM observation after acid attack showed that the marble samples protected by $5 \%$ oxalate had strong corrosion resistance. Moreover, as the calcium oxalate was insoluble on natural calcium carbonate at $\mathrm{pH}=5.5$, oxalate completely covered the marble surface and did not penetrate it at all. More interestingly, Sternberg et al. [74] made use of SEM to determine if ivy leaves collected on roadways can adsorb dust and contaminants to reduce the decay of historical stone walls and to affect human health in the urban environment. The results revealed that ivy acted as a 'particle sink' to accumulate particulate matter, especially in the areas with heavy traffic.

In contrast to SEM, ESEM technique is not suitable to be applied in the high vacuum environment. But it can 

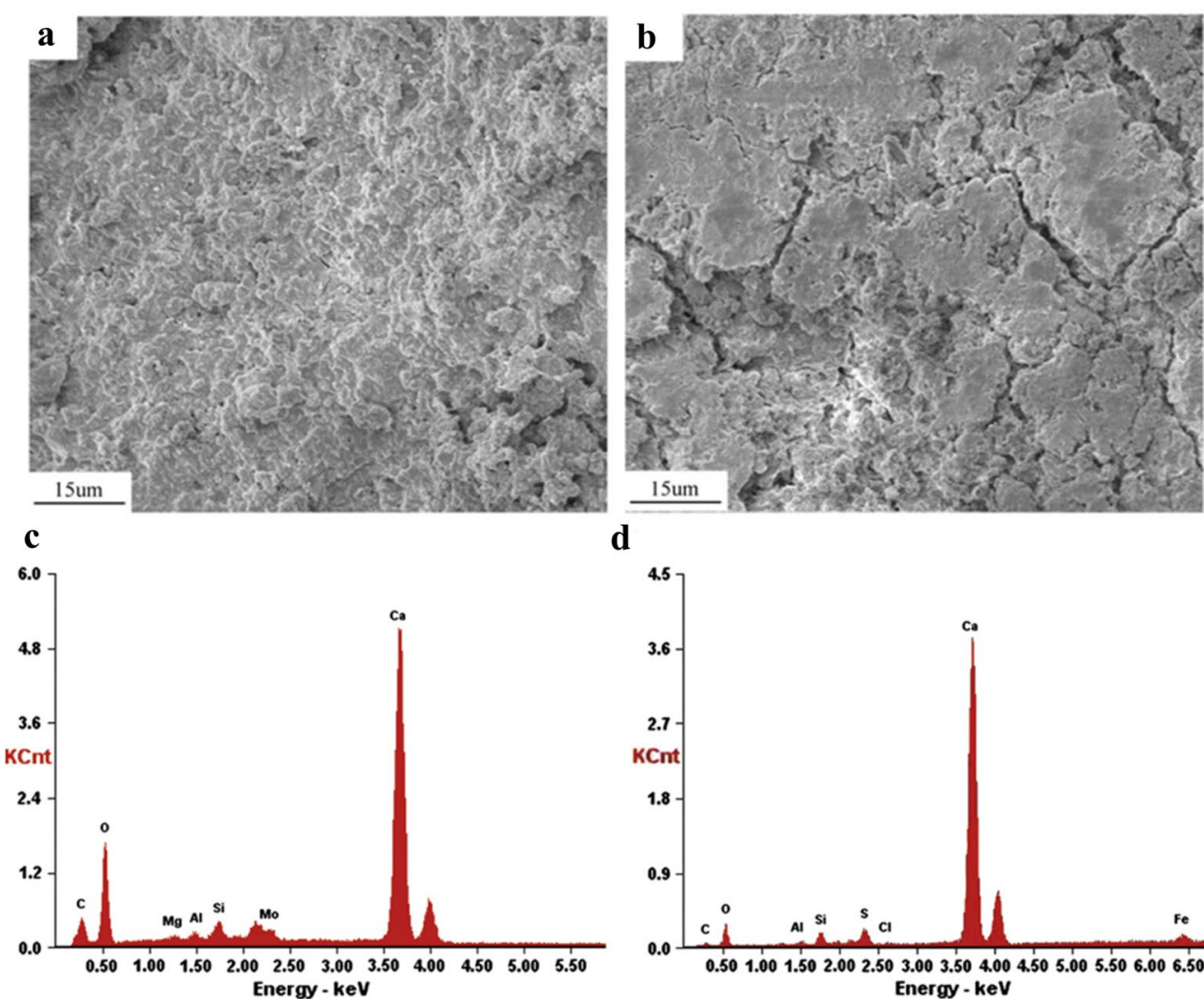

d

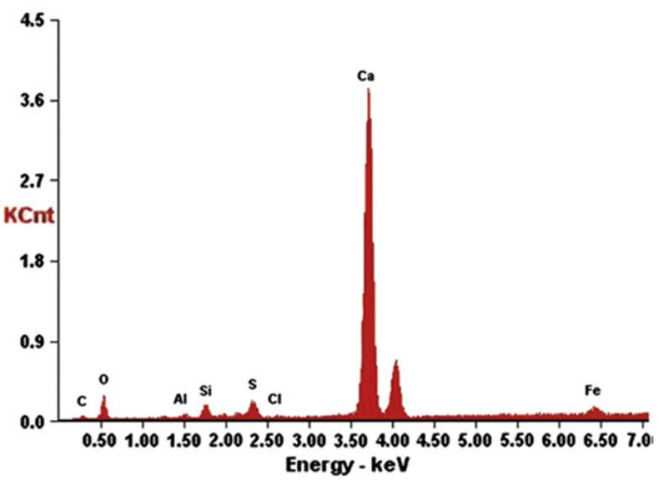

Fig. 5 SEM and EDX images of sticky rice-lime mortar sampled from $\mathbf{a}$ and $\mathbf{c}$ non-decayed region; $\mathbf{b}$, $\mathbf{d}$ decayed region in the Wugang Ming dynasty wall [71], copyright (2014) Elsevier

offer rapid and accurate biological deposition or biofilm images, supply corresponding spatial relationships and superficial micro-circumstance without strict pretreatment of samples. This instrument is equipped with an excellent secondary electronic detector, which can provide some high-resolution images in the $0.1-20$ torr pressures range. Under the above-mentioned high pressures, the microscopic images of non-conductive biological samples can be observed directly without metal coating or the other special treatment. For example, ESEM micrographs of moss forming green carpets on the limestone of the building in Palenque (Chapas, Mexico) can be seen in Fig. 6 [27]. If the chamber contains a certain amount of water vapor, the morphology and topography of water-bearing samples can be detected directly by ESEM, and elemental composition and relative content can also be characterized by EDX simultaneously. The substrates, biologically attacked area, abiotic depositions and biofilms can be analyzed by ESEM which can supply high-resolution images of biofilms and microorganism extracellular polymer materials due to the absence of extensive manipulation of the samples to be analyzed [75]. Furthermore, Rodriguez-Navarro et al. [52] explored the basic behavior of sodium sulfate crystallization in concrete and other building materials. The information obtained from the ESEM showed no hydration phenomena after wetting of thenardite; instead, followed by thenardite plus mirabilite crystallization upon drying, thenardite dissolution occurred. The results presented a new understanding of the damage which had been caused by sodium sulfate in the fields of natural geology, archaeology, architecture and engineering. Furthermore, it explained some controversial results of previous sodium sulfate crystallization tests.

Kontozova-Deutsch et al. [76] used TEM to investigate the effects of indoor and outdoor air pollutants on the composition and structure of architectural monuments (as illustrated in Fig. 7). The main results showed that the aerosols collected outside church were mainly composed of salt substances, especially chlorides and sulfate-rich salts; ammonium chloride was a common component, which may originate from the guano deposits on the surfaces of the historic building. With respect to the indoor particles, the major compounds were also the chlorides and sulfates, especially ammonium chloride and Ca-K-S rich particles (Fig. 7e,f). The results obtained 

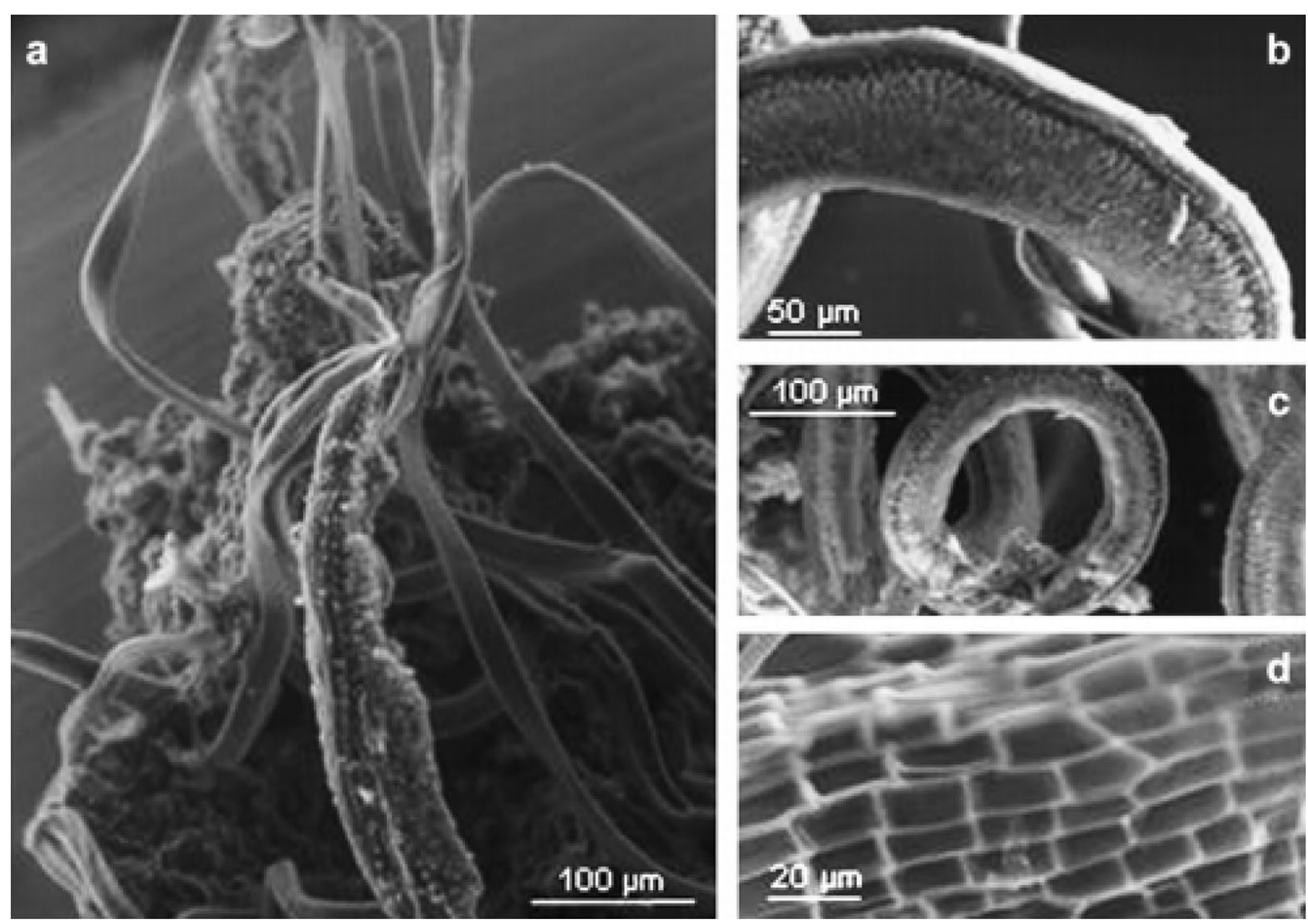

Fig. 6 ESEM microscopic photographs of moss forming green carpets on the stone surfaces of Palenque heritage. a Moss overview; b, c typical convolutions generated by the moss; $\mathbf{d}$ the arrangement of rectangular cells of tested moss [27], copyright (2009) Elsevier

by TEM suggested that the above compounds might originate from the outdoor aerosols. However, indoor sources like salt-containing stones could also contribute to some extent to the presence of these particles. In Miriello and co-workers' study [77], TEM was employed to demonstrate the formation mechanism of the amorphous calcium silicate hydrate $(\mathrm{C}-\mathrm{S}-\mathrm{H})$ in the brick-calcite interface. TEM images clearly exhibited different stages of $\mathrm{C}-\mathrm{S}-\mathrm{H}$ development. Crumpled sheets morphology showed the initial stage of $\mathrm{C}-\mathrm{S}-\mathrm{H}$ compounds, whereas the arrow indicated the increase of the crystal density.

\section{Commonly used spectroscopic techniques Infrared and Raman spectroscopy}

Fourier transform infrared spectroscopy (FTIR) is commonly applied to the characterization of ancient building materials. An infrared spectrometer can simultaneously collect high spectral resolution data over a wide wavelength range. More significantly, FTIR, as one of the most applied techniques, was often used in architectural heritage conservation due to the minimal amount of sample required (approximately $0.5 \mathrm{mg}$ ) and the rapid results of analysis (few minutes). The FTIR can distinguish the functional groups presented in an unknown substance. As each functional group can only absorb lights with characteristic frequencies, a plot of the radiation intensity (the transmittance is commonly used for intensity) versus frequency achieve the identification of chemical groups contained in a certain material [78]. Up to now, many infrared spectral databases are available for stone, mortar, ceramic, pigments, and the other historical architectural heritage materials. FTIR spectroscopy is extremely useful in distinguishing natural organic materials, especially organic compounds of ancient buildings. Many published papers related to this field can be found [79-82]. One of the earlier researches was reported by Zappia et al. [83]. In the research, FTIR was used for the analysis of effects of carbonaceous particles on different types of building materials in $\mathrm{SO}_{2}$-exposure experiments. The characteristic FTIR band for $\mathrm{SO}_{4}{ }^{2-}$ was recorded at $1120-1160 \mathrm{~cm}^{-1}$, while the two peaks at 980 and $640 \mathrm{~cm}^{-1}$ for $\mathrm{SO}_{3}{ }^{2-}$ were also found.

The most significant aspect of architectural heritage conservation is essential to diagnose and to make decision on the conservation process [84]. As mentioned above, one of the most common and negative phenomenon on stone materials and murals is that carboncontaining materials are eroded by sulphate substances [85]. Black crusts are considered as the main destruction forms impairing the architectural heritage in urban areas. Besides the obvious aesthetical damage, these crusts also cause severe and irreversible damage to carbonatic 


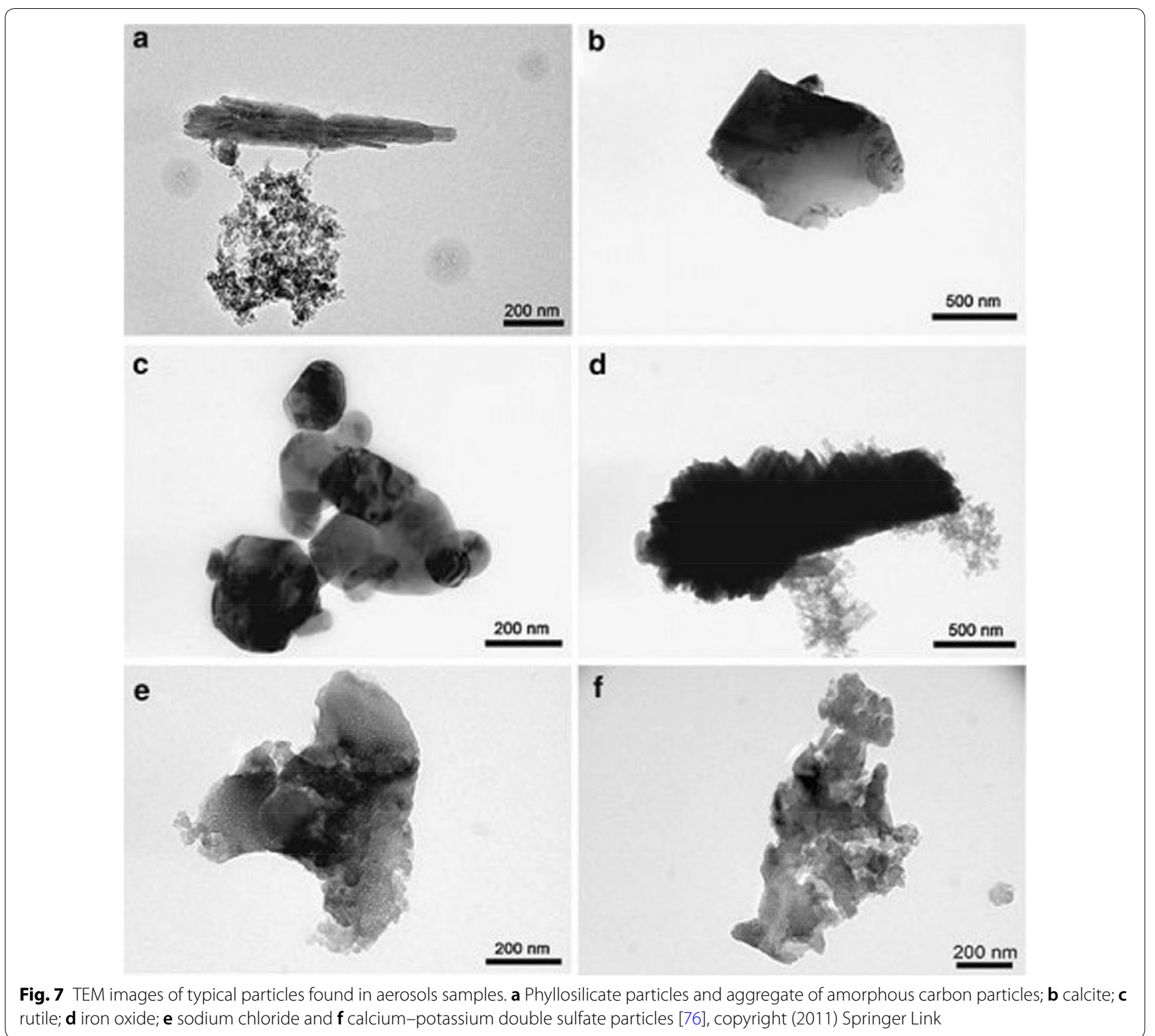

support. Therefore, numerous studies have been carried out on the formation and growth mechanism of the black crusts. Alessandrini et al. [86] applied FTIR technique to the exploration of the yellow and black crusts on the facade of a renaissance building in Bergamo in Italy (Fig. 8). In this study, the powdered samples were extracted with organic solvents, and a polymeric material (poly-isobutylmethacrylate) was found. This polymeric product was widely used in the conservation field in the $1970 \mathrm{~s}$. By further analyzing the FTIR data and reviewing the literatures, the building was possibly treated in 1972.

Furthermore, Barca et al. [87] used the FTIR technique to chemically characterize the black crusts collected from building stones of the historical city center of
Catania, Italy. In this study, the infrared spectra exhibited the characteristic absorption peaks of $\mathrm{CaSO}_{4} \cdot 2 \mathrm{H}_{2} \mathrm{O}$ centered at 1109, 667 and $596 \mathrm{~cm}^{-1}$, along with the distinctive signatures of stretching and bending vibrations of $\mathrm{O}-\mathrm{H}$ groups at $3525,3429,3401 \mathrm{~cm}^{-1}$ and at 1682 and $1627 \mathrm{~cm}^{-1}$, respectively. Also, the presence of calcium oxalate monohydrate $\left(\mathrm{CaC}_{2} \mathrm{O}_{4} \cdot \mathrm{H}_{2} \mathrm{O}\right.$, whewellite) was recognized. Both the stretching vibrations of $\mathrm{CaCO}_{3}$ with peaks at 1409,871 and $710 \mathrm{~cm}^{-1}$, and the band of silicates at $1032 \mathrm{~cm}^{-1}$, were identified in all samples (as illustrated in Fig. 9). Similarly, black crusts collected from relevant structures and churches of four European cities such as Corner Palace in Venice, St. Eustache Church in Paris, St. Rombouts Cathedral in Mechelen and the Cathedral 


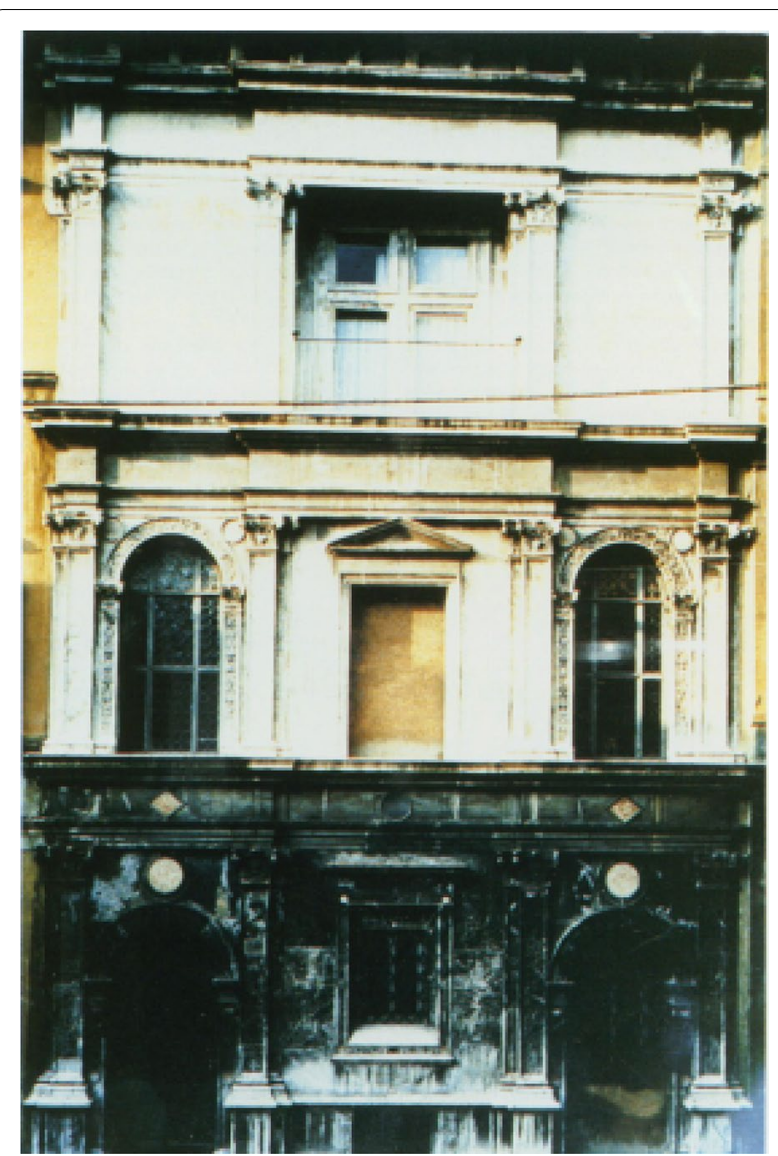

Fig. 8 The facade of the building in Bergamo (Italy) in 1993, before the conservation work [86], copyright (1996) Taylor \& Francis Group

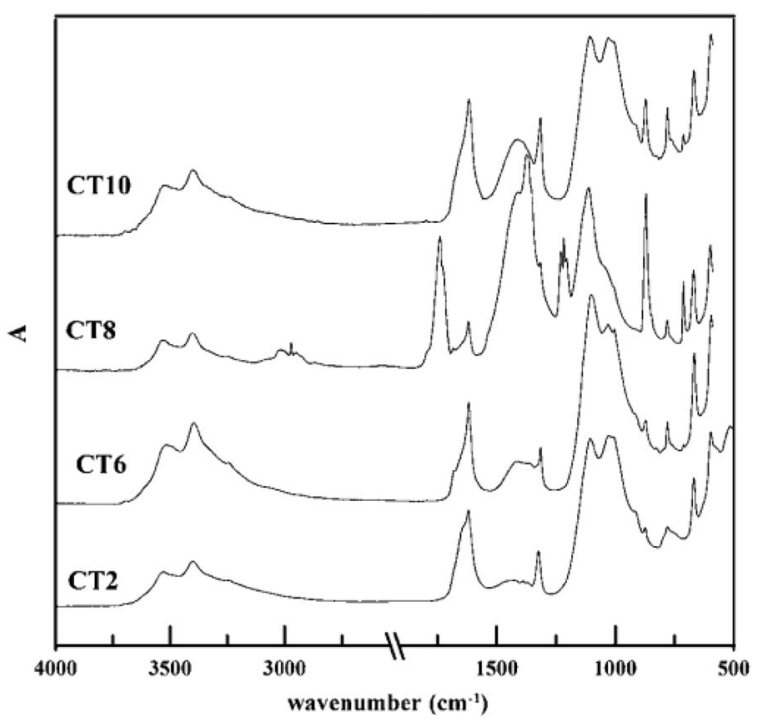

Fig. 9 FTIR spectra showing different sulphation levels of the building stones in Catania, Italy (CT2, CT10, CT6 and CT8 represented creamy-white calcarenite, yellowish calcarenite and lumachella calcarenite, respectively) [87], copyright (2011) Royal Society of Chemistry of Seville in Spain, also exhibited the characteristic peaks of $\mathrm{CaSO}_{4} \cdot 2 \mathrm{H}_{2} \mathrm{O}$ and corresponding $\mathrm{O}-\mathrm{H}$ stretching and bending vibrations [25]. In fact, due to the rapid development of industry and frequent human activities, the ancient buildings in cities and industrial areas were mostly polluted or blackened by the accumulation of air contaminants. Along with the rapid industrial development, the different fuels are commonly used in industrial production, domestic heating and transportation. However, as the development of low-sulfur fuels and strict government regulation, the composition and concentration of atmospheric pollutant are changed. Therefore, the control and treatment of air pollutants depend on their sources and types. Today, fuel combustion of motor vehicles are the dominant factor of air pollution in most countries, which is expected to be worsen in near future, thus significantly affecting the blackening and surface degradation of historical buildings [88, 89]. Therefore, most of previous studies used FTIR to identify the mineralogical phases of damaged layers. Several researchers had reported that the characterization of black crusts exhibited the changing pollution pattern over time. Particularly, the assessment of the geo-chemical composition could be favorable to understand the influence of the pollution sources on the formation of degradation products $[90,91]$. Since sulfation of building materials is a well-known decay process, ammonium carbonate is probably the most effective desulfurization agent in existing chemical remediation methods.

Another harmful phenomenon is that the stone materials contain salty substances, and their recrystallization processes will induce great pressure on the pore walls, thus seriously damaging the microstructure of the architectural heritage materials. Furthermore, in multilayered materials such as wall paintings, this process might lead to flaking off and powdering either of painted or of ground layers [92]. Charola et al. presented a review article on salts in the destruction of porous materials, making clear that salt effects were strongly dependent on ambient conditions (i.e., temperature and relative humidity), and changes of relative humidity led to their partial crystallization and dissolution. Furthermore, the masonry humidity level can also be increased through capillary rise, condensation, stormwater penetration, pipe leakage and water flooding, causing or worsening all the decay processes in architectural heritage [93]. It is noteworthy that salts may originate from a variety of sources like air contaminants, deicing salts, volatile salts in soil, sea spray, unscientific treatments or interaction among different building materials. Some specific materials may even contain salts inherently. For instance, Portland cement generally consists of alkaline sulphates released from concrete or cement mortars [94, 95]. In 
addition, bricks may contain sodium sulfate if they are not fully fired, which can contribute to efflorescence on masonry materials [96]. Moreover, Varas-Muriel et al. [97] investigated the decay process of Romanesque apse on a church located at Madrid, Spain where the dolostone was severely destroyed by rainwater and salts. The FTIR spectrum contained an especially intense vibration band at around $1440 \mathrm{~cm}^{-1}$ which could be assigned to $\mathrm{CO}_{3}{ }^{2-}$ groups. The bands detected at around 714, 730, 876, 1440, 1880 and $2530 \mathrm{~cm}^{-1}$ could be assigned to $\mathrm{CaCO}_{3}$. The weak vibration band at $1080 \mathrm{~cm}^{-1}$ was associated with the presence of $\mathrm{Si}-\mathrm{O}-\mathrm{Si}$ bonds from silicic acid. In general, the FTIR technique is very reliable and useful for identifying the presence of salts such as nitrates, sulfates and oxalates [39, 98].

The FTIR technique was also successfully applied to the characterization of other materials of ancient architecture. For example, the origin, component and degradation of ancient mortars raise much interest among scientists. As a major component of mortars, lime was widely applied in Greek architecture [59, 99]. In ancient Rome, "Roman mortar" known as hydraulic materials such as ground volcanic ash, ceramic debris and grinding bricks had been widely used in building materials [100, 101]. However, the hydraulic mortar technology was not popularized in ancient China partly due to the absence of natural hydrualic materials. The utilization of natural organic compounds such as rice soup, the juice of vegetable leaves, egg white, tung oil, fish oil or even animal blood can greatly improve the performance of lime mortars. Sticky rice-lime mortar was commonly used in the important buildings such as city walls, palaces, tombs and even water conservancy facilities in ancient China [102]. Yang et al. [103] and Xiao et al. [71] used FTIR to analyze mortar samples obtained from Nanjing and Wugang Ming dynasty city wall. In the Yang's study, the FTIR spectra for sticky rice, the mortar sample and the calcite were discussed (as illustrated in Fig. 10). The absorbance bands at 712, $876,1429,1794$ and $2513 \mathrm{~cm}^{-1}$ were attributed to the presence of calcite. And these characteristic bands also appeared in Fig. 10b, revealing that there was calcite in the traditional Chinese mortars. With respect to the sticky rice, the absorption bands at 847 and $761 \mathrm{~cm}^{-1}$ could be assigned to the $-\mathrm{CH}_{2}$ group, the absorption bands at $1000-1154 \mathrm{~cm}^{-1}$ were assigned to the $\mathrm{C}-\mathrm{O}$ group of the glucose anhydride ring, and the absorption bands at $1654 \mathrm{~cm}^{-1}$ can be attributed to the absorbance of the $-\mathrm{OH}$ group. In Fig. 10b, there are no $-\mathrm{CH}_{2}$ absorption bands of sticky rice at 761 and $847 \mathrm{~cm}^{-1}$, which may be the influence of adjacent strong calcite absorption bands at 712 and $876 \mathrm{~cm}^{-1}$. But the $\mathrm{C}-\mathrm{O}$ absorption bands of the glucose anhydride ring

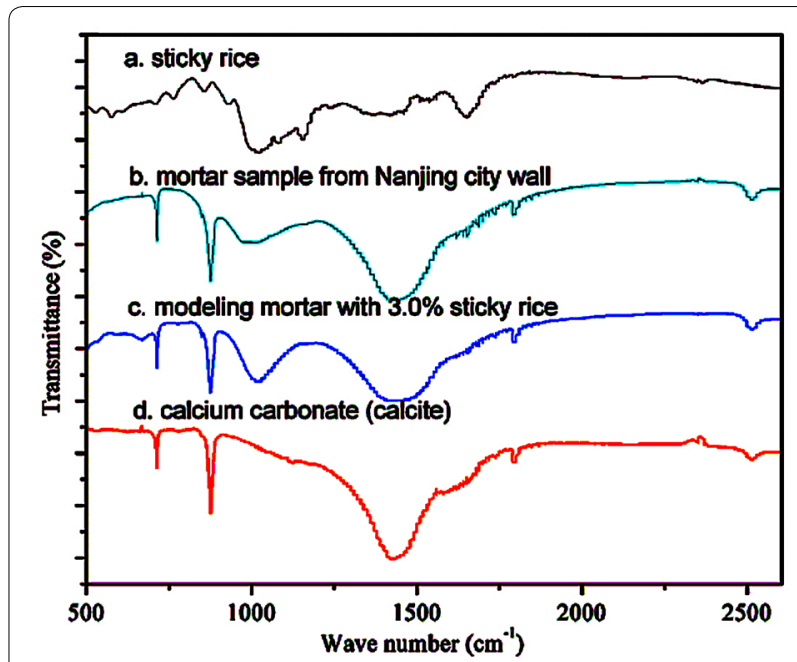

Fig. 10 FTIR spectra of sticky rice, mortar samples and calcium carbonate (calcite) [103], copyright (2010) American Chemical Society

at $1000-1154 \mathrm{~cm}^{-1}$ were still detected, suggesting that the ancient mortars contain rice soup. It could be concluded from these observations that the mortars applied in Ming dynasty city wall were a kind of inorganic-organic hybrid material mainly constituted of calcium carbonate and carbohydrates [71].

The FTIR can also detect the composition of mural paintings $[104,105]$, wooden structures [106-108] and stained glasses [50, 109-111]. It was well-known that infrared spectroscopy in the range of $4000-600 \mathrm{~cm}^{-1}$ (middle IR) is one of the most widely used techniques for the detection of organic materials $[112,113]$. Since 1970 s, only a few researchers employed far IR spectroscopy $\left(600-50 \mathrm{~cm}^{-1}\right)$ to determine the types and contents of inorganic substances [114]. The applications of FTIR technique are limited due to the ultrahigh resolution in the range of low wave numbers of Raman spectroscopy and its obvious advantages in detecting inorganic matters. However, Prati et al. [115] described the application of FTIR in raster scanning mode for the assessment of the distribution of protective materials used on corroded bronzes. The results showed that the combination of far IR spectroscopy with ATR module was especially suitable for characterization of non-active compounds in middle IR technique, such as mural paintings, metal corrosion and stone degradation products. Up to now, FTIR was introduced to detect either natural or artificial pigments such as cinnabar, hematite, red ochre, celadonite, Egyptian blue, yellow ochre, goethite, carbon and so on $[116,117]$.

In general, the process of obtaining the FTIR spectra is to grind a small part of the sample, mix it evenly with potassium bromide and prepare the sample tablet. All 
these analytic procedures are absolutely destructive to the materials. In the small diameter range $(\mu \mathrm{m}$ level $)$ and the reflectance mode, more detailed results of cross-section layer by layer of architectural samples can be achieved by the combination of microscopy with FTIR spectroscopy (micro-FTIR). According to the previous studies [118, $119]$, a variety of pigments and binders in samples collected from the architectural heritage in Spain, Greece and Italy were characterized by micro-FTIR spectroscopy. Micro-FTIR spectroscopy could supply unambiguous spectral data on ancient building materials to correctly explain the observed anomalies. Cross-section microphotographs of some samples studied by Franquelo and the co-workers were showed in Fig. 11 [120], blue, red, ochre, green, orange, yellow and white pigments present in polychromed wall paintings were discerned by micro-FTIR. This work suggested that the study of cross-sections by micro-FTIR was an extremely helpful technique in the characterization of components containing inorganic polyatomic anions (most of them were oxo-anions), which was attributed to the "fingerprint" peaks and bands could be show in the spectra. Moreover, this technique permitted not only the characterization of the stoichiometry of the component, but also the phases
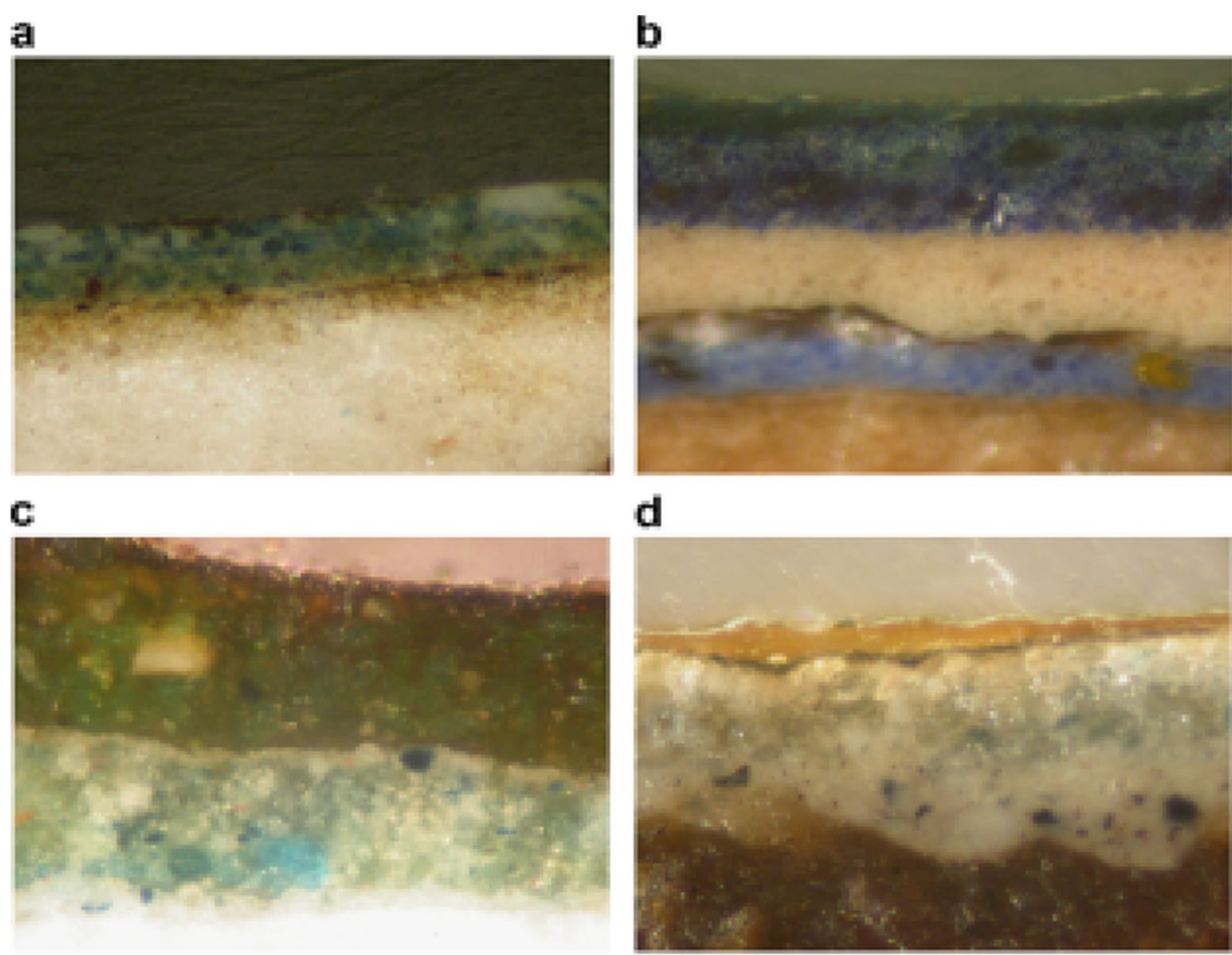

e
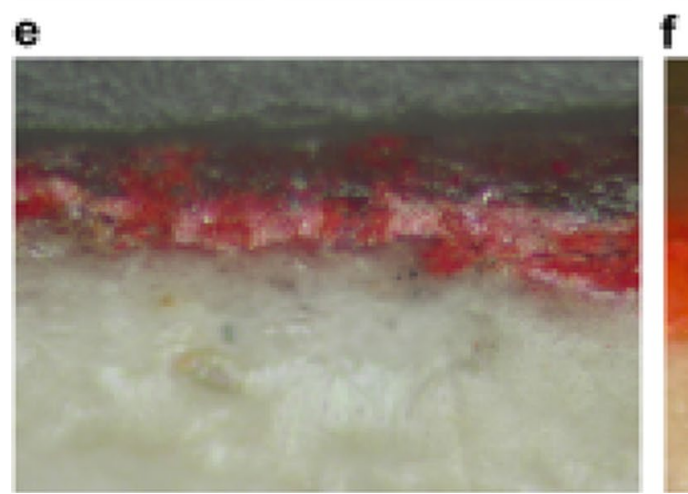

f

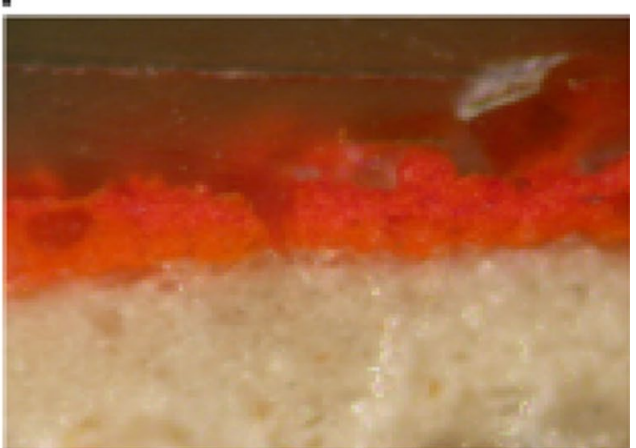

Fig. 11 Microphotographs of cross-sections in Franquelo and co-workers' work a Kings' Room in Alhambra from Granada; b Our Lady Santa Ana; c El Salvador Church; d Murillo's painting; e Kings' Room in Alhambra from Granada; and f Our Lady Santa Ana [120], copyright (2009) Elsevier 
present in the natural or synthetic materials of architectural heritage. Alternatively, the cross-section analysis can be acquired by micro-FTIR in transmission mode, which can provide higher sensitivity and enhance spectral quality. However, in this case, the samples are commonly compressed within a diamond anvil cell (DAC). This method might distort the stratigraphy and confuse the original configuration of the different layers [121]. In Papliaka and the co-workers' study [122], they proposed a new method for preparing thin section samples. The procedure was based on the application of cyclododecane $\left(\mathrm{C}_{12} \mathrm{H}_{24}\right)$ as embedding material and a subsequent double-side polishing of the specimen. Being compared with traditional method for FTIR analysis in transmission mode using DAC device, this method allowed the samples to be detected in FTIR transmission mode without loss of information on the spatial distribution.

When compared to the FTIR, the Raman spectroscopy is also a helpful technique for the characterization of architectural heritage due to its reliable, fast, sensitive and nondestructive characteristics. Because of the different mechanisms and selection rules, infrared and Raman spectroscopies measure different vibrational modes and therefore provided complementary information on the analyzed materials. The mechanism of Raman scattering is that the incident radiation actually deforms the atomic charge which further induces an instantaneous dipole moment within the molecule. Depending on the polarizability of the molecule, if the electron charge deformation corresponds to a possible vibrational state of the molecule, then a Raman scattering peak will be observed.

The Raman spectroscopy was utilized to analyze various heritage materials [123-126], though it was particularly useful in the analysis of pigments [127-130] due to the easy access to the low wavenumber region $\left(<500 \mathrm{~cm}^{-1}\right)$. Extensive databases of Raman spectra have been developed for identification of pigment phases: for example, a very useful on-line resource is the collection of spectra available at the UCL Department of Chemistry website (www.chem.ucl.ac.uk/resources/raman/ index.html). On this basis, most of natural or synthetic pigments used in historic construction were characterized by Raman techniques, as summarized in Table 2 . In many successful cases, Edwards et al. [131] explored the composition and structure of painting materials along with their degradation products. In this case, the difficulty was to apply Raman spectroscopy to the characterization of complex biological encrustation including substrate materials and lichen metabolites. However, some of the pigments were fully identified, which demonstrated that Raman spectroscopy had the potential to aid heritage conservation. Furthermore, Edwards et al. [132] elaborated on the advantages of combination historical researches with scientific researches to analyze the color palette and pigments composition of 11th-century medieval wall paintings. Raman spectroscopy achieved the comparison between these pigments with others found in similar sites, confirming the hypothesis expressed by art historians. Besides the characterization of pigments, Raman spectroscopy is very practical in analyzing stone materials. As demonstrated in Prieto and co-workers' study [133], the lapis lazuli samples showed different Raman spectra due to the instability of the sulfur concentrations. Raman spectroscopy allowed for the correlation of some radical molecular ions $\mathrm{S}_{2}{ }^{-}, \mathrm{S}_{3}{ }^{-}$and $\mathrm{SO}_{4}{ }^{2-}$, with the color centers and coloration of lapis lazuli. As well, Raman spectroscopy can act as an auxiliary tool to characterize the corrosion products and ancient glass [15, 134]. Herrera et al. [27] studied the corrosion mechanism of amalgams in antique mirrors of the Andalusian baroque. The Raman spectra of the samples displayed two additional intense bands at 633 and $636 \mathrm{~cm}^{-1}$, which could be attributed to $\mathrm{SnO}_{2}$. The bands at 470, 513 and $750 \mathrm{~cm}^{-1}$ could be assigned to the presence of $\mathrm{SnO}$. In Won-in and co-workers' study [134], they paid attention to the fragments of the ancient Thai glass samples which was originally a part of decoration on the stucco at the collapsed Temple of the Emerald Buddha in the Grand Palace (Bangkok) built in 1782 A.D. To get additional information on the functional groups of the glass samples and to verify the data from the Raman spectra, the samples were analyzed by using Raman microscope. In the spectra of the sampled glass fragments, two characteristic peaks of lead-alkali glass were found around 970 and $1030 \mathrm{~cm}^{-1}$.

Micro-Raman spectroscopy had also been used in the field of historical building conservation. Pineda et al. [135] summarized the primary superiorities of this technique. It can be summarized as non-destructive analysis, high resolution, giving the possibility of detecting trace samples, in situ detection and the ability to characterize most of the inorganic and organic materials. Similarly, Smith et al. [136] confirmed the tremendous advantages of micro-Raman spectroscopy when it acted as the only technique to detect pigments in architectural heritage. Particularly, it can be used for direct non-destructive analysis of the unpretreated samples. In this study, three phases were definitively identified: blue cuprorivaite, black amorphous carbon and orange-red minium. The results contributed to the establishment of a standard Raman spectral database of materials, which were related to architectural heritage, such as pigments, geological materials and biomaterials. Kramar et al. [47] assessed the deterioration of limestone due to salt formation. Among the weathering types, it was observed that the efflorescences were more 
Table 2 List of main pigments used in architectural heritage characterized by Raman spectroscopy

\begin{tabular}{|c|c|c|c|c|c|c|}
\hline Color & Pigment name & Chemical formula & $\begin{array}{l}\text { Band wavenumber }\left(\mathrm{cm}^{-1}\right) \\
\text { and relative intensity }\end{array}$ & Chromophore & Sampling site & Refs. \\
\hline \multirow[t]{2}{*}{ Black } & Ivory black & $\mathrm{Ca}_{3}\left(\mathrm{PO}_{4}\right)_{2}+\mathrm{C}+\mathrm{MgSO}_{4}$ & $961 \mathrm{~m} ; 1325 \mathrm{vs} ; 1580 \mathrm{vs}$ & $C$ & Wall painting & {$[143,144]$} \\
\hline & Lamp black & $\mathrm{C}$ & 1325vs; 1580vs & $C$ & Wall painting & [145] \\
\hline \multirow[t]{8}{*}{ Blue } & Azurite & $\mathrm{Cu}_{3}\left(\mathrm{CO}_{3}\right)_{2}(\mathrm{OH})_{2}$ & $\begin{array}{l}\text { 145w; 180w; 250m; 284w; 335w; } \\
\text { 403vs; 545w; 746sh; 767m; } \\
\text { 839m; 940w; 1098m; 1432m; } \\
\text { 1459w; 1580m; 1623vw }\end{array}$ & $\mathrm{Cu}^{2+}$ & Marble monument/wall painting & {$[146]$} \\
\hline & Cerulean blue & $\mathrm{CoO} \cdot \mathrm{nSnO}_{2}$ & $495 \mathrm{~m} ; 532 \mathrm{~s} ; 674 \mathrm{vs}$ & $\mathrm{Co}^{2+}$ & Wall painting & [147] \\
\hline & Cobalt blue & $\mathrm{CoO} \cdot \mathrm{Al}_{2} \mathrm{O}_{3}$ & $203 v s ; 512 v s$ & $\mathrm{Co}^{2+}$ & Glazed tile decorative material & [148] \\
\hline & Egyptian blue & $\mathrm{CaCuSi}_{4} \mathrm{O}_{10}$ & $\begin{array}{l}\text { 114m; 137m; 200w; 230w; 358m; } \\
\text { 377m; 430vs; 475m; 571w; } \\
\text { 597vw; 762w; 789w; 992w; } \\
\text { 1012w; 1040w; 1086s }\end{array}$ & $\mathrm{Cu}^{2+}$ & Wall painting & {$[136,149]$} \\
\hline & Lazurite & $\mathrm{Na}_{8}\left[\mathrm{Al}_{6} \mathrm{Si}_{6} \mathrm{O}_{24}\right] \mathrm{S}_{\mathrm{n}}$ & 258w; 548vs; 822w; 1096m & $\mathrm{S}_{3}^{-}$ & Wooden tower/monstrance & {$[16,133]$} \\
\hline & Posnjakite & $\mathrm{CuSO}_{4} \cdot 3 \mathrm{Cu}(\mathrm{OH})_{2} \cdot \mathrm{H}_{2} \mathrm{O}$ & $\begin{array}{l}\text { 135vw; 208vw; 278vw; 327vw; } \\
\text { 467w; 612w; 983vs; 1092vw; } \\
1139 v w\end{array}$ & $\mathrm{Cu}^{2+}$ & Copper-based alloy/wall painting & {$[150,151]$} \\
\hline & Prussian blue & $\mathrm{Fe}_{4}\left[\mathrm{Fe}(\mathrm{CN})_{6}\right]_{3} \cdot 14-16 \mathrm{H}_{2} \mathrm{O}$ & 282vw; 538vw; 2102m; 2154vs & $\mathrm{Fe}^{3+}$ & $\begin{array}{l}\text { Damaged stuccowork/wooden } \\
\text { materials }\end{array}$ & [152] \\
\hline & Smalt & $\mathrm{CoO} \cdot \mathrm{nSiO}_{2}$ & $462 v s ; 917 m$ & $\mathrm{Co}^{2+}$ & Wall painting & [136] \\
\hline \multirow[t]{8}{*}{ Green } & Atacamite & $\mathrm{CuCl}_{2} \cdot 3 \mathrm{Cu}(\mathrm{OH})_{2}$ & $\begin{array}{l}122 \mathrm{~m} ; 149 \mathrm{~m} ; 360 \mathrm{w} ; 513 \mathrm{vs} ; 821 \mathrm{~m} ; \\
846 \mathrm{~s} ; 911 \mathrm{~s} ; 974 \mathrm{~s}\end{array}$ & $\mathrm{Cu}^{2+}$ & Wall painting & [153] \\
\hline & Chromium oxide & $\mathrm{Cr}_{2} \mathrm{O}_{3}$ & $221 v w ; 308 w ; 349 w ; 552 v s ; 611 w$ & $\mathrm{Cr}^{3+}$ & Wall painting & [154] \\
\hline & Cobalt green & $\mathrm{CoO} \cdot n \mathrm{ZnO}$ & $328 \mathrm{br} ; 434 \mathrm{vs} ; 471 \mathrm{~m} ; 555 \mathrm{~s}$ & $\mathrm{Co}^{2+}$ & Wall painting & [155] \\
\hline & Chrysocolla & $\mathrm{CuSiO}_{3} \cdot \mathrm{nH}_{2} \mathrm{O}$ & $\begin{array}{l}\text { 274w; 331w; 429w; 460w; 674w; } \\
\text { 744w; 906vw; 938vw }\end{array}$ & $\mathrm{Cu}^{2+}$ & Wall painting & [156] \\
\hline & Green earth & $\begin{array}{l}\text { Variations on } \mathrm{K}\left[\left(\mathrm{Al}^{3+}\right.\right. \\
\left.\left.\mathrm{Fe}^{3+}\right)\left(\mathrm{Fe}^{2+}, \mathrm{Mg}^{2+}\right)\right]\end{array}$ & $\begin{array}{l}\text { 1194w; 1225m; 1270w; 1350s; } \\
\text { 1459w; 1486m; 1600s }\end{array}$ & $\mathrm{Fe}^{2+}, \mathrm{Fe}^{3+}$ & Wall painting & [157] \\
\hline & Malachite & $\mathrm{Cu}_{2}(\mathrm{CO})_{3}(\mathrm{OH})_{2}$ & $\begin{array}{l}\text { 155s; 178s; 217m; 268m; 354m; } \\
\text { 433vs; 509m; 533s; 558w; } \\
\text { 757vw; } 1051 \mathrm{~m} ; 1085 \mathrm{~m} ; 1492 \mathrm{vs}\end{array}$ & $\mathrm{Cu}^{2+}$ & Wall painting/glass & {$[19,158]$} \\
\hline & Verdigris & $\mathrm{Cu}\left(\mathrm{C}_{2} \mathrm{H}_{3} \mathrm{O}_{2}\right)_{2} \cdot 2 \mathrm{Cu}(\mathrm{OH})_{2}$ & $\begin{array}{l}\text { 139vw; 181w; 231w; 328w; } \\
\text { 392w; 512w; 618w; 680w; 939s; } \\
\text { 1351w; 1417m; 1441m; 1552w; } \\
\text { 2937vs; 2988m; 3026w }\end{array}$ & $\mathrm{Cu}^{2+}$ & Stone architecture & {$[159]$} \\
\hline & Scheele's green & $\mathrm{Cu}\left(\mathrm{AsO}_{2}\right)_{2}$ & $\begin{array}{l}\text { 136s; 201m; 236w; 275m; 370vs; } \\
\text { 445w; 495m; 537vw; 657vw; } \\
\text { 780s }\end{array}$ & $\mathrm{Cu}^{2+}$ & $\begin{array}{l}\text { Polychrome decoration of archi- } \\
\text { tectural facade }\end{array}$ & [160] \\
\hline Orange & Mars orange & $\mathrm{Fe}_{2} \mathrm{O}_{3}$ & 224vs; 291vs; 407m; 494w; 608m & $\mathrm{Fe}^{3+}$ & Glazed tile decorative material & [161] \\
\hline \multirow[t]{6}{*}{ Red } & Litharge & $\mathrm{PbO}$ & $145 \mathrm{vs} ; 285 \mathrm{vw} ; 336 \mathrm{w}$ & $\mathrm{Pb}^{2+}$ & Wall painting & [162] \\
\hline & Cinnabar & $\mathrm{a}-\mathrm{HgS}$ & $\begin{array}{l}\text { 544vs; 478s; 390w; 312w; 227w; } \\
161 w\end{array}$ & $\mathrm{Hg}^{2+}$ & Stone architecture/wall painting & {$[163,164]$} \\
\hline & Realgar & $\mathrm{a}-\mathrm{As}_{4} \mathrm{~S}_{4}$ & $\begin{array}{l}\text { 142w; 164w; 171w; 182vs; 192s; } \\
\text { 220s; 233m; 327vw; 342m; } \\
\text { 354s; 367w; 375w }\end{array}$ & $\mathrm{As}^{2+}$ & Wall painting & [165] \\
\hline & Red lead & $\mathrm{Pb}_{3} \mathrm{O}_{4}$ & $\begin{array}{l}\text { 122vs; 149m; 223w; 313w; } \\
\text { 340vw; 390w; 480vw; 548vs }\end{array}$ & $\mathrm{Pb}^{2+}, \mathrm{Pb}^{4+}$ & Wall painting & {$[136,166]$} \\
\hline & Vermilion & $\mathrm{HgS}$ & $252 v s ; 282 w ; 343 m$ & $\mathrm{Hg}^{2+}$ & $\begin{array}{l}\text { Polychrome decoration of } \\
\text { wooden structure }\end{array}$ & [167] \\
\hline & Red ochre & $\mathrm{Fe}_{2} \mathrm{O}_{3}+$ clay + silica & 220vs; 286vs; 402m; 491w; 601w & $\mathrm{Fe}^{3+}$ & Stone architecture/wall painting & {$[54,166]$} \\
\hline
\end{tabular}


Table 2 (continued)

\begin{tabular}{|c|c|c|c|c|c|c|}
\hline Color & Pigment name & Chemical formula & $\begin{array}{l}\text { Band wavenumber }\left(\mathrm{cm}^{-1}\right) \\
\text { and relative intensity }\end{array}$ & Chromophore & Sampling site & Refs \\
\hline \multirow[t]{12}{*}{ Yellow } & Barium yellow & $\mathrm{BaCrO}_{4}$ & $\begin{array}{l}352 \mathrm{~m} ; 355 \mathrm{sh} ; 403 \mathrm{w} ; 427 \mathrm{vw} ; \\
863 \mathrm{vs} ; 901 \mathrm{~m}\end{array}$ & $\mathrm{Cr}^{6+}$ & Wooden tower & {$[16]$} \\
\hline & Cadmium yellow & $\mathrm{CdS}$ & $304 v s ; 609 s$ & $\mathrm{Cd}^{2+}$ & Wall painting & {$[168]$} \\
\hline & Chrome yellow & $\mathrm{PbCrO}_{4}$ & $338 \mathrm{w} ; 360 \mathrm{~s} ; 372 \mathrm{~m} ; 403 \mathrm{w} ; 841 \mathrm{vs}$ & $\mathrm{Pb}^{2+}, \mathrm{Cr}^{4+}$ & Wall painting & [145] \\
\hline & Cobalt yellow & $\mathrm{K}_{3}\left[\mathrm{Co}\left(\mathrm{NO}_{2}\right)_{6}\right] \cdot \mathrm{xH}_{2} \mathrm{O}$ & $\begin{array}{l}\text { 179m; 274s; 304vs; 821vs; 836m; } \\
\text { 1257w; 1326vs; } 1398 \mathrm{w}\end{array}$ & $\mathrm{Co}^{2+}$ & Wall painting & [168] \\
\hline & Gamboge & $\mathrm{C}_{38} \mathrm{H}_{44} \mathrm{O}_{8}$ and $\mathrm{C}_{29} \mathrm{H}_{36} \mathrm{O}_{6}$ & $\begin{array}{l}1215 \mathrm{w} ; 1246 \mathrm{~m} ; 1265 \mathrm{w} ; 1330 \mathrm{w} ; \\
1433 \mathrm{~m} ; 1592 \mathrm{~s} ; 1633 \mathrm{~m}\end{array}$ & Gambocic acid & Wall painting & {$[150]$} \\
\hline & Indian yellow & $\mathrm{MgC}_{19} \mathrm{H}_{16} \mathrm{O}_{11} \cdot 5 \mathrm{H}_{2} \mathrm{O}$ & $\begin{array}{l}\text { 484w; 610w; 631w; 697w; 772vw; } \\
811 \mathrm{w} ; 877 \mathrm{vw} ; 1009 \mathrm{vw} ; 1047 \mathrm{w} ; \\
\text { 1097w; 1127s; 1178m; 1218m; } \\
\text { 1266vw; 1345s; 1414w; 1476s; } \\
\text { 1503s; 1599vs }\end{array}$ & Euxanthic acid & Wall painting & [18] \\
\hline & Lead tin yellow & $\mathrm{Pb}_{2} \mathrm{SnO}_{4}$ & $\begin{array}{l}\text { 129vs; 196s; 275w; 291w; 303w; } \\
\text { 379w; 457m; 525w }\end{array}$ & $\mathrm{Pb}^{2+}, \mathrm{Sn}^{4+}$ & Glazed tile & [148] \\
\hline & Massicot & $\mathrm{PbO}$ & 143vs; 289s; 385w & $\mathrm{Pb}^{2+}$ & Wall painting & {$[63]$} \\
\hline & Naples yellow & $\mathrm{Pb}_{2} \mathrm{Sb}_{2} \mathrm{O}_{7}$ & $140 v s ; 329 m ; 448 w$ & $\mathrm{~Pb}^{2+}, \mathrm{Sb}^{5+}$ & Wall painting & [18] \\
\hline & Orpiment & $\mathrm{As}_{2} \mathrm{~S}_{3}$ & $\begin{array}{l}\text { 136w; 154s; 181vw; 202w; } \\
\text { 220vw; 230vw; 292m; 309s; } \\
\text { 353vs; 381w }\end{array}$ & $\mathrm{As}^{3+}$ & Monstrance & [133] \\
\hline & Saffron & $\mathrm{C}_{20} \mathrm{H}_{24} \mathrm{O}_{4}$ & 1165m; 1210w; 1282vw; 1536vs & Crocetin & Wall painting & [169] \\
\hline & Zinc yellow & $\mathrm{ZnCrO}_{4}$ & $\begin{array}{l}\text { 343m; 357sh; 370w; 409w; 772w; } \\
872 \text { vs; } 892 \mathrm{~m} ; 941 \mathrm{~m}\end{array}$ & $\mathrm{Cr}^{6+}$ & Copper-alloy monuments & {$[170]$} \\
\hline \multirow[t]{7}{*}{ White } & Barium white & $\mathrm{BaSO}_{4}$ & 453m; 461w; 616w; 647w; 988vs & - & Stucco surface & {$[171]$} \\
\hline & Zinc white & $\mathrm{ZnO}$ & $331 w ; 383 w ; 438 v s$ & - & Stone surface & {$[172]$} \\
\hline & Lead white & $2 \mathrm{PbCO}_{3} \cdot \mathrm{Pb}(\mathrm{OH})_{2}$ & $\begin{array}{l}667 v w ; 665 v w ; 687 v w ; 829 v w ; \\
\text { 1050vs }\end{array}$ & - & Stone surface & [173] \\
\hline & Bone white & $\mathrm{Ca}_{3}\left(\mathrm{PO}_{4}\right)_{2}$ & $\begin{array}{l}431 \mathrm{w} ; 590 \mathrm{w} ; 961 \mathrm{vs} ; 1046 \mathrm{w} ; \\
1071 \mathrm{vw}\end{array}$ & - & Wall painting & [174] \\
\hline & Chalk & $\mathrm{CaCO}_{3}$ & 157vw; 282vw; 1088vs & - & Stone architecture & {$[175]$} \\
\hline & Gypsum & $\mathrm{CaSO}_{4} \cdot 2 \mathrm{H}_{2} \mathrm{O}$ & $\begin{array}{l}\text { 181w; 414m; 493w; 619vw; } \\
\text { 670vw; 1007vs; } 1132 \mathrm{~m}\end{array}$ & - & Stone architecture & {$[36]$} \\
\hline & Lithopone & $\mathrm{ZnS}+\mathrm{BaSO}_{4}$ & $\begin{array}{r}216 w ; 276 v w ; 342 \mathrm{~m} ; 453 \mathrm{~m} ; \\
461 \mathrm{w} ; 616 \mathrm{w} ; 647 \mathrm{w} ; 988 \mathrm{vs}\end{array}$ & - & Wall painting & {$[165]$} \\
\hline
\end{tabular}

s strong, $m$ medium, $w$ weak, $v$ very, sh shoulder, $b r$ broad

complicated in terms of mineral assemblage in which the gypsum was associated to hexahydrite, pentahydrite and niter. In this work, micro-Raman spectroscopy was successfully used to determine the forms of mineral phases in limestone samples and their weathering products in ancient buildings and monuments. Since recently it is possible to perform in situ measurements by employing a more professional device named laser excited Fourier transform module. Burgio and coworkers offered a detailed FT-Raman spectra database of pigments and minerals [137] in which 60 pigments and related materials were collected. Seaward et al. [138] even applied FT-Raman technique to the demonstration of the highly destructive properties of calcium oxalate resulted from lichen thalli.

It should be noted that portable Raman spectroscopy is also an important instrument for the assessment of desalinization or cleaning treatments of heritage buildings, since it may help monitor the progressive salts removal and judge the time to stop the treatment [139, 140]. Assessment of stone deterioration by salt crystallization or identification of inorganic degradation products of mortars, stones and mural paintings can also be achieved by portable Raman equipment [141]. For example, Veneranda et al. [142] investigated the impact of agricultural activities on the degradation of a middle age mural painting. The results suggested that $\mathrm{Na}^{+}$and $\mathrm{NH}_{4}{ }^{+}$cations as well as $\mathrm{Cl}^{-}, \mathrm{NO}_{3}{ }^{-}$and $\mathrm{SO}_{4}{ }^{2-}$ anions were released from the used industrial unpurified $\mathrm{NaCl}$ and common fertilizers such as $\mathrm{NH}_{4} \mathrm{NO}_{3}$ and $\left(\mathrm{NH}_{4}\right)_{2} \mathrm{SO}_{4}$ against the snow and ice, as illustrated in Fig. 12. However, some salt efflorescences such as chlorides which are frequently found in buildings cannot be detected with portable Raman spectroscopy. Therefore, it is important 
to note that, although portable Raman does reduce dramatically the need of sampling and laboratory testing, it cannot replace the other traditional techniques.

\section{Ultraviolet-visible spectroscopy}

The generation of UV-vis spectra is related to the electron transitions among the outermost energy levels of the atoms. Their energies are in the range from near infrared (750-2500 nm), through visible $(400-750 \mathrm{~nm})$, to ultraviolet (200-400 nm). Both UV and Vis spectroscopies are extremely important to architectural heritage because they can deal with the measurement of materials related to colors originated from pigments [176-178], dyes $[179,180]$, stained glasses [181, 182], etc. From the physico-chemical point of view, these spectroscopies give us insight into the electronic mechanisms of color [40].

Routinely, the measurements of absorption spectra are performed by means of transmission spectrophotometry, similarly to IR techniques. Considering that the oxidation state of elements and the coordination modes are the determinants of color of materials, Fernandes et al. [15] used UV-vis absorption spectroscopy to investigate the stained glass fragments from Monastery of Batalha. The results revealed that there were many kinds of transition metal ions such as cobalt, copper and cobalt/manganese mixture in blue, green and purple glass matrix, respectively. As illustrated in Fig. 13, spectrum (a) showed the characteristic absorption bands of $\mathrm{Co}^{2+}$ ions in the tetrahedral configuration $\left[\mathrm{Co}^{\mathrm{II}} \mathrm{O}_{4}\right]$, which demonstrated that a triple band with maxima located at 540,590 and $640 \mathrm{~nm}$, respectively. Spectrum (b) demonstrated that $\mathrm{Cu}^{2+}$ presented in the octahedral configuration $\left[\mathrm{Cu}^{\mathrm{II}} \mathrm{O}_{8}\right]$ form with maximum absorption at approximately $800 \mathrm{~nm}$. Spectrum (c) presented the optical absorption of the purple glass which was attributed to cobalt and manganese

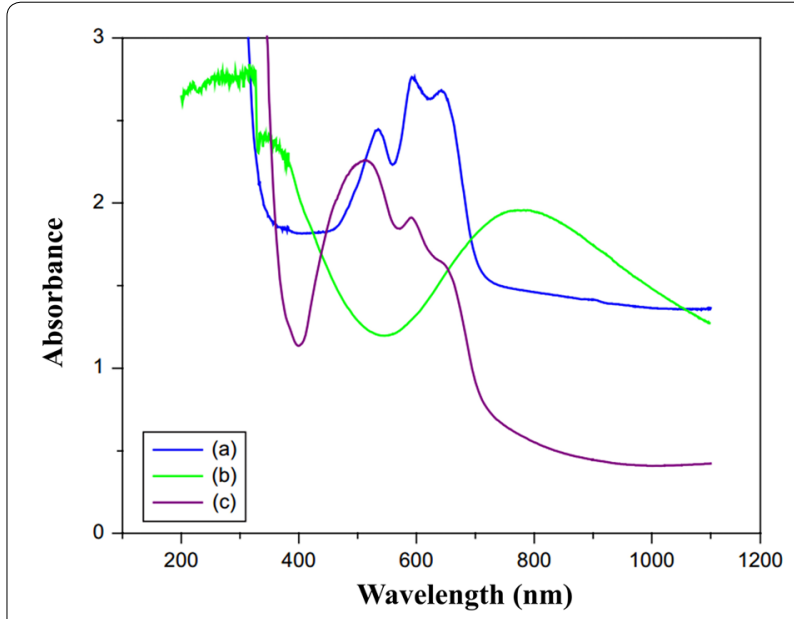

Fig. 13 UV-vis spectra achieved from a blue; $\mathbf{b}$ green and $\mathbf{c}$ purple glass samples [15], copyright (2008) Elsevier

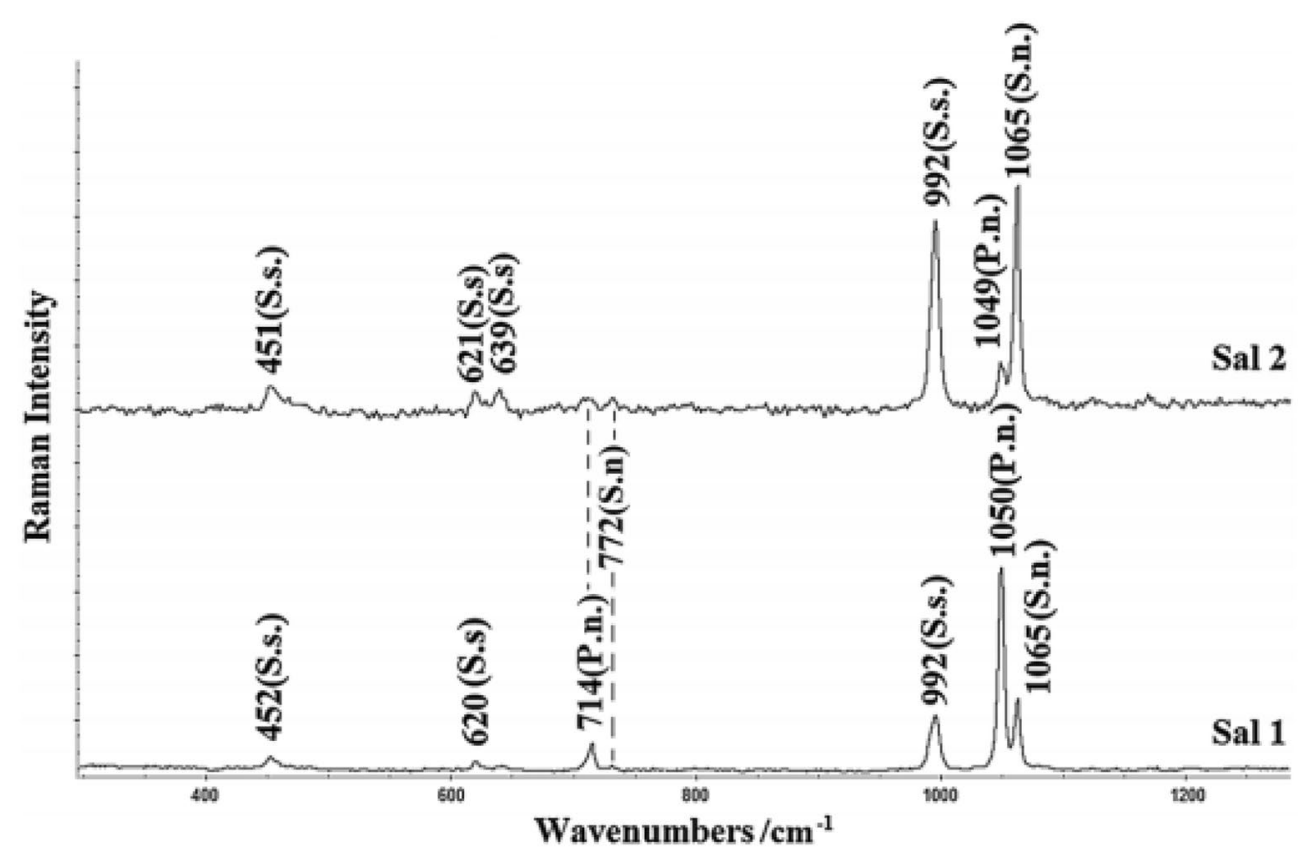

Fig. 12 Comparison of the Raman spectra obtained from Sal1 and Sal2 samples. The first efflorescence showed an intense peak due to the potassium nitrate (P.n.), while the major signals of Sal2 are attributed to the presence of sodium sulfate (S.s.) and sodium nitrate (S.n.) [142], copyright (2014) John Wiley and Sons 
matrix. $\mathrm{Co}^{2+}$ exhibited the same triple band as in spectrum (a) resulting from the $\left[\mathrm{Co}^{\mathrm{II}} \mathrm{O}_{4}\right]$ configuration, while the $\mathrm{Mn}^{3+}$ ions in octahedral $\left[\mathrm{Mn}^{\mathrm{III}} \mathrm{O}_{6}\right]$ illustrated band peak at $500 \mathrm{~nm}$. Vilarigues et al. [183] adopted optical absorption spectroscopy in the UV-vis range to characterize the stained glass fragments from the 15th, 16th and 20th centuries collected in Batalha, Portugal. The glass with yellow silver stain showed the characteristic peak located around $420 \mathrm{~nm}$, which was attributed to the surface Plasmon resonance of colloidal silver particles. In addition, since materials of ancient buildings were commonly contaminated by the chemical reagents applied in the cleaning processes, Dei et al. [184] found that the mixtures of acetone and ammonium carbonate applied to clean murals and stone materials in the past were unstable and usually produced by-products within a few days and then affected the health of mural surfaces. In particular, this cleaning agent was inclined to change color after 3 or 4 days, turning pale yellow and the mixtures changed color dramatically to red-brown after 2 or 3 weeks. Finally, the degradation products (ammonia and pyrimidine products) were identified by UV-vis spectroscopy, which suggested that the application of acetone and ammonium carbonate mixture must be prohibited since these two products can interact with building materials and destroy their composition and structure. Overall, the above cases confirmed the validity of UV-vis spectra for surveying the color materials. Even more interesting, Rodriguez-Navarro et al. [185] applied UV-vis spectroscopy to the investigation of the quality enhancement of lime mortars and plasters when the mucilaginous juice extracted from nopal cladodes was used as additive, and this can be found in ancient Mesoamerica and Southwest of USA. The UV-vis spectrum results showed that polysaccharides in nopal aqueous extract and citrus pectin (a strong band centered at approximately $210 \mathrm{~nm}$ corresponding to carboxyl groups, $n \rightarrow \pi^{*}$ transitions) suffered from significant structural modification in contact with the slaked lime putty (a small shoulder at $260 \mathrm{~nm}$ ). Such modifications promoted steric stabilization, which limited aggregation, and thus enhance the colloidal nature of the lime putty.

The in situ measurement of architectural heritage materials such as wall paintings or decorative materials were frequently needed so a large number of advanced surface reflection techniques based on optical fiber and digital recording have been developed. For example, in Edreira and co-workers' series of studies [186-188], they combined reflectance spectra and normalized CIE64 system [189] to chromatic characterization of Roman wall paintings located in Spanish historic buildings. Similarly, Garofano et al. [144] used reflectance spectra to identify natural earth pigments of Roman and Arabic wall paintings. The results showed that most ferric oxide/ oxyhydroxide minerals possessed reflectance maxima between 700 and $800 \mathrm{~nm}$. Bluish and greenish pigments presented dominant wavelength values around 480 and $570 \mathrm{~nm}$, respectively. In the case of the fragments from Pompeii, reflection wavelengths at 473, 530 and $707 \mathrm{~nm}$ were observed, which indicated the presence of Egyptian blue and hematite. Furthermore, the dominant wavelengths at 531 and $473 \mathrm{~nm}$ were attributed to the presence of glauconite and celadonite. In general, for the characterization of pigments in situ, UV-vis diffuse reflectance spectroscopy is a supporting technique to further testify the analysis by FTIR and Raman spectroscopy measurements [190].

\section{Laser-induced breakdown spectroscopy}

Laser-induced breakdown spectroscopy (LIBS) is a rapid analytical technique for qualitative and semi-quantitative characterization of the target samples [191-193]. The theory is that when a high energy laser pulse excites the surface of a target sample, a small amount of the sample (ng to $\mu \mathrm{g}$, invisible to the naked eye) will be ablated, and then the luminous laser-induced plasma (LIP) about a few microseconds is generated. The optimal condition for LIBS detection is when the plasma plume begins to cool down, since intensive ionic and atomic emission lines can be identified in the elemental spectra at this moment. Thus, the presence of many major, minor and trace elements in different types of materials can be detected by LIBS analysis. The laser beam normally focused on the $100-150 \mu \mathrm{m}$ micro-regions so that the analysis performed in the LIBS technique can be deemed to a microdestructive way.

Over the past two decades, studies in several research groups had proved that LIBS is a reliable method for solving problems related to characterization of architectural heritage materials. LIBS was adopted to analyze the constituents in pigments of mural painting [105, 191, 194], stones [192, 195], bricks [11, 196] and roof sheets [197]. For example, Brysbaert et al. [198] used LIBS technique to determine the elemental contents in pigments of a wall painting at Eastern Mediterranean Bronze Age. Their results revealed the presence of Egyptian blue material $\left(\mathrm{CuCaSi}_{4} \mathrm{O}_{10}\right.$, cuprorivaite), as illustrated in Fig. 14a. In addition, they found elements other than copper, such as iron and magnesium in the Palaikastro blue pigments (Fig. 14b). Meanwhile, the above experimental results may confirm the existence of another type of blue pigment on Crete and elsewhere, and it was called glaucophane [199]. In terms of red pigments, it was proved that abundant iron elements are in all the samples by means of observing the strong emission characteristics of LIBS spectra. The presence of 


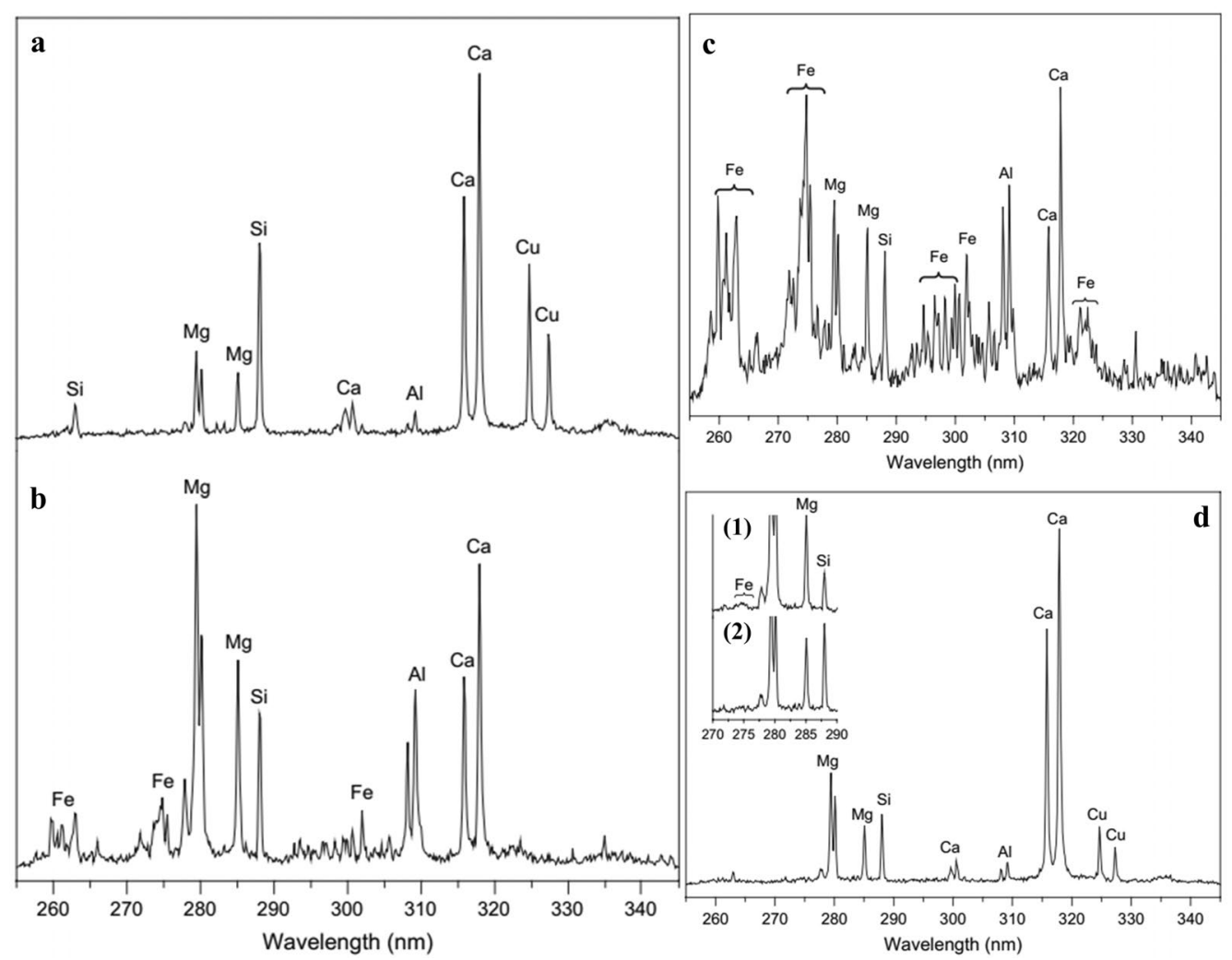

Fig. 14 LIBS spectra of different pigments collected from three different sampling sites in the Bronze Age Eastern Mediterranean. $\mathbf{a}$, b Blue colored samples; c red colored samples; d green colored samples [198], copyright (2006) Elsevier

iron can be identified on the basis of numerous spectral signatures in the range of 258-264, 271-275, 293-302 and $321-323 \mathrm{~nm}$, respectively (Fig. 14c). The existence of iron in the red pigment further verified the fact that most materials used in Bronze Age Aegean painting were haematite $\left(\mathrm{Fe}_{2} \mathrm{O}_{3}\right)$. Furthermore, the analysis of green samples exhibited a spectrum extremely similar to the blue pigment. The enhancement of emission spectrum of the copper element indicated that the green pigment was a copper-based material such as malachite. However, the emission spectra of copper and silicon increased simultaneously, which suggested the possibility of the existence of the blue pigment. In addition, a weak emission spectrum from the first pulse showed a small amount of iron (less than 5\%), which might be the presence of minimal amount of yellow ochre (as shown in Fig. 14d, inset (1)). Therefore, they concluded that green areas on the surfaces of the wall painting were caused by the mixture of yellow ochre and Egyptian blue. Similarly, LIBS technique was used to discriminate the elemental composition of the pigments from Taxiarhis Church which was built by Architect Emanuel Kounas in 1873 [18]. LIBS analysis of the brown mural surfaces revealed the existence of iron and lead. The existence of iron confirmed the use of iron-containing pigments, such as iron oxide. The detection of accidental lead emission signal was attributed to impurities originated from the priming layer, and the dominating component was anglesite $\left(\mathrm{PbSO}_{4}\right)$. LIBS analysis of green mural surfaces showed the presence of sodium, magnesium, aluminum and iron, and suggested the use of "green earth" (celadonite and glauconite) as pigment in the painting [200]. Moreover, the LIBS spectrum showed that the red colored mural surface exhibited strong signals of lead and chromium, implying the employment of chrome red $\left(\mathrm{PbCrO}_{4} \cdot 2 \mathrm{PbO}\right)$ as pigment.

Another impressive analytical advantage of LIBS is the possibility to achieve a depth cross-section analysis of the successive coating materials. The rationale behind this feature is that in the process of characterization, each laser pulse can be used to remove a small amount of material's surface, and therefore the following pulse always detects a new part of the paint layer slightly deeper than the former one. The continuous LIBS spectra of the same point in the sample revealed the stratified distribution of the paint layers by carrying out essentially an in situ cross-sectional analysis [201]. For instance, during the investigation of a fresco fragment collected from the Italian archeological area of Pompeii, the intensity ratios 
of silicon, calcium and magnesium and the other elements relative to iron were used as indexes for pigment identification and the assessment of the thickness of the mural paintings [202]. Klein et al. used LIBS technique to conduct online cleaning of contaminants on the sandstone and stained glasses in which the relative intensities of relevant emission peaks of elements can be selected as a control parameter to monitor the cleaning process [203]. Their relative intensities changed due to the laser ablation removed the superficial encrustation and moved toward the substrate.

In practical application, the LIBS technique cannot completely replace other traditional and destructive techniques, but under particular circumstances, it can perfectly identify several organic and inorganic pigments by combining with Raman spectra [204, 205]. Trusso et al. combined LIBS with Raman techniques to investigate the elemental composition of decorative coating materials from an ancient building near Licata, Sicily [205]. LIBS spectrum on yellow pigment showed the emission feature lines of iron at 426.1, 427.2, 432.6, 438.4 and $440.5 \mathrm{~nm}$, and the characteristic Raman bands were centered at about 240, 246, 300, 387, 416, 482, 551 and $1008 \mathrm{~cm}^{-1}$, which affirmed that the compound containing iron elements was goethite $\alpha-\mathrm{FeOOH}$, which was the most familiar and stable iron oxy-hydroxide. Particularly, the yellow pigment was identified as ochre which has a large content of hydrated iron oxide $\mathrm{Fe}_{2} \mathrm{O}_{3}-\mathrm{H}_{2} \mathrm{O}$ or $\mathrm{FeOOH}$ (goethite). Recently, Syvilay et al. [206] introduced LIBS and Laser Ablation-Inductively Coupled Plasma-Mass Spectroscopy (LA-ICP-MS) to detect the trace elements in a lead based roof sheets of Beauvais Cathedral. Similar conclusions can be drawn via both techniques (the correlation coefficient was estimated at 0.86 ), but LIBS is more portable and suitable to in situ analysis. It is noteworthy that matrices in different samples are complicated, leading to the LIBS spectra are always extremely complex and a great deal of information is lost during the univariate analysis. Hence, the combination of multivariate methods and LIBS technique has achieved a great success in recent years, such as PCA, LDA and artificial neural network (ANN). The above mentioned methods can interpret data obtained from LIBS characteristic spectra, reduce the number of variables and even screen significant emission lines, which facilities to provide solutions to classification and identification composition of material with high degree of precision and accuracy $[11,207$, 208].

\section{Thermal gravimetric analysis}

Thermal analysis (TA) is a method of analyzing the relationship between thermodynamic and physicochemical parameters with the changes of temperature. Now the TA mainly contains three methods which are thermosgravimetry (TG, also called differential TG or DTG), differential thermal analysis (DTA) and differential scanning calorimetry (DSC). TG detects the changes in weight of materials driven by the changes in temperature (weight loss curve), which is closely related to their chemical, structure and textural nature. DTA measures the temperature difference between the material under study and an inert reference material (typically $\mathrm{Al}_{2} \mathrm{O}_{3}$ ) during heating under identical conditions. Therefore, a DTA curve offers information on all transformation that occurs during heating, such as structure decomposition, phase transformation, crystallization, sublimation, etc. With respect to DSC, it is a thermo-analytical technique of measuring the energy difference between the target sample and the reference material with the temperature variations. DSC which is quite similar to DTA can be used to characterize a large amount of characteristic properties of the sample. Specially, this technique takes the heat flux as the ordinate and the temperature as the coordinate, revealing the information about heat capacity, reaction heat, transformation heat, phase diagram, reaction rate, crystallization rate, etc. Because of the sensitivity in detecting subtle phase transitions and also reactions in amorphous, organic and polymeric materials, thermal analysis has been largely used in the measurement of composition properties of materials used in architectural heritage $[40,209,210]$. For example, weight losses at reaction temperatures around $750{ }^{\circ} \mathrm{C}$ indicates loss of $\mathrm{CO}_{2}$ from recarbonated lime, not from the pure $\mathrm{CaCO}_{3}$. As for the clay minerals, the endothermic peak near $100^{\circ} \mathrm{C}$ is attributed to hygroscopic moisture (also known as physically adsorbed water), whereas those appearing at approximately $200-250{ }^{\circ} \mathrm{C}$ are due to hydrated inter-layer cations (i.e. bound water) [211]. Carbonates exhibit distinctive endothermic peaks: the characteristic peak of calcite is about $840{ }^{\circ} \mathrm{C}$ and the doublets of dolomite are around $780{ }^{\circ} \mathrm{C}$ and $860{ }^{\circ} \mathrm{C}$. Their positions may change depending on grain size, analyses environment and the other coexistence factors, and they are mainly attributed to the escape of $\mathrm{CO}_{2}$ during their structure breakdown. DTA can also distinguish between high-calcium limestones and dolomites, even the intermediate materials such as dolomitized limestones [212]. Furthermore, the thermal analysis methods permit the quantification of the main deterioration products found on black crusts [213-217], such as carbonate carbon (CC) constituting the monument, organic carbon $(\mathrm{OC})$ of both biological and human sources, and elemental carbon (EC) emitted by combustion processes. 
Among all the materials of historic buildings, the origin, component and degradation of ancient mortars have aroused great interest among restorators in both laboratory and in-field researches. As an important tool, thermal analysis can identify the degree of carbonation and hydration reactions of mortars [209]. In the early studies, Bakolas et al. [218] applied thermal techniques to investigate the major compounds of traditional mortars in Venice. The weight loss was detected in the temperature range of $500-600{ }^{\circ} \mathrm{C}$, which was due to the decomposition of carbonates. In view of the long tradition of using pozzolanic additions in mortars during the existence of Roman Empire, Velosa et al. [219] applied TG/DTG techniques to characterize the ancient pozzolanic mortars from Roman time to the 19th century. In the case of mortars from the Azores island of S. Miguel, a peak at $460{ }^{\circ} \mathrm{C}$ appeared in the DTG curve was attributed to the loss of hydration water from pozzolanic additions, either from calcium silicate hydrates, alumino-silicate phases or iron oxide contained in the mortar. Similarly, in Schueremans and co-workers' study [220], TG/DTG analysis was used to carry out the quantification of percentage composition of calcium carbonate, carbon dioxide, calcium hydroxide, and hydration degree of ancient Roman mortars. The results matched well with the PXRD and chemical analysis which further demonstrated the ancient Roman mortars containing brick particles. Pineda et al. [135] used TG/DTA techniques to characterize the mortars of the medieval building materials of a Hispanic-Islamic construction. The results suggested that mortars were prepared by employing lime as the binder and quarzitic sand as the aggregate. Silva et al. [55] used TG/DTA techniques to detect mineralogical and chemical composition of ancient mortars from military fortifications in Lisbon harbor, Portugal. Important weight loss occurred at higher temperature than $600{ }^{\circ} \mathrm{C}$, corresponding to $\mathrm{CaCO}_{3}$ decomposition processes and revealing high calcite level in the mortars. Moreover, weight loss occurring in the range of $120-200{ }^{\circ} \mathrm{C}$ can be attributed to hydrated salt components, which were compatible with the geographical position of this construction at the stream outlet, close to the open sea.

In addition to the above ancient buildings, an increasing number of mortars collected from important monuments of the world heritage were also analyzed by thermal techniques in recent years. The hydraulicity of the mortars collected from Serapis temple built in Roman period in the city of Pergamon. Turkey was evaluated by TGA. The analysis results suggested that the samples contained $2.33 \%$ structurally bound water (weight loss occurring at the range of 200 and $600{ }^{\circ} \mathrm{C}$ ) and $6.87 \%$ carbon dioxide (weight loss being found higher than $600{ }^{\circ} \mathrm{C}$ ). The ratio of $\mathrm{CO}_{2} / \mathrm{H}_{2} \mathrm{O}$ was 2.95 , indicating the mortars can be treated as hydraulic lime mortars [221, 222]. Unlike the European mortars, the hydraulic mortar technology was not developed in ancient China due to the absence of natural hydraulic materials such as volcanic ash. In China, organic-inorganic hybrid mortars were mainly fabricated by some natural organic compounds, such as vegetable leaves juice, sticky rice soup, egg white, animal blood, tung oil or even fish oil [102]. Interestingly, Xiao et al. [71] used TG/DSC techniques to characterize the composition of sticky rice-lime mortars collected from the city wall of Wugang Ming dynasty. The TG/DSC results of the mortar samples were illustrated in Fig. 15a. Due to high thermal stability of calcium sulfate with decomposition temperature above $1200{ }^{\circ} \mathrm{C}$, it could be decomposed at temperature below $900{ }^{\circ} \mathrm{C}$. As shown in DSC curve, three endothermic peaks at approximately 110,420 and $720{ }^{\circ} \mathrm{C}$ could be observed, which was ascribed to the evaporation of water in mortars, decomposition from $\mathrm{Ca}(\mathrm{OH})_{2}$ into $\mathrm{CaO}$ and $\mathrm{H}_{2} \mathrm{O}$ [211], and decomposition from $\mathrm{CaCO}_{3}$ into $\mathrm{CaO}$ and $\mathrm{CO}_{2}$, respectively. It was noticeable that a very weak and
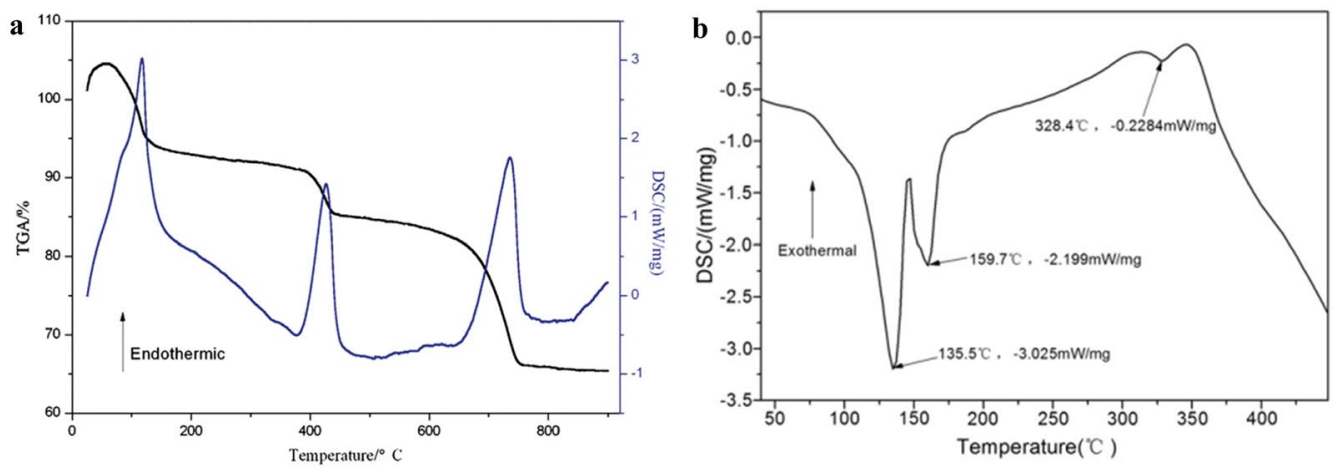

Fig. 15 TG-DSC curves of sticky rice-lime mortars sampled from the Wugang Ming dynasty city wall [71], copyright (2014) Elsevier 
broad endothermic peak can be observed at approximately $320-380{ }^{\circ} \mathrm{C}$ as well. In order to further verify the existence of this weak endothermic peak, individual DSC measurement was carried out (as illustrated in Fig. 15b). The DSC results clearly showed the existence of an endothermic peak centered at $328{ }^{\circ} \mathrm{C}$. It is well known that amylopectin, a major substance of sticky rice, usually starts to decompose at approximately $320{ }^{\circ} \mathrm{C}$ [223]. It is believed that the endothermic peak at approximately $328{ }^{\circ} \mathrm{C}$ was ascribed to the decomposition of sticky rice. Furthermore, the content of $\mathrm{CaCO}_{3}, \mathrm{Ca}(\mathrm{OH})_{2}$, water and organic compounds were quantified through the percentage of weight loss of TG curves. According to the TG curve, weight losses of $\mathrm{Ca}(\mathrm{OH})_{2}$ and calcite were calculated to be about $6 \%$ and $20 \%$ respectively, implying the weight percentages of $\mathrm{Ca}(\mathrm{OH})_{2}$ and $\mathrm{CaCO}_{3}$ in mortars were $25 \%$ and $45 \%$ respectively. By contrast, weight loss of organic compounds from the TG curves was estimated to approximately $3 \%$. The results indicated the presence of amounts of organic and inorganic compounds in mortars collected from the Wugang Ming dynasty city wall.

As mentioned above, hydraulic property is an important indicator of the composition of mortars [224, 225]. The weight loss occurred at temperatures lower than $600{ }^{\circ} \mathrm{C}$ is attributed to loss of chemically bound water of hydraulic products (calcium silicate hydrates and calcium aluminate hydrates) [218]. The weight loss at temperatures above $600{ }^{\circ} \mathrm{C}$ is assigned to the $\mathrm{CO}_{2}$ release in the process of decomposing carbonates. When $\mathrm{CO}_{2} /$ $\mathrm{H}_{2} \mathrm{O}$ ratio is less than 10 , mortars can be considered as hydraulic substances [226]. Maravelaki-Kalaitzaki et al. [227] used a graphical method $\left(\mathrm{CO}_{2} / \mathrm{H}_{2} \mathrm{O}\right.$ ratio vs $\mathrm{CO}_{2}$ percentage, as illustrated in Fig. 16) to differentiate the hydraulicity of four typical mortars, i.e., crushed brick lime mortars, pozzolanic mortars, lime mortars and hydraulic lime mortars. The results showed that the typical lime mortars correspond to less than 1.5\% chemically bound water to hydraulic composition and $\mathrm{CO}_{2}$ values were in the range of $30-38 \%$. The hydraulic lime mortars released $27-34 \%$ of $\mathrm{CO}_{2}$ and contained not greater than $5 \%$ of chemically bound water, indicating intermediate hydraulic feature. The crushed brick lime mortars showed hydraulic water and $\mathrm{CO}_{2}$ content ranging from $4-5 \%$ to $24-26 \%$, respectively, indicating higher hydraulic feature than the hydraulic lime mortars. Finally, the pozzolanic mortars showed not less than 7\% hydraulic water and less than $20 \% \mathrm{CO}_{2}$, indicating the super hydraulic feature. Furthermore, Theodoridou et al. [56] used TG-DTA techniques to characterize the Late Bronze Age mortars from Cyprus. The results showed that hydrated lime and finely ceramic particles were used as binders, siliceous or carbonaceous components which were performed as fine aggregates. This paper combining

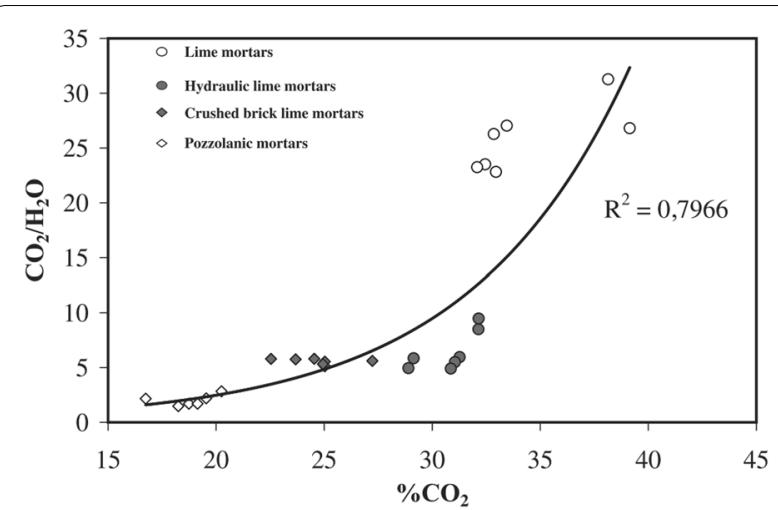

Fig. 16 The hydraulic curves of the four mortars were fitted through $\mathrm{CO}_{2} / \mathrm{H}_{2} \mathrm{O}$ ratio (weight loss percentage $>600^{\circ} \mathrm{C} /$ weight loss percentage between 200 and $600^{\circ} \mathrm{C}$ ) versus $\mathrm{CO}_{2}$ percentage (weight loss percentage $>600^{\circ} \mathrm{C}$ ) [227], copyright (2003) Elsevier

with historical data clearly demonstrated the pathway of technological transfer in that era. For instance, in the region of Levant, crushed igneous rock was potentially imported from Cyprus at Iron Age. For this reason, the results can be cited by some researchers and historians to further investigate the composition of ancient mortars and the provenance of raw materials.

\section{X-ray based techniques}

X-ray methods are now ubiquitous in architectural heritage studies and mainly involve laboratory-based procedures. These procedures include well-documented analytical techniques, such as X-ray diffraction (XRD) to determine crystal structure, X-ray fluorescence (XRF) to measure elemental composition, X-ray photoelectron spectroscopy (XPS) to measure electronic structure of solid surface and X-ray absorption spectroscopy (XAS) to identify the electronic structure of a material. In this part, the application examples of X-ray techniques in heritage conservation were discussed.

\section{$X$-ray fluorescence spectroscopy}

$\mathrm{XRF}$ is one of the most popular instruments for the elemental analysis of ancient materials. The essentials of this technique are simple: core electrons ( $\mathrm{K}$ or $\mathrm{L}$ ) of the atoms are expelled by high energy primary X-rays, the unstable ionized atom then relaxes to the base state by a series of electron jumps into lower orbitals to fill the vacancies, thereby emitting fluorescence photons in the X-ray region which correspond to the quantum structure of the atom. The fluorescence emission, also called secondary $\mathrm{X}$-rays, represents the "characteristic" spectrum of the atom, and it may be readily used to perform the qualitative and quantitative analysis of the chemical elements. 
The experimental instrument for the measurement of XRF spectra is composed of an X-ray or $\gamma$-ray source used to irradiate the target sample, a sample stage and holder, and a system for detecting the fluorescent X-rays. Typical XRF spectrum shows the intensity of fluorescence X-rays emitted by sample (commonly in counts/ unit time) as a function of energy (in eV). After appropriate calibration and correction for matrix self-absorption effects and detector efficiency, the integrated areas of the fluorescence peaks are converted into relative concentrations of the analyzed chemical elements. In general, it can measure specific elements whose atomic numbers are greater than 15 , even a small quantity of exceptional detectors can measure light elements such as carbon, oxygen and nitrogen so it can be very helpful in analyzing historic building materials.

There are two main types of detector systems: those depended on solid-state detectors and multi-channel analyzers which are capable of directly detecting the energy of the fluorescent X-rays (the system is called EDS: energy dispersive spectrometry) and those based on a diffraction grating, typically a single crystal analyzer which detects the energy produced by fluorescent X-ray indirectly via diffracting the different wavelengths of the collimated fluorescent signal at different angles (the system is called WDS: wavelength dispersive spectrometry). The range of detectable elements of EDXRF varies from sodium $(\mathrm{Na})$ to uranium $(\mathrm{U})$, whereas WDXRF can widen this scope down to beryllium (Be). The detection limit is generally at the ppm level, and in some cases can reach the sub-ppm level [228]. Furthermore, the WDXRF has lower counting rates but higher energy resolution (typically $5-10 \mathrm{eV}$ ) and therefore they can discriminate overlapping fluorescence lines more efficiently. The EDXRF has higher counting rates but sensibly lower energy resolution (typically 150-200 eV). As a consequence, EDXRF systems are often used to carry out fast low-resolution measurements [229, 230], but WDXRF systems is commonly used for off-line and high-resolution analysis in the laboratory. Being compared with other spectrometers, both EDXRF and WDXRF require longer counting times and/or larger amounts of samples. As the inherent advantages, the studies about characterization of historic building material are various. For example, the Casas de Paredes is an example of 18th century neoclassical architecture built with granitic rocks. A large number of neoformation coatings were generated on the main facades of the buildings, causing a visible soiling and affecting the aesthetics. Sanchez et al. [214] applied XRF technique to explore the types of coatings. The results showed that $\mathrm{CaO}, \mathrm{SO}_{3}, \mathrm{SiO}_{2}, \mathrm{Al}_{2} \mathrm{O}_{3}, \mathrm{Fe}, \mathrm{K}, \mathrm{P}, \mathrm{Pb}$ and $\mathrm{Cu}$ are the major elements, indicating that the composition of coatings originated from deposition of atmospheric pollution.
Moreover, XRF can be applied to analyze the major and trace elements of ancient materials to explore the geographic origin of the quarries, as described by Colao and co-workers [231]. In this study, 48 different types of specimens were measured. Data obtained by XRF were analyzed by using multivariate statistical method which included the linear discriminant analysis (LDA), principal component analysis (PCA) and soft independent modeling of class analogy (SIMCA). The results revealed that all the samples can be divided into certain quarries located in Seville province and unknown provenance. Furthermore, Gotze et al. [232] applied XRF to the investigation of the major and trace elements of building sandstones from Saxony, Germany. The results revealed that the main elements contained in the samples were very representative and monotonous. The content of silica was large and the concentrations of the other elements were relatively low.

Recent developments of XRF instruments in the field of architectural heritage aimed at making the equipment portable and non-destructive [233, 234]. XRF instrument equipped with a handheld analyzer is generally employed to conduct surface and layer elementary analysis toward samples. In particular, the elemental composition acquired by the portable XRF (PXRF) analyzer can provide valuable information for subsequent sampling operations, and then minimize the damage from aimless sampling. For example, Calva et al. [235] applied PXRF technique to the analysis of colored fragments of plasters and floors collected from ancient Sicilian constructions. The results demonstrated that the mortars were mainly constituted of calcite in which the red or pinkish substrates were composed of iron oxides and ochres, while the white pigments were mainly composed of $\mathrm{CaCO}_{3}$. Furthermore, the PXRF was used by Gomez-Laserna et al. [236] to explore the origin and deterioration mechanisms caused by atmospheric weathering and infiltration water erosion, suggesting that despite the signals of heavy metal elements can be detected on the appearance of the facade, no signals corresponding to toxic metal pollutants such as $\mathrm{Zn}, \mathrm{Cu}, \mathrm{Pb}$ or $\mathrm{Mn}$ were measured at a significant level either in damaged areas or in intact areas. From this point, it was not necessary to detect heavy metal contaminants by the other destructive techniques, especially regarding transportation and industrial activities. Synchrotron radiation is a continuous spectrum with intense power, high intensity, super brightness and variable wavelength. The major advantages of synchrotron radiation are: (1) high flux and brilliance, ability to generate a rapid data collection and the feasibility of utilizing small sample sizes (small beam footprint 2D and 3D studies to sub-mm/micro length scale); (2) possibility of wavelength tunability and selection of energy 
region to meet the test requirements [237, 238]. Synchrotron radiation techniques are especially suitable for non-destructive or micro-destructive analysis of different types of materials including organic and inorganic components, either amorphous or crystalline materials. The new developments of synchrotron radiation techniques have made great progress in the characterization of various materials with different non-destructive techniques (X-ray fluorescence and diffraction) at $\mu \mathrm{m}$ length scale. In Figueiredo and co-workers' study [239], the chemical characterization of stone alteration materials and lichen encrustations were performed by a non-destructive instrument which was synchrotron radiation X-ray fluorescence spectroscopy (SR-XRF). The SR-XRF spectra collected from lichen encrustations over granite blocks revealed the contribution of biogenically concentrated elements such as lead and bromine which were mainly originated from lichen biological activities. The recent developments of combination of X-ray fluorescence and synchrotron radiation sources have permitted determination of relative elemental abundance with high precision and accuracy and explained correlations among the different elements. Therefore, these advantages may allow measurement of the iron oxides and oxyhydroxides present in the dark brown layer of wall paintings. Herrera et al. [240] applied SR- $\mu$-XRF to the analysis of the micro cross-section of the samples. The XRF maps showed the elemental distribution in the samples (as illustrated in Fig. 17). It can be divided into two layers from the base to the surface. In the upper brown layer, the XRF maps showed the elemental distribution of iron and manganese. The deeper part mainly contained lead, calcium and

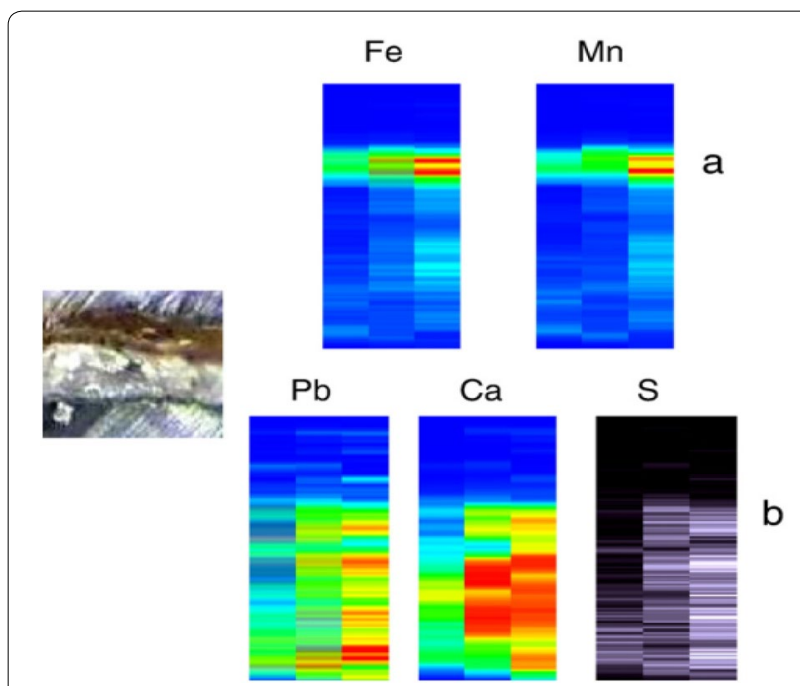

Fig. 17 Elemental mapping detecting by SR- $\mu$-XRF technique: a brown layer; b white layer [240], copyright (2008) Elsevier sulphur, and lead was the major component while calcium and sulfur were derived from the basement of the wall painting (as shown in Fig. 17b).

More interestingly, Veerle et al. [241] used SR- $\mu$-XRF to reveal the elements distribution as function of the depth from the Bray sandstone surface (as illustrated in Fig. 18). The results revealed that the highest content of calcium was found at the surface of the crust, and the amount of calcium was strongly reduced $0.5 \mathrm{~mm}$ below this surface. The same explanation can be done for almost all of elements except for silicon which was detected in the point spectra. More importantly, this study revealed that SR- $\mu$ XRF can measure more elements than the laboratorial XRF technique which was attributed to the $90^{\circ}$ geometry at the synchrotron. With respect to the samples, SR- $\mu$ $\mathrm{XRF}$ found that the calcium and sulfur elements were enriched at the surface layer and the concentrations of titanium, potassium, iron and manganese at the surface layer were much higher than the other depths which could not be detected by traditional XRF technique. Furthermore, Maguregui et al. [35] combined analytical diagnosis methodologies to assess nitrate impact on architectural heritage materials. SR- $\mu$-XRF was utilized to distinguish the original elements of the brick and the

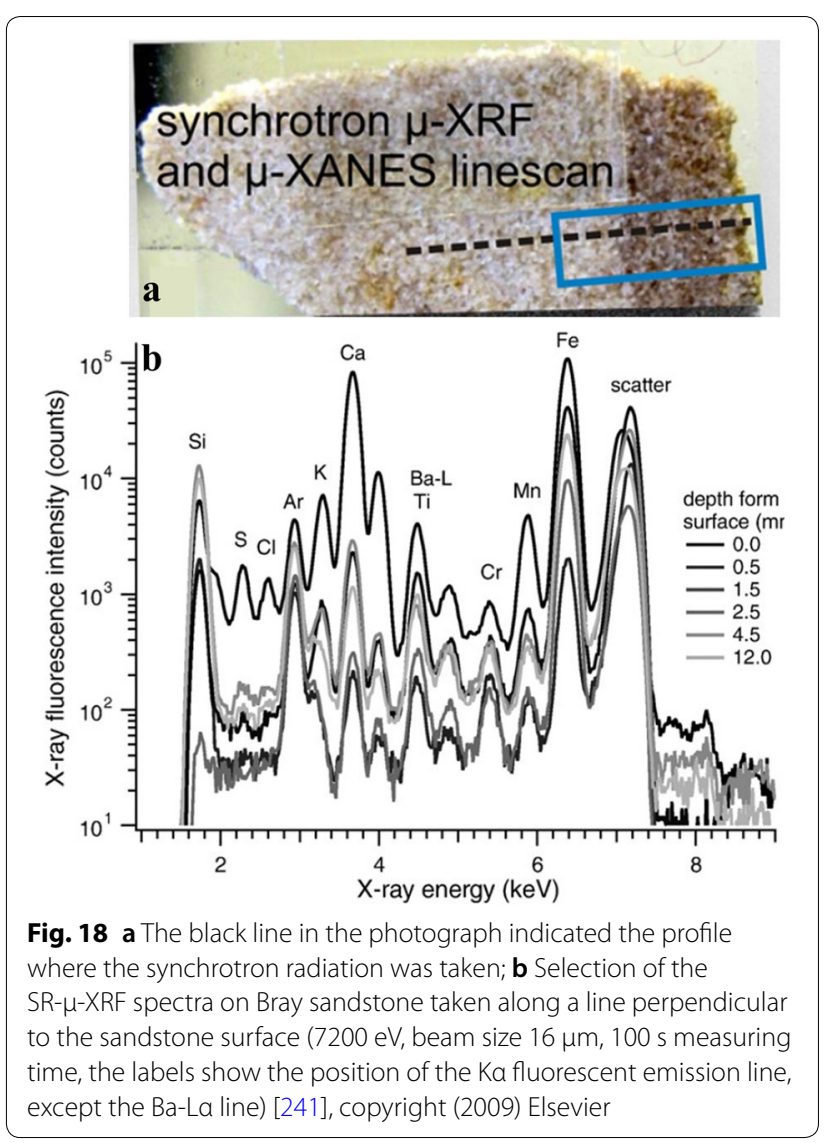


subsequent elements which appeared in the efflorescence. Besides the original composition, arsenic, lead and chlorine were measured in all the efflorescence. The presence of lead in the efflorescence could be contributed to the airborne lead deposited in the porous material. The chloride resulted from the infiltration water. Furthermore, the presence of nitrobarite was determined by SR- $\mu$-XRF.

\section{Powder X-ray diffraction spectroscopy (PXRD)}

PXRD is an elementary instrument for the identification of synthetic and natural materials. The discovery of Bragg-type X-ray diffraction from periodic crystal lattices made the technique as a fundamental tool for: (1) the identification of crystalline phase, (2) the quantitative analysis of polyphasic mixtures, (3) the research of the long-range order structures of crystalline materials, and (4) the physical analysis of crystalline aggregates including orientation texture, crystallite size distribution and lattice micro-strain effects. During the first half of last century, such conventional applications were developed into standard characterization processes of construction materials, and the accumulated data are now available for most known inorganic substances and minerals. Also, the online databases are now available for automatic discrimination, rapid searching for crystallographic and structural information of crystalline substances [242].

PXRD data acquisition and analysis are routinely completed in a lot of laboratories dealing with materials characterization. Samples are usually in the form of small single crystals (with sizes in the range $0.1-1.0 \mathrm{~mm}$ ), polyscrystalline aggregates (powders, i.e. assemblages of $10^{3}-10^{6}$ crystallites with size around $1 \mu \mathrm{m}$ ), or oriented specimens (fibers, thin films, polished surfaces). Therefore, depending on the physical state, the chemical structures and the properties of the desired information, the PXRD test parameters and data analysis methods may vary greatly. In the field of architectural heritage, PXRD is one of the cheapest and most reliable technique to identify crystalline phases both in natural and man-made materials such as mortars [243, 244], bricks [245, 246], pigments $[18,233]$, building stones $[247,248]$ and so on.

The weathering of stone is a very complicated process involving mixtures of biological, chemical and physical reactions. It depends on rain, temperature, sunlight and pollution. The degradation processes of buildings constructed from natural stones are very dependent on the local conditions [249-251]. Inorganic or organic acids in the air originated from vehicles and industry emissions are a major cause of degradation which can react with many materials to form soluble nitrates and sulfates. About 30 years ago, Monte et al. [31] used PXRD technique to investigate the status of the stone surfaces of Reggio Emilia Cathedral, in which both the natural weathering and pollution-linked processes contributed to the erosion of the building materials. The PXRD data obtained from the samples showed that sulphation $\left(\mathrm{CaCO}_{3}\right.$ transformed into $\left.\mathrm{CaSO}_{4} \cdot 2 \mathrm{H}_{2} \mathrm{O}\right)$ was the most common and significant feature of the deterioration while the conversion of calcite to ankerite $\left[\mathrm{CaCO}_{3}\right.$ transformed into $\left.\mathrm{Ca}\left(\mathrm{Mg}_{0.67} \mathrm{Fe}_{0.33}\right)\left(\mathrm{CO}_{3}\right)_{2}\right]$ on the surfaces was infrequent. The existence of the calcium oxalates $\left(\mathrm{CaC}_{2} \mathrm{O}_{4}\right)$, weddellite $\left(\mathrm{CaC}_{2} \mathrm{O}_{4} \cdot 2 \mathrm{H}_{2} \mathrm{O}\right)$ and whewellite $\left(\mathrm{CaC}_{2} \mathrm{O}_{4} \cdot \mathrm{H}_{2} \mathrm{O}\right)$ in the surface crusts was always associated with a forceful proliferation of epilithic and endolithic blue algae and lichens. A highly insoluble salt uricite $\left(\mathrm{C}_{5} \mathrm{H}_{4} \mathrm{~N}_{4} \mathrm{O}_{3}\right)$ originated from the excrement of birds was found in a few samples collected from the horizontal areas. Also, the existence of quartz $\left(\mathrm{SiO}_{2}\right)$, feldspars (orthoclase: $\mathrm{KAlSi}_{3} \mathrm{O}_{8}$, albite: $\mathrm{NaAlSi}_{3} \mathrm{O}_{8}$ ) and a large number of phyllosilicates (kaolinite: $\mathrm{Al}_{4}(\mathrm{OH})_{8} \mathrm{Si}_{4} \mathrm{O}_{10}$, chlorite: $\left(\mathrm{Mg}, \mathrm{Fe}, \mathrm{Al}_{6}(\mathrm{OH})_{8}(\mathrm{Si}\right.$, $\mathrm{Al})_{4} \mathrm{O}_{10}$, serpentine: $\left.(\mathrm{Mg}, \mathrm{Fe})_{6}(\mathrm{OH})_{6} \mathrm{Si}_{2} \mathrm{Al}_{2} \mathrm{O}_{10}\right)$ in plentiful related samples can be ascribed to soil dust. Similarly, the effects of air contaminants and humidity on the damage of limestone materials in architectural heritage of tropical coastal cities were studied by Crovo and coworkers [252]. The PXRD analysis revealed that the main mineral phase of low humidity area was calcite $\left(\mathrm{CaCO}_{3}\right)$, whereas the main component of relative high humidity area was gypsum $\left(\mathrm{CaSO}_{4} \cdot 2 \mathrm{H}_{2} \mathrm{O}\right)$. The results showed the atmospheric sulfur compounds may accelerate the damage of limestone materials under high humidity conditions which can be attributed to atmospheric pollutants can be dissolved easier in the porous materials with the presence of moisture. Furthermore, the chemical composition of different rubble stone masonry walls located in Santander, Northern Spain was systematically evaluated via PXRD analysis, as shown in Fig. 19 [253]. It can be observed that the limestone (Fig. 19a) was mainly composed of $\mathrm{CaCO}_{3}$, with a small quantity of $\mathrm{SiO}_{2}$. The presence of the latter component was more important in the marlstone (Fig. 19b) which also had lots of $\mathrm{CaCO}_{3}$ in its chemical composition. Massive $\mathrm{NaCl}$ were also measured in this sample. The sandstone (Fig. 19c) was basically composed of silica in which the iron silicate and calcium can also be detected. Finally, there was significant presence of both silica and calcium carbonate in the lime mortar (Fig. 19d).

Besides characterization of traditional stone materials, mortars and even environmental influence on historic buildings, XRD technique can also analyze other components. Ostrooumov [254] applied XRD to the characterization of damage on ancient monuments (Morelia, Mexico). Forty-three pyroclastic volcanic rocks (ignimbrites) collected from San Francisco and San Agustin, 

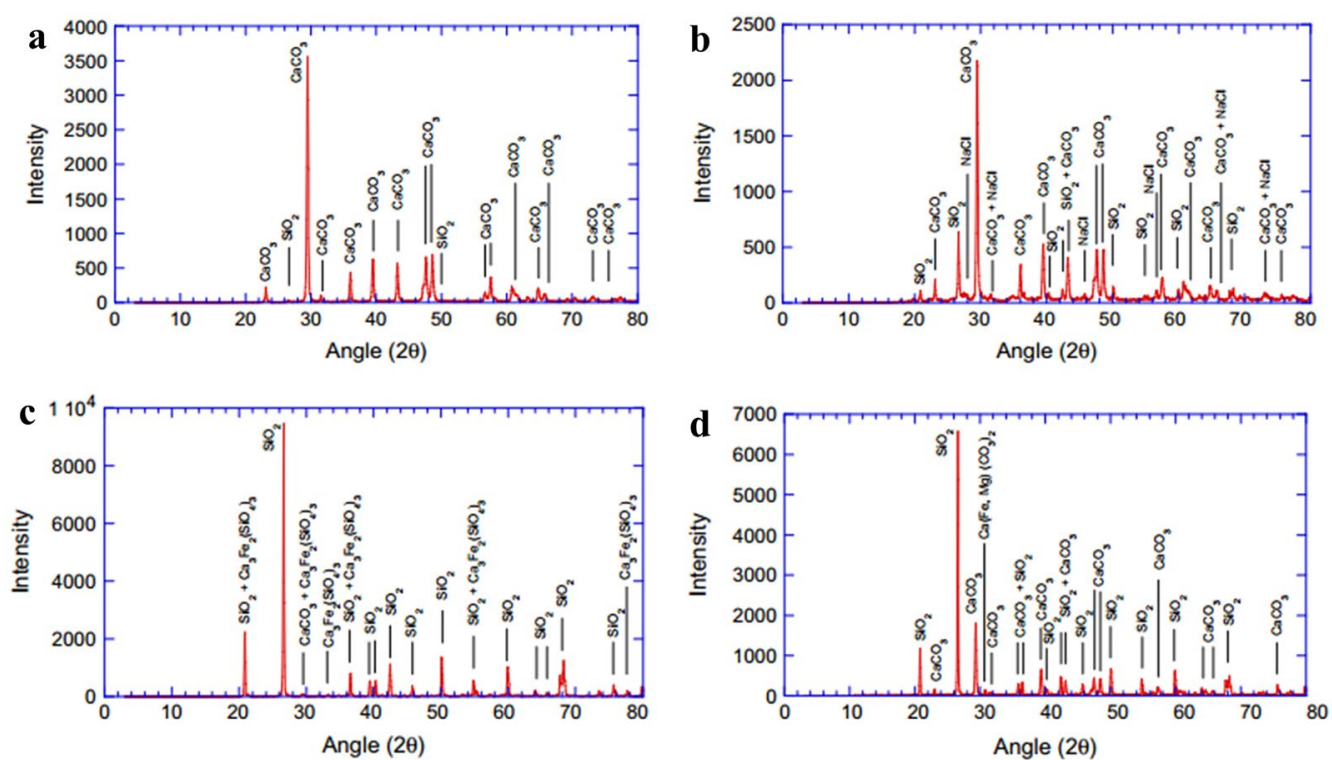

Fig. 19 X-ray diffraction patterns of materials detected in the Riva-Herrera palace: a limestone; $\mathbf{b}$ marlstone; c sandstone and $\mathbf{d}$ lime mortar [253], copyright (2013) Elsevier

the first building groups in the city of Morelia, had been studied. Numerous new mineral neoformation such as phosphates, sulfates, halides and carbonates, were detected in the above samples. Ventolà et al. [255] investigated the mineral composition of lime mortars before and after addition of traditional organic additives which included polysaccharides, animal proteins and fatty acids. The XRD results revealed that no mineralogical changes were detected before and after using organic additives. Except for variations of the content of aragonite $\left(\mathrm{CaCO}_{3}\right)$, calcite $\left(\mathrm{CaCO}_{3}\right)$ and portlandite $\left(\mathrm{Ca}(\mathrm{OH})_{2}\right)$, the same mineralogical ingredients were detected in all the samples. Gianoncelli et al. [233] conducted characterization of the pigments of mural paintings with portable PXRD instrument with low power, which was particularly suitable for on-site identification of non-moveable or/and irregular building materials.

The surveys of inorganic compounds with synchrotron X-ray diffraction contain in situ dynamic diffraction investigations, phase transformations, structural identification at ultra-high pressures, and the utilization of resonant scattering effects for element-selective structural characterization. Pedrazzani et al. [256] used SR- $\mu$ XRD technique to study the sulphation of Candoglia marble which was a detached and deteriorated fragment collected from a decorative floral frieze of a lunette. The SR- $\mu$-XRD patterns of the sample were collected using micro-diffraction at SRS MAD10 beamline and ESRF beamline ID13 (as illustrated in Fig. 20). The maps showed horizontal diffraction patterns for each point, since the X-ray beam was scanned into the interior of the cross-section from the exterior surface of the facade. The vertical lines arose from diffraction peaks of crystalline phases. The interface between the surface crust and the intact marble was between steps 60 and $70 \mu \mathrm{m}$. In both maps as illustrated in Fig. 20, the sample at $60-70 \mu \mathrm{m}$ was marked by a significant drop in the intensity of the gypsum line at $7.55 \AA$. The high background in the crust was assigned to the existence of non-crystalline components, such as amorphous by-products of deterioration. Moreover, bassanite (strong reflections at 3.00 and $6.01 \AA$ ), calcite (reflection at $3.03 \AA$ ) and weddellite (reflection at $6.03 \AA$ ) can be detected by SR- $\mu$-XRD technique.

Interestingly, Grousset et al. [257] introduced SR- $\mu$ $\mathrm{XRD}$ technique to better understand the decay processes occurring on steel reinforcements in mortar exposed to chlorinated environment simulated with $\mathrm{NaCl}$ solution $(0.5 \mathrm{M})$, which can confirm the short-lived erosion products and their transformation with different time. The 2D maps obtained by SR- $\mu$-XRD suggested that the chlorinated green rust was inclined to be changed into akaganeite or goethite substances (as illustrated in Fig. 21). The properties of the precipitated phase relied on the temporal chloride content, the existence of dissolved oxygen and the migration of ferrous ions in the pore structures of the binder. It is noteworthy that the green rust began to disappear after $20 \mathrm{~h}$, whereas akaganeite remained present near the iron rebar. After $44 \mathrm{~h}$ of experiment, the green rust had completely disappeared from the map, revealing that the system was stabilized. 

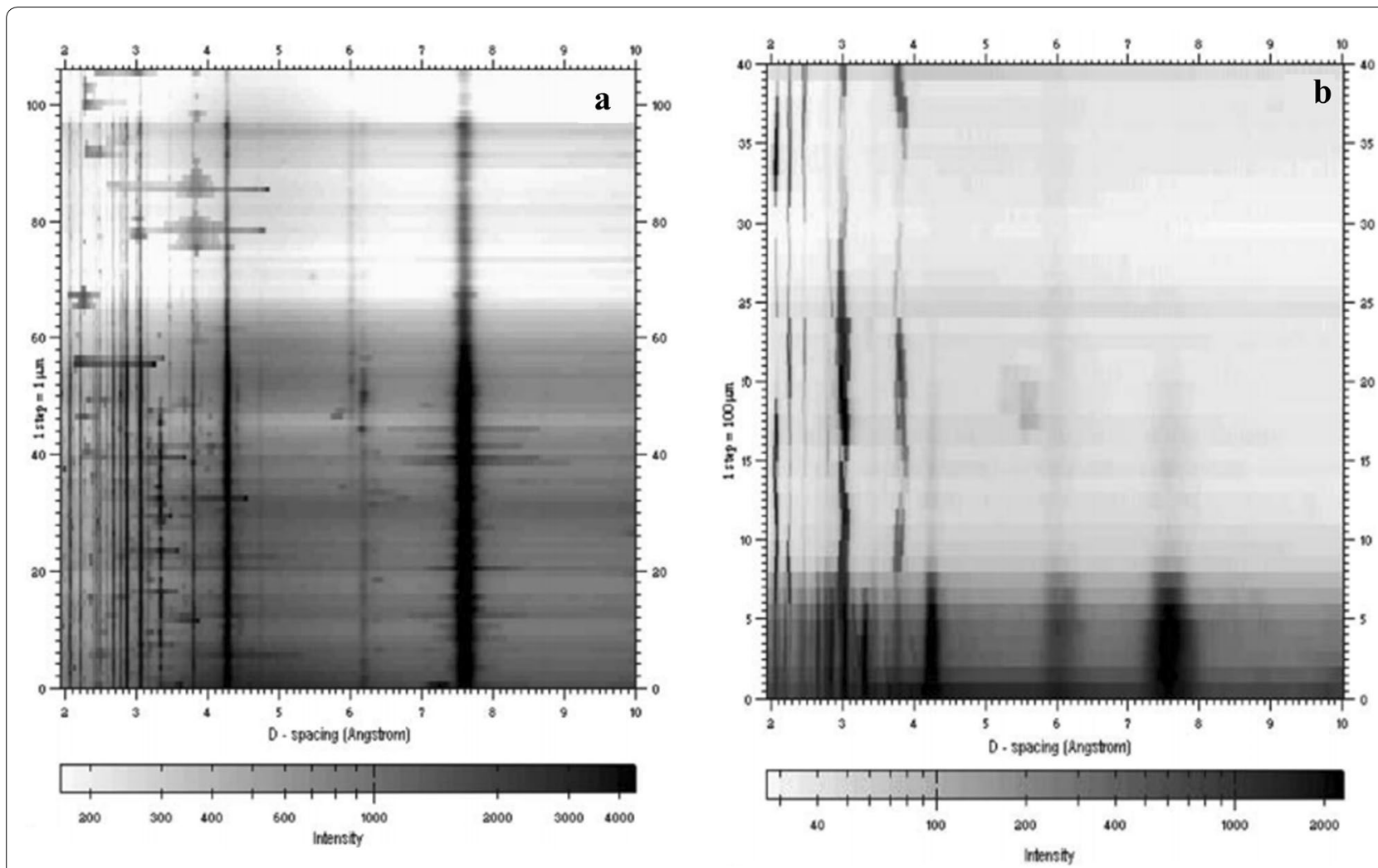

Fig. 20 a 2D diffraction pattern of data collected on ID13 with $5 \mu \mathrm{m}$ beam spot and in steps of $1 \mu \mathrm{m}$. The ordinate axis is step number, 1 step was equal to $1 \mu \mathrm{m} ; \mathbf{b}$ 2D diffraction pattern of data collected at SRS MAD10 with $100 \mu \mathrm{m}$ beam spot in steps of $100 \mu \mathrm{m}$ [256], copyright (2006) Springer Link

\section{$X$-ray photoelectron spectroscopy}

The XPS is applied to identify valence and the electronic levels of the specific elements in a substance. The XPS spectra are achieved by irradiating a material with a beam of X-rays, and by detecting the number and kinetic energy of the electrons escaping from the top surface of the material being analyzed $(1-10 \mathrm{~nm})$. The XPS requires ultra-high vacuum conditions. Since many material samples are easily contaminated by adsorbed molecules and ions, it is necessary to adopt special treatments just before or during the measurement (by ion beam etching, laser ablation, UV irradiation, ion beam implantation or other means) to clean up the contaminants on the surface of the target sample, or even to check the material's reaction to bombardment, deposition, or treatment. Generally, it is a typical surface technique to characterize surface contamination or corrosion products of architectural heritage $[258,259]$.

To measure the chemical reactions on the marble caused by $\mathrm{SO}_{2}$ in atmosphere, Luque et al. [32] selected calcitic and dolomitic samples to undertake the accelerated weathering test in which the samples were exposed to atmospheric $\mathrm{SO}_{2}$ with high concentration for $24 \mathrm{~h}$ in a simulative climate chamber under the given temperature $\left(20{ }^{\circ} \mathrm{C}\right)$ and relative humidity $(>90 \%)$. The changes on marble surfaces caused by reactions between $\mathrm{SO}_{2}$ with calcite and dolomite were analyzed by XPS technique, demonstrating that the sulphation rates of calcitic marbles were much higher than dolomitic marbles. Also, in both calcitic and dolomitic marbles, sulphite concentrations were commonly higher than sulphate. It is well known that the easy oxidation of $\mathrm{MgSO}_{3}$ into $\mathrm{MgSO}_{4}$ is a common effect [260,261], and the same sulphation process can occur on both calcitic and dolomitic marbles. However, Przepiorski et al. [262] noticed that it is difficult to determine the existence of $\mathrm{MgSO}_{3}$ via PXRD, while it is feasible to achieve the distinguish sulphur species (sulphite and sulphate) on the surface of porous carbon with the aid of XPS. Moreover, Böke et al. [26] aimed at determining the primary factors, which influenced the formation rate of sulphite and sulphate species. In this study, $4 \mathrm{keV} \mathrm{Ar}^{+}$bombardment was used to enable chemical analysis at greater depth. The spectra recorded in each marble surface showed that the main chemical elements present on unaltered marble were $\mathrm{C}, \mathrm{O}, \mathrm{Ca}$ and $\mathrm{Mg}$, while additional $\mathrm{S}$ were present on the altered marbles. 
a

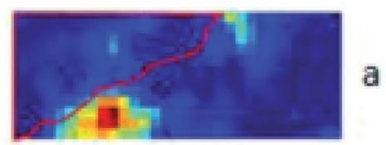

b

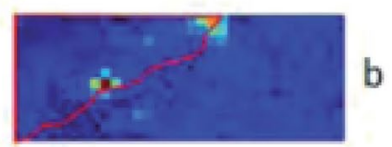

b

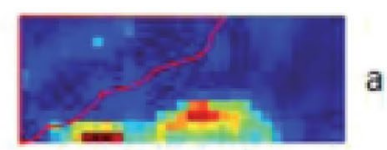

a
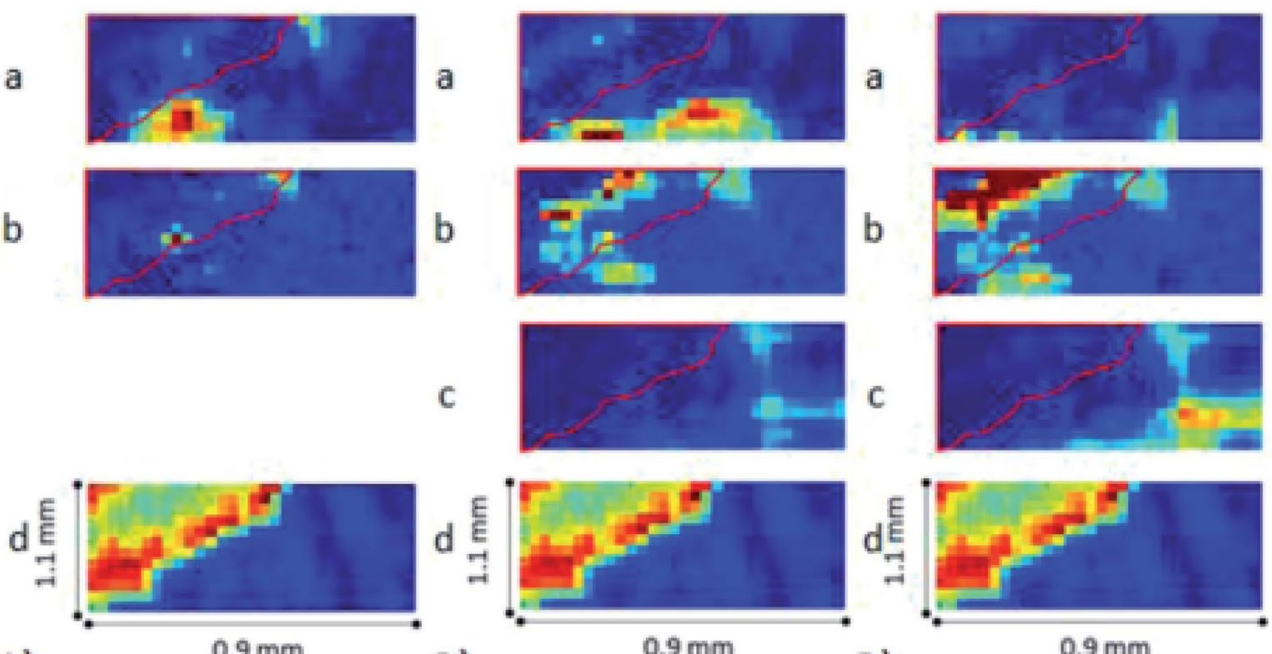

1)

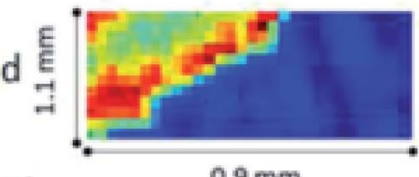

2)

$0.9 \mathrm{~mm}$

3)

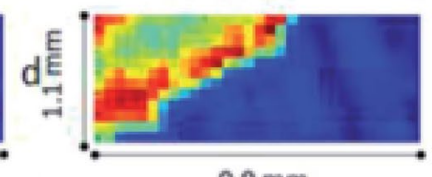

$0.9 \mathrm{~mm}$

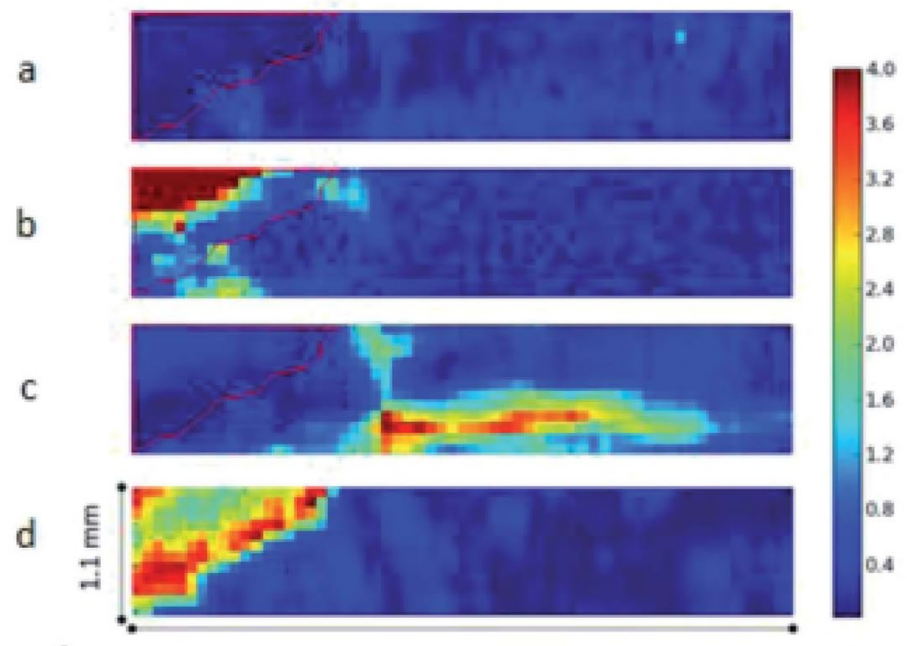

4)

$1.8 \mathrm{~mm}$

Fig. 21 X-ray diffraction patterns obtained on the DiffAbs beamline at Synchrotron SOLElL: distribution of a chlorinated green rust; $\mathbf{b}$ akaganeite; $\mathbf{c}$ goethite; diron; after (1) 1 h, (2) 8 h, (3) 20 h and (4) 44 h of testing [257], copyright (2015) Royal Society of Chemistry

The S $2 p$ spectra obtained on the surface of calcitic marbles were deconvoluted into two contributions: $\mathrm{CaSO}_{3}$ $(166.8 \pm 0.1 \mathrm{eV})$ and $\mathrm{CaSO}_{4}(168.8 \pm 0.2 \mathrm{eV})$. On the surface, the $\mathrm{CaSO}_{3}$ contents (approximately 83\%) were four times higher than the $\mathrm{CaSO}_{4}$ values (approximately $17 \%)$. While, at depth of $45.6 \mathrm{~nm}$, a strong decrease of $\mathrm{CaSO}_{3}$ content (approximately 53\%) and a slight increase of $\mathrm{CaSO}_{4}$ content (approximately 34\%) can be observed. The $\mathrm{S} 2 p$ spectra obtained on the surface of dolomitic marbles were deconvoluted into four contributions: $\mathrm{CaSO}_{3}(166.8 \pm 0.1 \mathrm{eV}), \mathrm{MgSO}_{3}(167.4 \pm 0.2 \mathrm{eV}), \mathrm{CaSO}_{4}$ $(168.8 \pm 0.2 \mathrm{eV})$ and $\mathrm{MgSO}_{4}(169.4 \pm 0.3 \mathrm{eV})$. Overall, sulphite $\left(\mathrm{SO}_{3}{ }^{2-}\right)$ concentrations were always higher than sulphate $\left(\mathrm{SO}_{4}{ }^{2-}\right)$ concentrations due to the calcium sulphite hemihydrate formation via the reaction between $\mathrm{SO}_{2}$ with calcareous stones under relative high humidity conditions and subsequently oxidation into calcium sulphate. This research further confirmed that XPS was a great instrument to identify different chemical reactions on stone surface after a transitory exposure to air contaminants, because it can test the development of damage crusts by detecting only a few micrometers.

Zhu et al. [263] employed XPS technique to obtain the chemical state of some elements in the greenish pigments of murals from the Cizhong catholic church which reflected Chinese traditional architectural styles and art 
skills, and witnessed the influence of Catholic culture on the architectural design of late Qing Dynasty. The results demonstrated that the binding energy of As $3 p$ was $140.06 \mathrm{eV}$ which can be assigned to the As in arsenate [264]. The $\mathrm{Cu} 2 p$ spectrum was not very smooth, however, there were two peaks at 945 and $964 \mathrm{eV}$, which indicated that the copper was mainly the divalent state. In Salvi and co-workers' study [265], they analyzed samples collected from the travertine basement of the Statua dello Studente, La Sapienza, and they focused their research on the chemical components of the copper-stained areas applying XPS technique as a surface-specific technique. The XPS wide spectrum acquired with $\mathrm{MgK} \alpha$ was shown in Fig. 22a, which represented the powdered samples collected from both green and grey areas of the travertine basement (sampling sites were shown in Fig. 22b, c). The red-marked peaks were directly related to the photo-emitted electrons, while the Auger peaks (blackmarked peaks) were assigned to relaxation processes. The results suggested that copper complexes and the mixture of calcium/copper carbonates were closely related to the stains of the stone surfaces, and the chemical state of other elements with respect to chemical structures varied with the chromatic characteristics.

Considering that the commercial Si-based resin (Alpha ${ }^{\circledR}$ SI30) can be used as protective reagent to enhance the hydrophobic properties of different types of materials, Fermo et al. [259] used XPS technique to characterize the resin-stone interactions. The stone samples were collected from Angera, Botticino and Carrara, Italy. The results showed no big changes in the $\mathrm{Ca} 2 p, \mathrm{O} 1 s$ and $\mathrm{C} 1 s$ binding energies of both the original and the covered stones. However, valuable information was obtained by comparing the Si $2 p$

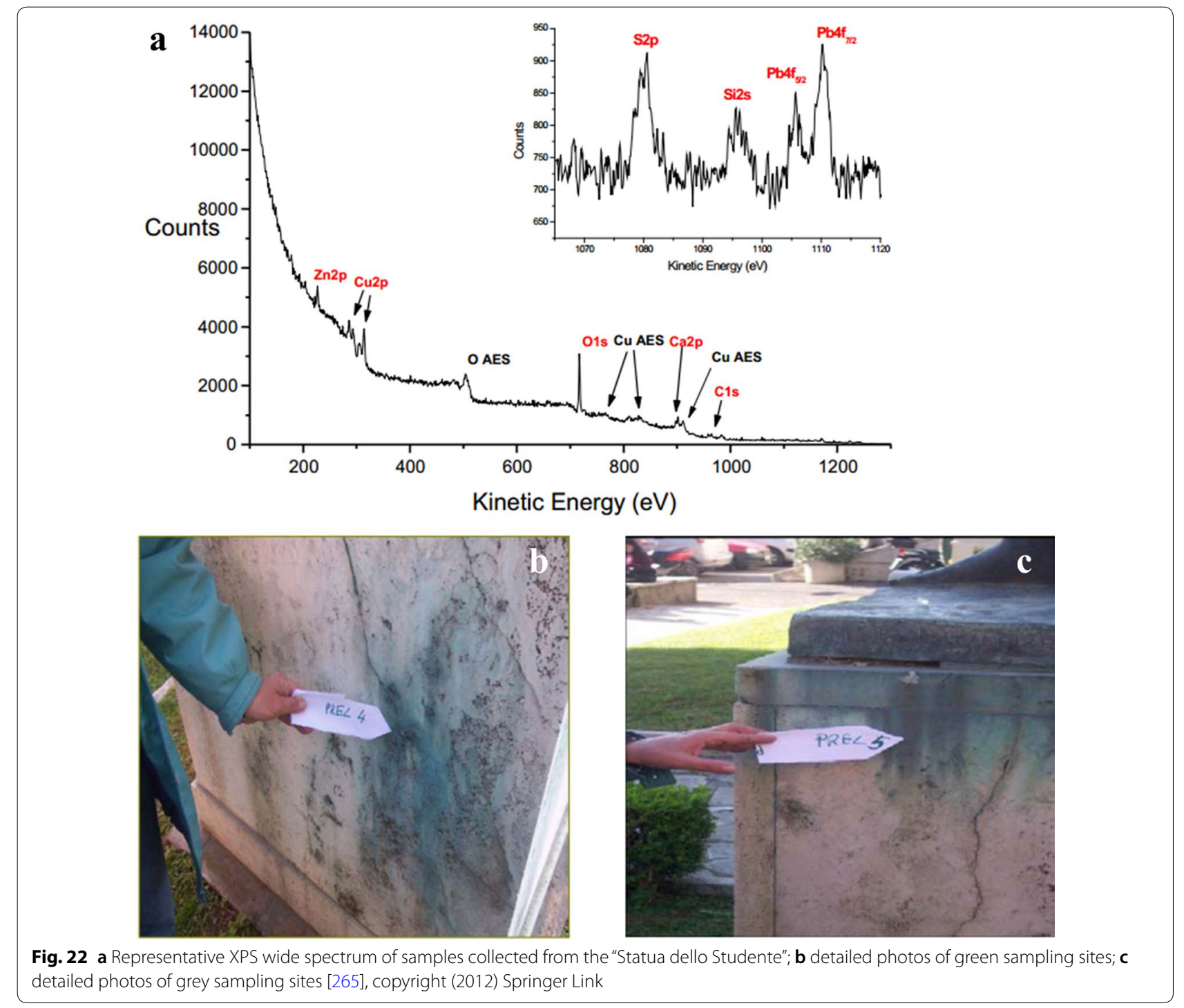


spectra of the original and the coated stones with the pure Alpha ${ }^{\circledR}$ SI30 (as illustrated in Fig. 23, the case of Angera as a representative sample). The $\mathrm{Si} 2 p$ spectrum for the neat stone was fitted to the two peaks (Fig. 23a), corresponding to silica $(103.1 \mathrm{eV})$ and phyllosilicate impurities $(100.8 \mathrm{eV})$ [266]. The Si $2 p$ spectrum of pure Alpha ${ }^{\circledR}$ SI30 (Fig. 23b), acquired from the resin depositing on a gold foil, was deconvoluted by two peaks at 102.8 and $104.2 \mathrm{eV}$. The lower binding energy corresponded to the poly-dimethyl-siloxane, while the higher one to the silane component of the resin. Figure 23c showed the Si $2 p$ line of the Alpha ${ }^{\circledR} \mathrm{SI} 30$-clad Angera stone, and three peaks can be contributed to the resin (102.8 and 104.2 eV) and silicon-based impurities $(101.7 \mathrm{eV})$. Furthermore, to testify the coverage uniformity on the surfaces of stones, XPS imaging was obtained in the case of Botticino limestone (Fig. 23d, e). After the acquisition of photoemission peak (P) and background (B) images, the images were corrected for the sample topography by calculating the ratio $\mathrm{P} /$ $(\mathrm{P}+\mathrm{B})$. As it can be seen from both images after topographic correction, the distribution of calcium and silicon over the surface of the sample was nearly complete uniform. From XPS analysis, the different types of silicon were distinct and it exhibited evidence of the quite homogeneous distribution of the resin over the stones. Another similar application of XPS and XPS imaging techniques was presented by Bakolas et al. [267]. The XPS determination offered significant information concerning the segregation of the constituents and their concentration profiles at the interface between binder and load-bearing elements. The results showed that the segregation of calcium at the interface was very selective, and magnesium did not diffuse towards the interface. In addition, many researches have proved that XPS surface analysis is a practical instrument for the
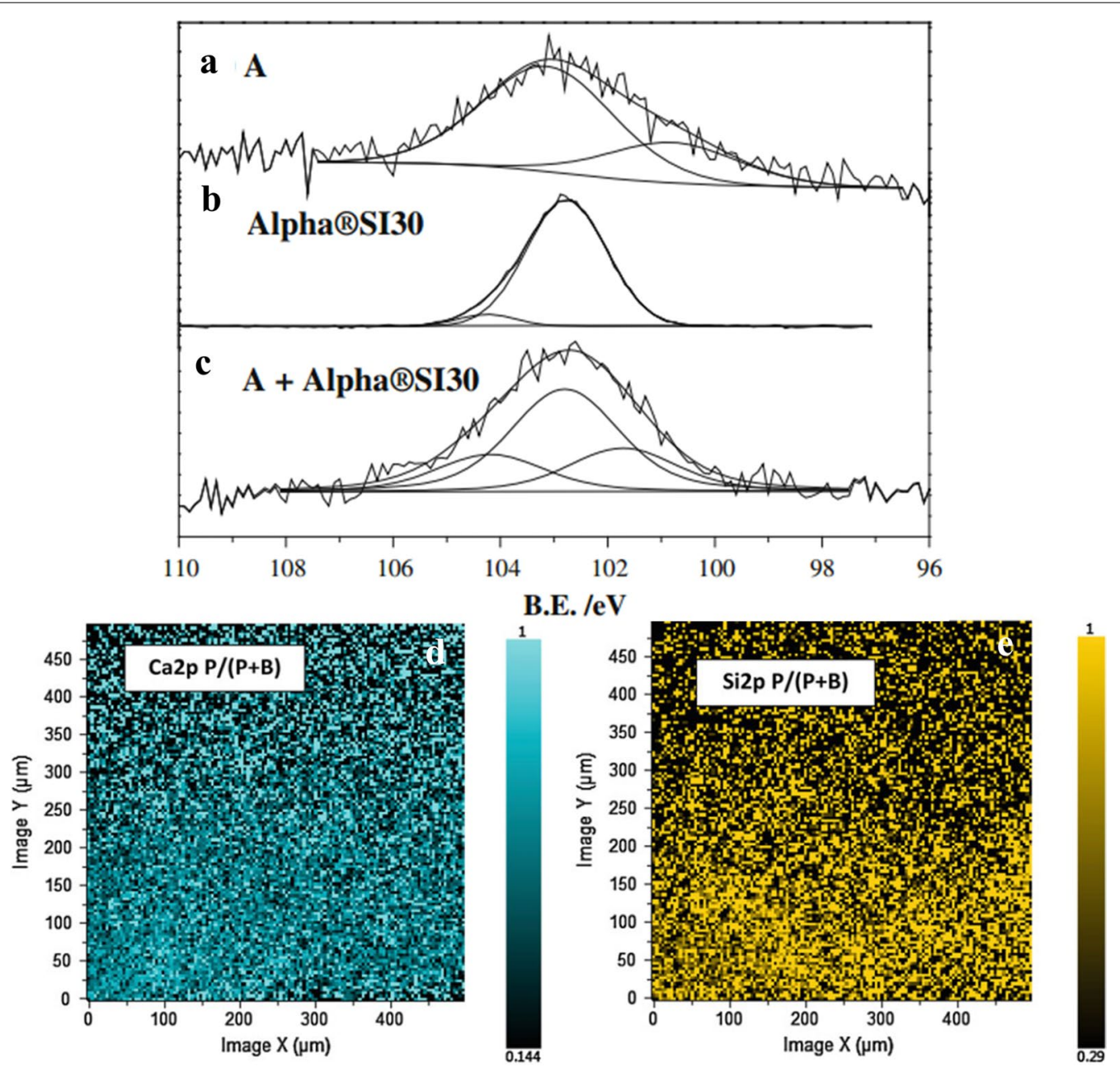

Fig. 23 Si $2 p$ XPS spectra of $\mathbf{a}$ the bare Angera stone; $\mathbf{b}$ the resin Alpha ${ }^{\circledR}$ SI30 deposited on a gold foil; $\mathbf{c}$ the Angera stone coated by Alpha ${ }^{\circledR}$ SI30; XPS imaging obtained by Botticino limestone $\mathbf{d}$ Ca and e Si surface distributions [259], copyright (2014) Springer Link 
detection of airborne particles $\left(\mathrm{PM}_{10}\right.$ or $\left.\mathrm{PM}_{2.5}\right)$ due to these small fractions which have a greater surface area to volume ratio than larger particles $[268,269]$. The chemical shifts permit the qualitative analysis of the different elements, for example, C1s curve can supply information about elemental carbon (EC) and organic carbon $(\mathrm{OC})$, thus quantifying the carbon-based substances that might be present in the PM [270].

\section{$X$-ray absorption spectroscopy}

At present, the application of synchrotron-based X-ray absorption spectroscopy (SR-XAS) in the field of ancient building materials is still limited [256]. XAS data are obtained by measuring variation of absorption coefficient when the energy of the probing X-rays photos was scanned in a narrow region around an absorption edge. A table of all electron binding energies is given in the famous X-ray booklet, which is available at the LBNL web site (http://xdb.lbl.gov/). The analysis of the XAS data considers three significant regions: the dominant edge feature together with its pre-edge (few hundred $\mathrm{eV}$ below the edge) region is called the $\mathrm{X}$-ray absorption near-edge structure (XANES). This region is extremely sensitive to coordination environment and oxidation state. Thus the edge position is a reliable indicator of the valence state of the probed element [271, 272]. The interpretation of the modulated region extending from the edge to higher energies and containing the positive and negative interference effects is called extended XAFS (EXAFS) region [273]. It can provide the local atomic environment and yielding information on local chemistry and geometry, the determination of the surrounding atoms, specific bond lengths and coordination numbers [274]. Overall, XAS is a nondestructive technique with low detection limit, high resolution and high sensitivity to exceptional elements. These advantages are highly compatible with precious, heterogeneous and complicated characterization. In particular, the combination of XAS and mapping techniques with high spatial resolution offers information about chemical composition and elemental states, even for trace elements [275]. However, it is noteworthy that XAS is an averaging instrument. It detects the microscopic environment of all the surrounding atoms of the target element. Thus if the target elements are in more than one local chemical environment, then the resulting spectrum will be an appropriately weighted average of all the environments [228].

Indeed, besides the above-mentioned superiorities, another reason for XAS to be practical is that it can perfectly measure crystalline or amorphous materials [40]. Bertrand et al. [276] summarized the studies of XAS techniques during 1986-2010 to study the architectural heritage materials like glass, mural painting materials, stone, ceramics, metals, mortars and woods. For instance, color changes are commonly acquired in glass by modulating the oxidation states of transition metal elements such as copper, manganese, cobalt and iron. Each element possesses characteristic absorption frequencies in visible region resulting from $d$ - $d$ electronic transitions [277]. Quartieri et al. [278] applied XANES instrument to analyze ancient glasses collected from the Patti Roman Villa (Messina, Sicily). The manganese and iron K-edges spectra verified the hypothesis that pyrolusite $\left(\mathrm{MnO}_{2}\right)$ should be added deliberately as a de-colorant during the melting process. Similarly, Farges et al. [279] used XAS to explore chemical composition of medieval glasses from various gothic buildings (14th century) in Normandy, France. The Mn K-edge spectra suggested that manganese was divalent and located at a silicate-type environment in the fresh glasses. When being weathered, manganese can be oxidized to $\mathrm{Mn}^{4+}$, which gave rise to the deposition of manganese oxi-hydroxides, resulting into opacification and a color change of the glass panes. Similar spectra were detected at the iron K-edge where ferrihydrite-type materials deposited in the erosion areas. Furthermore, as copper gives various colors in stained glasses, Farges et al. [280] also used synchrotron $\mu$-XANES/EXAFS spectroscopies at copper K-edge to investigate the "copper ruby red" glasses from the St Gatien Cathedral in Tours (windows from the 13th century). Figure 24a showed five representative copper K-edge XANES spectra measured in the various interest regions of the glasses. In the $\mathrm{Cu}$-poor areas (spots \#1 and \#2), the copper K-edge XANES spectra were nosier but matched well with those collected in the $\mathrm{Cu}$-rich layers (spots \#3 and \#4). These four $\mu$-XANES spectra could be assigned to $\mathrm{Cu}^{+}$along with some nanocrystalline metal copper (on the average about 10 at\% based on linear combinations). Figure 24b-e showed the normalized copper K-edge $\mu$-EXAFS spectra and their Fourier transformation (FT) for the spots \#4 and \#5. The $\mathrm{Cu}-\mathrm{O}$ peak for the spot \#4 showed a peak located at $\sim 1.4 \AA$ on the FT, indicating the existence of linear units of $\mathrm{Cu}^{+}$. Furthermore, a wavelet analysis found weak contributions arising from siliconcontaining compounds located between 3 and $4 \AA$ on the FT (as illustrated in Fig. 24d). The results confirmed that silicon-containing compounds replaced a significant of well crystallized native copper or cuprite. In contrast, the $\mathrm{Cu}-\mathrm{O}$ peak of spot $\# 5$, located at higher $(R+\Delta)$ values (centered near 1.5 and $2.2 \AA$ ), was a doublet, which suggested the presence of $\mathrm{Cu}^{2+}$. In addition, the EXAFS for spot \#5 showed a significant $\mathrm{Cu}-\mathrm{Si}$ contribution near $4.2 \AA$ on the FT, indicating the weathering product may be chrysocolla and the other Si-containing minerals.

XAS techniques are often used to explore chemical reactions resulted from pigment alteration process of 

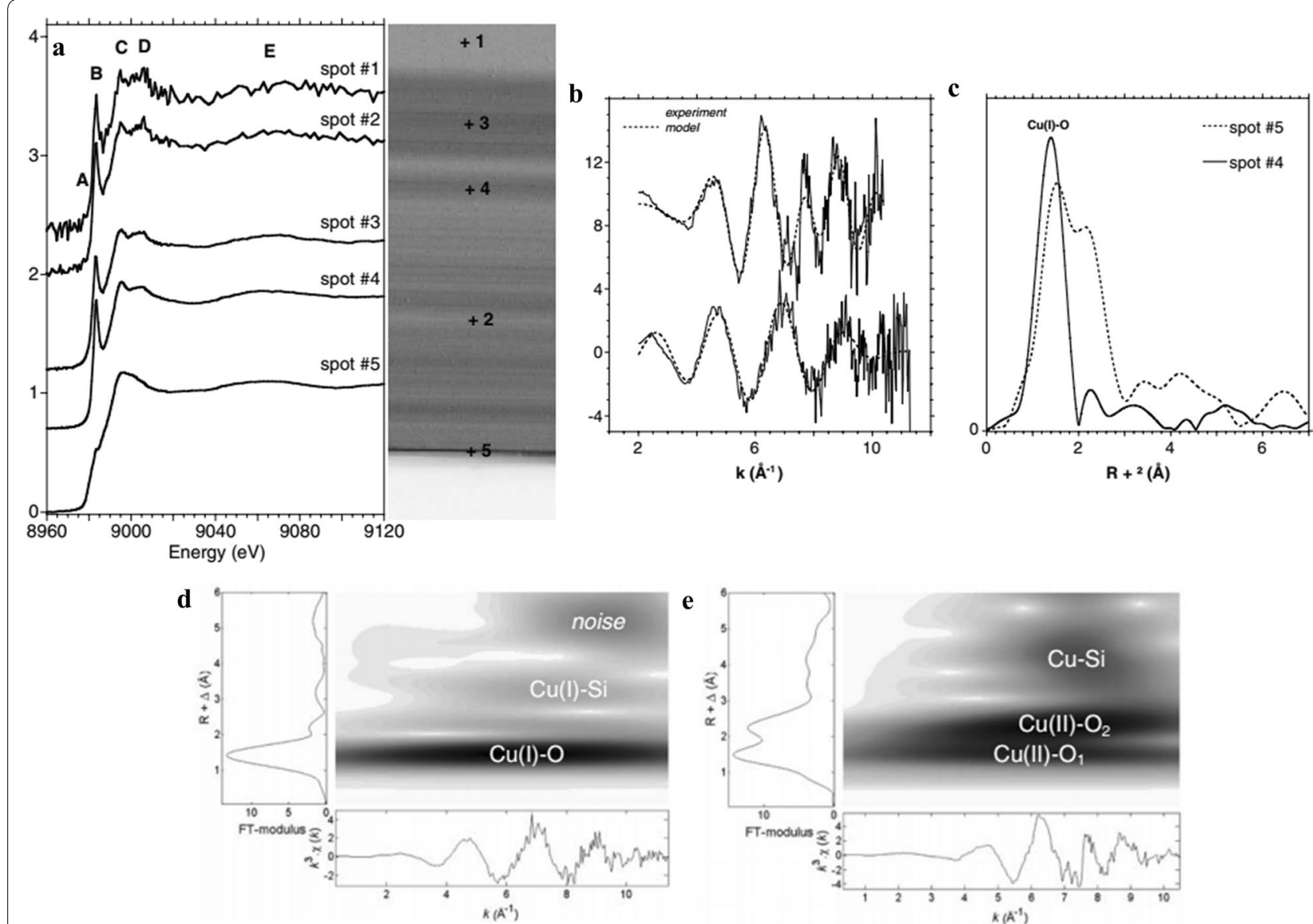

Fig. $24 \mu$-XANES/EXAFS spectra for the glass samples. a Normalized Cu K-edge $\mu$-XANES collected in the profile shown on the left; $\mathbf{b}$ normalized Cu K-edge $\mu$-EXAFS spectra, their best simulation (using cuprite as a model); $\mathbf{c}$ FTs for the spots \#4 and \#5; $\mathbf{d}$, e wavelets diagrams (k-R correlation) computed for the EXAFS of spot \#4 and \#5 [280], copyright (2006) Elsevier

ancient constructions. For example, sulfur-based pigments such as HgS (natural cinnabar, synthetic vermilion) can change from red to grey or black. Cotte et al. [281] used XANES at the sulfur K-edge to reveal both above-stated HgS in Pompeian mural paintings (as illustrated in Fig. 25a). The results suggested that XANES can detect the sulfur oxidation states directly and can be applied straightforwardly to distinguish the different sulfur components. Except for sulfur oxidation, the results demonstrated that chloride was an additional active substance in cinnabar degradation. In some Pompeian [281] and Gothic mural paintings collected from Barcelona [282], XANES offered solid information of mercury-chloride chemical bonds formation, especially in gray altered areas. However, the existence of the element chlorine was not systematically related to alteration, but originated from the inert contaminant $(\mathrm{NaCl})$ on a surface of red Pompeian mural painting. The XANES spectra of chlorine showed characteristics which make it possible to differentiate mercury chloride substances from alkaline and alkaline earth chlorides (as illustrated in Fig. 25b). In Cotte and the co-workers' study, they combined XRF with XANES techniques to selectively measure the distribution of mercury chloride components in crosssections of a Gothic painting, revealing the blackening of cinnabar. As illustrated in Fig. 25c, mercury chloride components were trapped in the grey area, while other chlorides, perhaps the calcium chlorides, were present beneath the pigment [277].

XAS technique is also applied to acquire a better understanding of the other architectural heritage materials [22]. Walker et al. [283] used XAS techniques to demonstrate the efficacy of hydrophobic and super hydrophobic surface coatings for enhancing limestone resistance to sulfate attack, which can be used to determine the reactively generated crystalline and amorphous calcium substances. Hormes et al. [284] used XANES spectra to explore the chemical compounds of mortar samples from the Abbey of Saint John which is a UNESCO World Heritage Site since 1983. The 

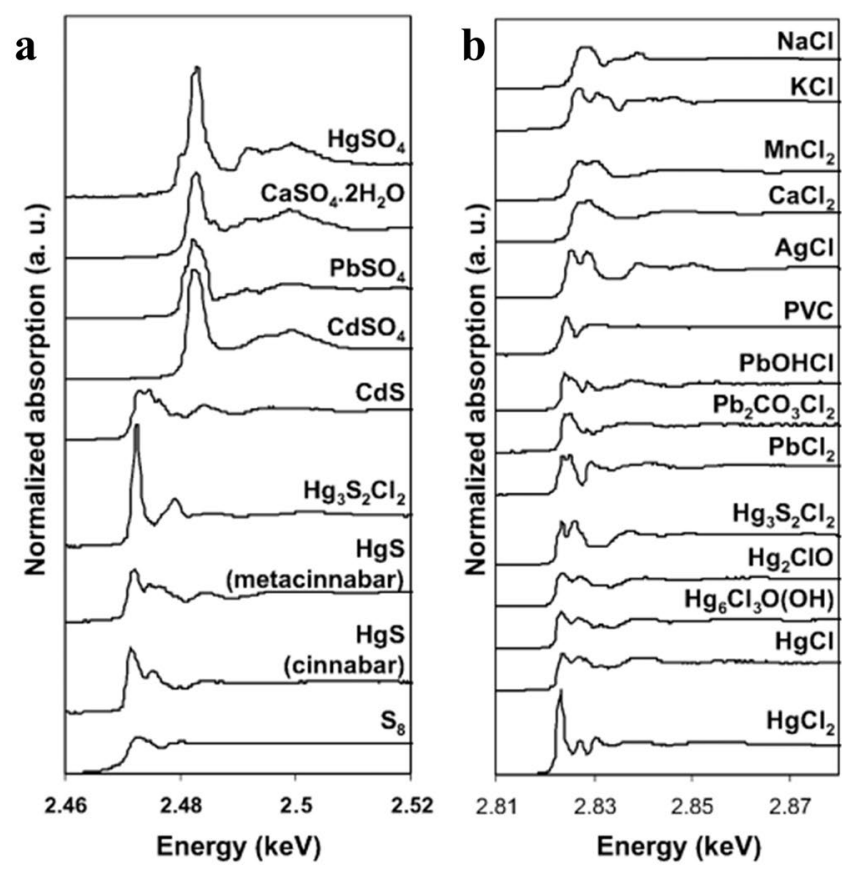

c
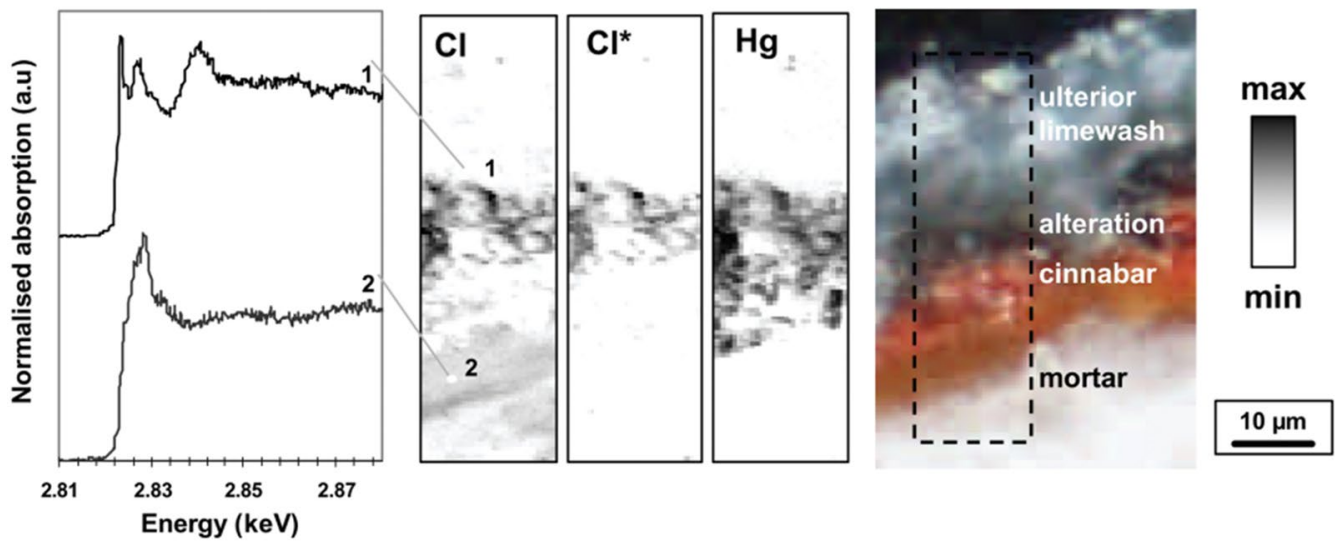

Fig. 25 a, $\mathbf{b}$ XANES spectra of sulfur and chlorine K-edge compounds detecting in architectural heritage materials; $\mathbf{c}$ XANES spectra and chemical mapping of a blackening cinnabar from Pedralbes monastery [281], copyright (2010) American Chemical Society

calcium K-edge XANES spectra suggested that calcite was the major calcareous components in the samples. However, the form of vaterite and hydroxyapatite were also existed. Furthermore, Monnier et al. [285-287] published a series of papers to explain the long-term atmospheric corrosion behavior of different phase and elements on ferrous alloys from the Amiens Cathedral built in the 13th century. The sulfur and phosphorus K-edge spectra showed that the components absorbed on ferrihydrite surfaces mainly existed under the form of phosphate and sulphate. Based on this view, all the papers above fully showed the great contribution of SR$\mathrm{XAS}$ as a major part of characterization methodology for complex systems.

\section{Ion beam analysis techniques}

Ion beam analytical method is a significant family of modern characterization instruments involving the application of $\mathrm{MeV}$ ion beams to detect the chemical composition and obtain elemental distribution of cross-sections in the near-surface layer of solid materials located on architectural heritage [40]. Among these methods, the most frequently applied analytical techniques are proton-induced X-ray emission (PIXE) and proton-induced $\gamma$-ray emission (PIGE). Many researchers apply them to detect historic building samples as the first step, which provide the chemical composition of various materials such as pigments [288-290], glasses [291, 292], mortars [293, 294], etc. Because 
historic building materials are extremely precious, a large number of materials are limited to use small original fragments. Furthermore, as most instruments are performed on destructive way, the samples used for characterization are difficult to be recovered completely. The advantages of the PIXE/PIGE analysis stem from its non-destructiveness and its high sensitivity to trace elements in a material. PIGE technique is relative to PIXE. It is a nuclear analytical method in which the protons can interact with the nuclei of the atoms in the target material, and then emit $\gamma$-rays instead of X-rays. This technique can determine the light elements as $\gamma$-rays which are less absorbed by the sample. Therefore, the combination of PIXE-PIGE arises increasing interests since it is the desired techniques for the characterization of valuable historic building materials.

For PIXE analysis, glass is frequently used as a convenient target: its main compositions are light elements, and the high- $Z$ trace elements are easily measured by covering the low energy $\mathrm{X}$-rays of the matrix with appropriate absorbers. Numerous improvements have been proposed to strengthen PIXE sensitivity for glassy materials, such as selective vanadium and aluminum filters, which are suitable to a number of glass types [295]. Sensitivity usually reaches a few $\mu \mathrm{g} / \mathrm{g}$ for transition metal elements, and several hundred of $\mu \mathrm{g} / \mathrm{g}$ for the major elements. For example, the stain glass windows from the Baume-lesMessieurs monastery are typical for history of glass [13]. 41 representative samples were detected by the PIXEPIGE analytical method to identify natron glass (2 pieces) and wood-ash glass (39 pieces) of 8th century. The results showed that the sodium content was high (18\%) in natron glasses, while the contents of potassium and magnesium remained low in soda glasses $(\mathrm{MgO}=0.6 \%$ and $0.9 \%, \mathrm{~K}_{2} \mathrm{O}=0.84 \%$ and $0.42 \%$ ). The percentages of potassium (8.79-16.7\%), magnesium (1.69-4.39\%) and phosphorus (1.23-3.43\%) of wood-ash glasses were relatively high, indicating the wood-ash glasses were made from a mixture of wood ashes and sand. Moreover, trace elements, such as zinc, nickel, copper, barium, strontium and rubidium, were also detected in wood-ash glasses, which might be contributed to the components of the soil in which the plants grown [296]. In Carmona and co-workers' study [14], the most important oxides (PbO, $\mathrm{K}_{2} \mathrm{O}, \mathrm{Na}_{2} \mathrm{O}, \mathrm{CaO}$ and $\mathrm{SiO}_{2}$ ) which influenced the glasses stability can be determined accurately with PIXE, XRF and EDX. As illustrated in Fig. 26, three different groups were identified as potassium lead silicate glasses (BUR and CRYS), soda lime silicate glasses (GOY, MAD and $M U$ ), and transition Medieval-Renaissance glasses (LE, CAR and TOL), which revealed the presence of sodium and potassium oxides with low content. Furthermore, the minor contents of glass coloring agents $\left(\mathrm{Ag}^{0}, \mathrm{MnO}, \mathrm{CoO}\right.$

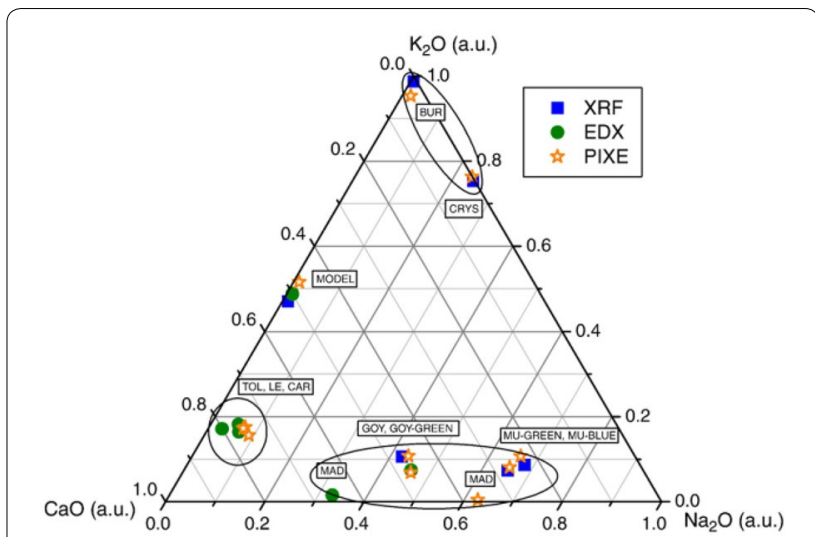

Fig. $26 \mathrm{~K}_{2} \mathrm{O}-\mathrm{Na}_{2} \mathrm{O}-\mathrm{CaO}$ ternary diagram of measured samples. MODEL/MU-blue/MU-green, LE/TOL/CAR, BUR, GOY/ GOY-green/MAD/CRYS represented glasses samples of Medieval, Medieval-Renaissance Transition, Early Modern, Modern period, respectively [14], copyright (2010) Elsevier

and $\mathrm{Fe}_{2} \mathrm{O}_{3}$ ) were analyzed by PIXE-PIGE with perfect accuracy. PIXE-PIGE could provide comparable results as conventional instruments and could be achieved with no sampling at all in above studies, and they are essential and powerful instruments for analyzing irregular-shaped materials.

Besides the characterization of glass, the pigments used in architectural elements (patera, panel, pilaster, etc.) could also be analyzed by PIXE instrument. Roascio et al. [297] applied the PIXE technique to characterize the different pigments in medieval polychrome architectural elements of Veneto-Byzantine style. The PIXE analysis demonstrated that the major content was calcite (the white pigment), and the contents of $\mathrm{MgO}$, $\mathrm{Al}_{2} \mathrm{O}_{3}, \mathrm{SiO}_{2}$ and $\mathrm{SO}_{3}$ were all around $1 \%$. Moreover, the results showed that sulfur, sodium, silicon and aluminum were the most abundant elements in blue pigments, which could be contributed by the existence of lapis lazuli. Because of the presence of trace of copper, azurite $\left(2 \mathrm{CuCO}_{3} \cdot \mathrm{Cu}(\mathrm{OH})_{2}\right)$ can be excluded. But the high amount of iron detected in the target sample may account for an artificial pigment created at the beginning of the 18th century, which is called "Paris blue" and its chemical formula is $\mathrm{Fe}_{4}\left[\mathrm{Fe}(\mathrm{CN})_{6}\right]_{3}$. With respect to the yellow pigment, the PIXE analysis of a $0.5 \times 0.5 \mathrm{~mm}^{2}$ area (Fig. 27a) revealed a large content of calcite and lead with moderate content of iron, copper and minor content of barium-oxide (1\%). As no ancient or modern yellow pigment is based on minimal contents of copper $(0.46 \%)$ or iron $(0.47 \%)$, the above elements may be related to the desire of modifying the yellow display through the addition of a small quantity of other pigments. Moreover, the absence of arsenic and antimony excluded the existence 

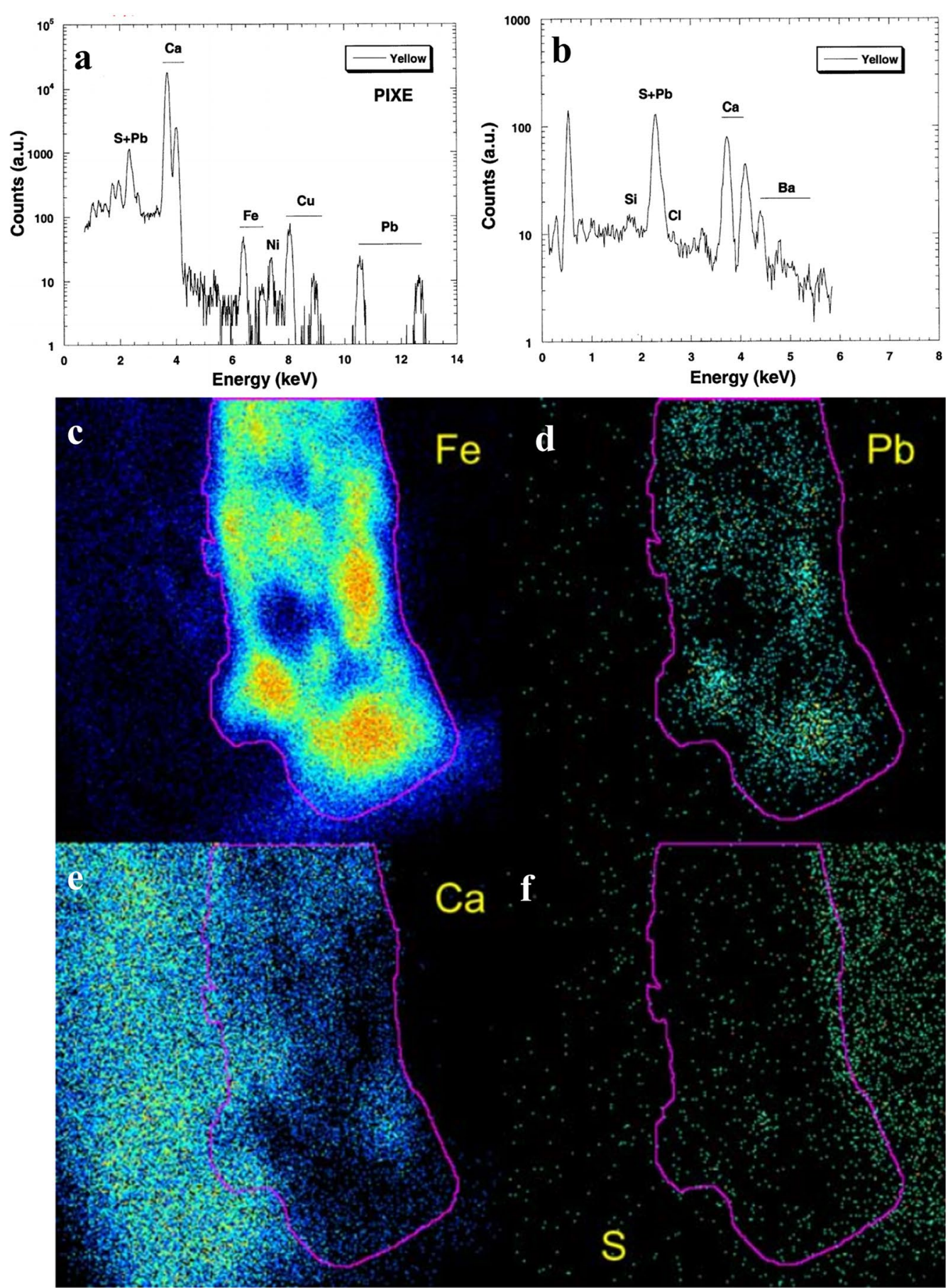

Fig. 27 a The PIXE spectrum collected from a $0.5 \times 0.5 \mathrm{~mm}^{2}$ area in the same sample. Here, the barium $L_{a^{\prime}} L_{\beta^{\prime}} L_{\gamma}$ peaks were not visible; $\mathbf{b}$ the $S E M-$ EDX spectrum of a barium-rich spot in the yellow pigments; $\mathbf{c}-\mathbf{f}$ PIXE elemental mapping for iron, calcium, lead, sulfur elements in a red section $[149,297]$, copyright $(2002,2004)$ Elsevier

of two traditional yellow pigments such as orpiment $\left(\mathrm{As}_{2} \mathrm{~S}_{3}\right)$ and Naples yellow $\left(\mathrm{Pb}_{3}\left(\mathrm{SbO}_{4}\right)_{2}\right)$ known in early medieval times. The absence of tin excluded the existence of lead-tin yellow $\left(\mathrm{Pb}_{2} \mathrm{SnO}_{4}\right)$ known in late medieval time. Furthermore, EDX analysis was carried out to identify the compounds in yellow pigments in which the existence of calcium and lead matched well with PIXE. A few spots contained $\mathrm{BaSO}_{4}$ and $\mathrm{Cl}$ (as shown in 
Fig. 27b), indicating that the white inorganic pigment available only from the second half of the 18th century might mix with mineral yellow $\left(\mathrm{PbCl}_{2} \cdot 7 \mathrm{PbO}\right)$. However, the data were also compatible with the existence of lead red $\left(\mathrm{Pb}_{3} \mathrm{O}_{4}\right)$ known from Roman times. It can be inferred that the yellow pigments might become orange-red, and finally turned to yellow with time. In red samples, the PIXE technique confirmed that the content of iron was quite abundant, and the absence of mercury and a small quantity of lead suggested that $\mathrm{HgS}$ or $\mathrm{Pb}_{3} \mathrm{O}_{4}$ were not the components of red pigments. In a similar study, Zucchiatti et al. [149] used PIXE technique to investigate the pigments of the 8-9th century frescoes of the Longobard temple of Cividale del Friuli in Italy. Notably, they used PIXE chemical mapping to investigate the major elements of cross-sections of a red piece (as shown in Fig. 27c-f), demonstrating that iron was the most abundant element which was quite different from the red averaged surface scanning. And the contents of calcium and lead were also abundant, while the contents of silicon and sulfur were relatively low. The results suggested that $\mathrm{Fe}_{2} \mathrm{O}_{3}$ was the main component in red samples, but lead-containing pigments (like litharge or massicot) cannot be excluded. In addition, it is noteworthy that PIXE technique will lead to produce dark brownish stains during irradiation on specific pigments. This strange phenomenon is called "dark spot", and they usually fade out progressively and disappear after a few weeks. In previous studies [298, 299], the purpose was to clarify the physicochemical processes of the stain production and search a way to make stains disappear. It was suggested that color centers were formed during irradiation processes and it was pointed out the significance to confirm the right experimental conditions to avoid any damage for materials of architectural heritage.

Besides the above applications, many papers can also be found concerning PIXE assessment of the threats to historic buildings exerted by air pollution in a semi-confined environment [33, 300]. For example, exfoliation and discoloration of the pigmented films were present in all the courtyard decorations of Palazzo Vecchio (14th century) located in the center of Florence. Chiari et al. [300] used a streaker sampler to collect fine (aerodynamic diameter $\left.d_{\mathrm{ae}}<2.5 \mu \mathrm{m}\right)$ and coarse $\left(2.5 \mu \mathrm{m}<d_{\mathrm{ae}}<10 \mu \mathrm{m}\right)$ fractions of $\mathrm{PM}_{10}$ with an hourly resolution. Two types of streaker samples related to the fine and coarse substances from the summer and winter campaigns were analyzed by PIXE. The results showed that elements with representative anthropocentric sources such as lead, nickel, zinc and copper were measured in courtyard with higher concentrations in the fine than in the coarse fraction, both in summer and winter. In fine fraction, sulfur was the most abundant element (mean values were $0.36 \mu \mathrm{g} / \mathrm{m}^{3}$ and $1.2 \mu \mathrm{g} / \mathrm{m}^{3}$ in winter and summer, respectively). Sulfur was mainly derived from gaseous $\mathrm{SO}_{2}$ in atmosphere and it was the major precursor of sulphate, which results in weathering and destruction of ancient building materials. [301]. Moreover, Sabbioni et al. [302] used PIXE technique to study the damaged layers on stone constructions and ancient buildings collected from eight urban sites of northern and central Italy. In the most abundant elements, silicon (in third place after calcium and sulfur), with a concentration varying between 2 and $9 \%$, and aluminum $(0.07-2 \%)$ must also be mentioned. Iron was the most abundant heavy metals, with percentage between 0.4 and $2 \%$, and followed by sodium, magnesium, potassium and chlorine. Also, some other heavy metals such as iron, lead, titanium, strontium, zinc, and manganese were detected. The detection of the major compounds and elements in black crusts generated on the carbonate surfaces of architectural heritage indicated that they were the result of both gaseous and aerosol deposition.

\section{MS-based molecular techniques}

Mass spectroscopy (MS) is a technique designed to separate charged atoms and molecules based on their mass number or mass-to-charge ratio $(\mathrm{m} / \mathrm{z})$. The MS-based techniques are mostly used for the quantification of atoms and molecules at trace level, and it is the only the technique which can identify and quantify individual isotopes from the same chemical element. Comparing with chromatographic techniques, MS techniques are necessary for the characterization of historic building materials due to numerous chemical compounds with similar retention times. At the same time, considering that a large number of compounds cannot be available as commercial standards, chromatography cannot provide accurate qualitative or quantitative analysis, thus researchers must rely on MS instruments to confirm the unknown organic or inorganic compounds. Several instrumental coupled with ion sources, mass analyzers and detectors have been optimized for specific applications, so that they have become recognized standard configurations for materials characterization. Recently, an increasing number of researchers used MS-based techniques to study the inorganic and organic materials of architectural heritage [303-307]. For example, the identification of the color layer chemical composition of mural paintings should distinguish inorganic pigments, organic pigments and binding media (oils, resins, wax or proteinaceous materials). Inorganic compounds of color layers were routinely analyzed by SEM-EDX, FTIR, Raman spectroscopy and PXRD techniques. Meanwhile, FTIR was also carried out to identify the chemical composition and structure of organic pigments and binders. But FTIR technique was found to be unable to differentiate organic substances 
with similar structures and functional groups, especially macromolecular peptides and proteins.

Gas chromatography-mass spectrometry (GC-MS) analysis is currently recognized as the best method for discriminating organic substances such as terpenic resins, waxes, proteins, drying oils and polysaccharide gums of micro-samples of painting layers. The method supplies elementary information for organic compounds, evaluating the optimal conditions for long-term conservation and planning restoration [308-311]. For example, Martinez et al. [308] used GC-MS to investigate the organic compounds (mainly polycyclic aromatic hydrocarbon, PAHs) of a palace house in Bilbao in Spain, a metropolitan which was identified as the World Heritage of UNESCO in 2006. PAHs in black crusts were extracted from non-rain-washed regions and determined as high as $20 \mathrm{mg} \mathrm{kg}$, in which about $80 \%$ of them were macromolecular organic matter with four to six rings. The computational values of phenanthrene/anthracene versus fluoranthene/pyrene, benzo $[a]$ anthracene divided by chrysene, benzo[ $b]$ fluoranthene divided by benzo $[k]$ fluoranthene, and indene[1,2,3-cd]pyrene divided by benzo(ghi)perylene were applied in this work. The former ratio Phe/Ant: Flu/Pyr being 15.0:1.4, indicating a pyrolytic source, and the later ratios were $0.44,1.53$ and 1.05 for $\mathrm{B}[a] \mathrm{A} / \mathrm{Chr}, \mathrm{B}[b] \mathrm{F} / \mathrm{B}[k] \mathrm{F}$, Ind/B(ghi)P, respectively, implying the pyrolytic source as heavy fuel-oils. However, most organic substances in mural painting belong to high molecular weight molecules [309]. In some researches, they were natural polymer such as proteins or plant gums. Others were polymerized or cross-linked by exposure to light and air, such as natural resins and drying oils [309]. For this reason, the above substances cannot be directly measured by GC-MS. It is necessary to transform the macromolecular analytes into low molecular weight molecules, which can be achieved by coupling analytical pyrolysis to the gas chromatographymass spectrometry (Py-GC-MS). As the Py-GC-MS is introduced, the original polymers were firstly added into the pyrolyzer apparatus for pyrolysis, and then the small molecular substances with low boiling point entered the GC-MS to carry out separation and detection. This instrument requires minimal sample manipulation and no special pretreatment, which can eliminate the possibility of contamination. Bonaduce et al. [310] used PyGC-MS technique to analyze the restoration of 14th century frescoes from the Monumental Cemetery in Pisa, Italy. Notably, the frescoes were detached from the wall and relocated on an asbestos cement support in 1945 by employing a type of glue containing casein and calcium hydroxide. In order to guarantee the detection accuracy, original materials and reference layers containing animal glue, egg, casein and several synthetic materials were analyzed and characterized to build a reference database of mass spectra. The spectra showed that the content of the most unstable amino acids such as methionine and lysine was much lower than expected, which demonstrated proteins degradation resulted from both natural ageing and human intervention. Furthermore, the solubilities of these proteins in ammonia solution were proved to be quite low, implying that a polymerisation process had occurred. These results matched well with those samples collected from other frescoes previously analyzed [20], and confirmed the extensive and known application of these natural materials during the restoration in 1945. Similarly, Mazzeo et al. [16] also applied Py-GC-MS to the study of the decorated surfaces of the Drum Tower in Xi'an, a Ming Dynasty monument built up in $1380 \mathrm{AC}$. The high concentrations of the dimethyl ester of the azelaic acid together with suberic acid dimethyl ester suggested the application of siccative oil as binding agent.

Although Py-GC-MS is a rapid and efficient instrument to acquire the fingerprint information of the organic substances in paint samples, wet chemical pretreatment is irreplaceable as it can elucidate the composition and structure of the target materials at molecular level. The wet chemical pretreatments commonly include hydrolysis and derivatization reactions. The first step is conducted to decompose macromolecules or polymers such as sugars from polysaccharides, amino acids from proteins and fatty acids from triglycerides into small molecules, thus supplying molecules are suitable for GC-MS determination. Derivatization reactions can transform the compounds containing polar functional groups such as carboxylic or alcoholic moieties, into less polar compounds like corresponding silyl esters or ethers to increase their volatilities. In the case of heterogeneous multi-material samples of historic buildings, the sophistication of the GC-MS testing procedure is increased due to separation and pretreatment of the different analytes $[312,313]$. For example, polysaccharides and proteins are required to experience acidic hydrolysis to release the sugars and amino acids, respectively. However, to ensure that the reaction is complete and to reduce the loss of active substances, hydrolysis conditions must be specifically optimized, that is, harsher for proteins and milder for polysaccharides. Glycerolipids and natural waxes demand alkaline hydrolysis, but the complete hydrolysis of wax esters is more difficult than that for glycerides. Alkaline hydrolysis is needed before the polyesters of shellac compounds carry out subsequent GC-MS analysis, but the choice of reagents should be careful as it can affect the resulting molecular profile. Furthermore, the characterization of various binders of mural painting may be affected by the presence of inorganic compounds 
originating from the support or pigments. For example, the characterization of proteinaceous and polysaccharide substances can be affected by the existence of a large number of inorganic species such as $\mathrm{Hg}^{2+}, \mathrm{Fe}^{3+}, \mathrm{Cu}^{2+}$, $\mathrm{Pb}^{2+}, \mathrm{Cd}^{2+}, \mathrm{Zn}^{2+}, \mathrm{Ca}^{2+}$ and inorganic/organic anions [314]. To overcome these troubles, a purification step for extracting target molecules by a miniaturized sorbent tip (C-18 or C-4 stationary phase) can be adopted during the analysis procedure [315]. For example, in Colombini and co-workers' study [309], beeswax used for mural paintings was characterized after hydrolysis and purification procedures, the existence of long chain fatty acids with an even number of carbons from palmitic to dotriacontanoic acid, ( $\omega-1)$-hydroxy acids with an even number of carbons from 15-hydroxyhexadecanoic acid to 23-hydroxytetracosanoic acid, long chain linear alcohols with an even number of carbons from tetracosanol to tetratriacontanol, long chain $(\alpha, \omega-1)$-diols with an even number of carbons from 1, 23-tetracosandiol to 1,27-octacosandiol, and long chain linear saturated hydrocarbons with the prevalence of an odd number of carbons from tricosane to tritriacontane testified their hypothesis about the chemical composition of the materials.

It is noteworthy that the above MS-based techniques require a large number of samples collected from historic buildings. For instance, the lowest sample consumption is $50-100 \mu \mathrm{g}$ for GC-MS and a few $\mu \mathrm{g}$ for Py-GC-MS [310]. Furthermore, sample pretreatments such as hydrolysis, extraction and derivatization are time-consuming along with the information loss of secondary fragments [316]. In order to completely characterize chemical composition of architectural heritage, particularly for proteinaceous materials, peptide mass mapping (PMM) applying specific cleavage with enzymes followed by detection of the resulting peptide fragments adopting matrix-assisted laser desorption/ ionization time-of-flight mass spectroscopy (MALDITOF-MS) is a common method. Compared to other methods, this technique generates a "mass fingerprint" which can supply faithful information of a protein. The target protein in either native or denatured state possessed little influence for material identification. It was reported that the detection limit ranges from pmol to fmol, implying extremely low consumption of samples. In addition, the total enzymatic cleavage/MALDI-TOFMS procedures can be completed within several hours. These superiorities encouraged scientists to examine this method also for characterization of protein substances collected from architectural heritage. In Hynek and co-workers' study [317], they demonstrated that MALDI-TOF-MS can be applied for rapid and trustworthy identification of proteins in mural paintings even in old, highly aged matrices. In the mass spectrum of the real tryptic digest, 12 peptides were observed, corresponding to fragments from a tryptic digest of rabbit glue (with precision $\pm 0.1 \mathrm{Da}$ ). Moreover, Kuckova et al. [318] used PMM method to characterize the protein additives in ancient building materials. The spectra showed that the amino acid sequences were assigned to $17 \%$ of individual peptides from the milk proteins $(m / z=903.57,1193.68,1658.78$ represented $\beta$-Lactoglobulin. $m / z=954.41,977.52$, 979.56, 1022.60, $1195.65,1251.75,1355.70,1367.70,1566.89,1979.84$ represented $\alpha_{\mathrm{S} 2}$-Casein. $m / z=955.53,1193.54,1251.71$ represented $\kappa$-Casein, etc.) and confirmed the reliability of the publicly available proteomic database Expasy and the program mMass.

The inhomogeneous range of organic substances with different structures such as indigoids, anthraquinones, flavonoids, tannins or macromolecules can be detected by liquid chromatographic separation and mass spectrometers, which usually equipped with either atmospheric pressure chemical ionisation (APCI) [319] or electrospray ionisation (ESI) instruments [320, 321]. These ionisation techniques are currently known as soft ionisation ones. Among all kinds of liquid mass spectrometers, high performance liquid chromatography mass spectroscopy (HPLC-MS) equipped with UV-vis or fluorescence detection (FLD) is nowadays becoming a routine technique for historical dyes analysis [322]. Furthermore, the use of sector field (SF) instrument decreased due to the relatively unfavorable price/performance ratio of this technique. In many cases, SF instruments had been replaced by time-of-flight mass spectrometry (TOFMS), which is the most successful high-resolution mass spectrometer. Its easy operation and fast data collection make them attract increasing attention [322]. Similarly, in spite of ion cyclotron resonance-Fourier transform mass spectrometry (ICR-FT-MS) provide ultimate mass resolution and accuracy. Based on this circumstance, hybrid mass spectrometers attracted lots of attention to carry out different kinds of analytical tasks. They combine one or more types of mass analyzers such as quadrupole-TOF (q-TOF), two-dimensional TOF (TOF-TOF) or ion trap-TOF (IT-TOF), to provide two-dimensional or multidimensional mass spectra with high resolution at the same time [323]. Additionally, inductively coupled plasma-mass spectrometry (ICP-MS) is commonly used to determine trace inorganic substances. Maguregui et al. [35] used ICP-MS technique to assess nitrate impact on architectural heritage materials. In this study, $\mathrm{Ba}\left(\mathrm{NO}_{3}\right)_{2}$ was the only detected nitrate salt in the black crust of samples. Considering that house was highly affected by road traffic and the pollutants of airborne barium particulates originated from tyre friction, the existence of nitrate salts mainly originated from the reaction between 
the nitrogenous aerosol $\left(\mathrm{NO}_{x}\right)$ and airborne barium particulate matters.

Most important of all, TOF secondary ion mass spectrometry (TOF-SIMS) is ideal to chemically or isotopically map a surface at the microscale and characterize alteration, corrosion and diffusion layers by depth profiling [324, 325]. For example, the existence of sapwood was indispensable to reckon felling dates of woods without bark in the past [326]. But the felling time of the discolored old woods couldn't be calculated, because it is difficult to distinguish between sapwood and heartwood only on account of color or morphological difference in the wood cell structures of old samples (the typical crosssection map of wood was shown in Fig. 28a). In Saito and co-workers' study [17], the TOF-SIMS technique verified the existence of sapwood and heartwood in the discolored ancient Hinoki wood via directly measuring the molecular ions of extractives in wood tissues without any special pretreatment. As illustrated in Fig. 28b, c, two prominent peaks located at $m / z=353$ and at $m / z=251$ could be assigned as $\mathrm{C}_{20} \mathrm{H}_{17} \mathrm{O}_{6}[\mathrm{M}-\mathrm{H}]^{+}$for hinokinin and $\mathrm{C}_{17} \mathrm{H}_{15} \mathrm{O}_{2}[\mathrm{M}-\mathrm{H}]^{+}$for hinokiresinol, respectively. As well, the relatively lower peaks at $m / z=299$ and $m / z=302$ could be assigned to $\mathrm{C}_{20} \mathrm{H}_{27} \mathrm{O}_{2}[\mathrm{M}-\mathrm{H}]^{+}$for hinokione and $\mathrm{C}_{20} \mathrm{H}_{30} \mathrm{O}_{2}[\mathrm{M}]^{+\cdot}$ for hinokiol, respectively. Furthermore, these characteristic molecular ions were identified by detecting their pure substances, as shown in Fig. 28dg. In brief, hinokinin is a good indicator for distinguishing sapwood from heartwood in Hinoki woods. TOF-SIMS technique will be helpful not only for identification of the presence or absence of sapwood in discolored woods but also for determination of the distribution of various chemical compounds in woods.

\section{Conclusions and outlook}

This review aimed at demonstrating the relevance of analytical techniques utilization in materials characterization of architectural heritage. Each technique applied either alone or in combination with other types of instruments, and multivariate analyses were presented and discussed. Three major areas of successful applications had been grouped as characterization of original material, recognition of restoration fakes, and identification of environmental impact. The applications of material science and scientific methods to the architectural heritage have matured considerably, some of recent trends are quite clear and can be tentatively outlined:

1. The use of a unique analytical technique is not competent to clarify a material present in architectural heritage. Given that materials are susceptible to environmental and anthropocentric impacts; new components may appear in the boundary or inner parts

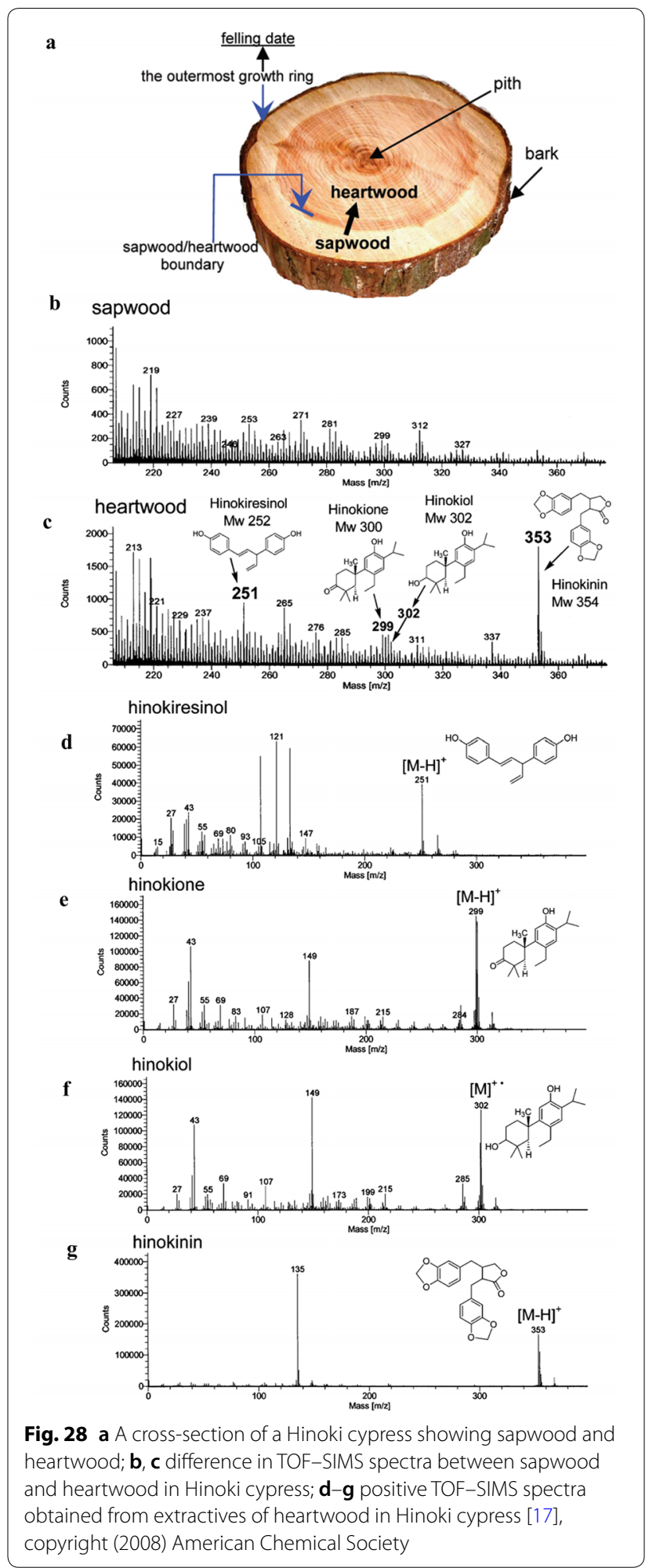

of the object, leading to a more complicated chemical matrix to be analyzed. Therefore, the application of various analytical techniques (the multianalytical approach) is imperative. In some special cases, 
if researchers want to ascertain the mechanism of damage process that are affecting a material, the experimental data should be treated by chemometrics to get as much relevant information as possible.

2. There is a general tendency toward the use of microbeam techniques. Synchrotron radiation sources have the lead, and they will continue to do so because of their intrinsic characteristics, such as high sensitivity, wide applicability (most of the periodic table), and no requirement for sample preparation and mostly can be undertaken in air. SR-XAS and SR-XRF are now recognized as appropriate methods for cracking the challenging questions in historic building conservation which can't be addressed via traditional laboratory methods.

3. Another general trend is to select some portable and non-destructive techniques. They can be used in situ, and free from destructive pretreatments, increasing the possibility to make decisions at the experimental sites. Recent researches and developments on detectors and data processing softwares of instruments have reinforced their usefulness and are nowadays an indispensable tool in the field of architectural heritage conservation.

4. With the widespread use of analytical tools, a desirable trend would be the standardization of results and the buildup of consistent reference databases. Each laboratory has its own standards for measurements and local databases, and sometimes the actual measured data are not even published. Especially in MS analysis, researchers usually utilize the existing databases to analyze organic compounds of historic building, but most of them are suitable use for prediction of pharmaceutical, hormone, food or environmental organics.

In all, this review will provide powerful evidences to highlight that the analytical techniques are effective to assess the ancient buildings and monuments. The corresponding researchers should choose the appropriate techniques according to features of target materials and their purposes. And more importantly, the conservation of architectural heritage is a multidisciplinary work, we should exchange our knowledge and achievements with other professionals.

\footnotetext{
Abbreviations

OM: optical microscope; AFM: atomic force microscope; SEM: scanning electron microscope; ESEM: environmental scanning electron microscope; TEM: transmission electron microscope; EDX: energy-dispersive X-ray spectroscopy; UV-vis: UV-Vis absorption spectroscopy; LIBS: laser-induced breakdown spectroscopy; FTIR: Fourier transform infrared spectroscopy; IRT: infrared thermography; TG: thermogravimetry; DTA: differential thermal analysis; DSC: differential scanning calorimetry; XRF: X-ray fluorescence; XRD: X-ray
}

diffraction; XPS: X-ray photoelectron spectroscopy; XANES: X-ray absorption near edge structure; EXAFS: extended X-ray-absorption final structure; PIXE: proton-induced $X$-ray emission; PIGE: proton-induced $\gamma$-ray emission; GC-MS: gas chromatography-mass spectrometry; Py-GC-MS: pyrolysis gas chromatography-mass spectrometry; MALDI-TOF-MS: matrix-assisted laser desorption ionization time-of-flight mass spectroscopy; APCl: atmospheric pressure chemical ionisation; HPLC-MS: high performance liquid chromatography mass spectroscopy; TOF-SIMS: time-of-flight secondary ion mass spectrometry; ICPMS: inductively coupled plasma-mass spectrometry.

\section{Acknowledgements}

Thanks to Novel Materials \& Technology for Environmental Remediation of Beijing University of Civil Engineering and Architecture for providing us with facilities and support. We would also like to thank Beijing Key Laboratory of Functional Materials for Building Structure and Environment Remediation.

\section{Authors' contributions}

$\mathrm{CZ}$ has written the main body and the conclusions. $\mathrm{AL}$ and $\mathrm{MH}$ have reviewed the whole text and have made comments and suggestions to improve it. CCW has written the abstract and the introduction, and has repeatedly reviewed the whole text, making precious comments and suggestions. YZ polished the English language during the preparation of revised manuscript. All authors read and approved the final manuscript.

\section{Funding}

This work was co-funded by Project of Construction of Innovation Teams and Teacher Career Development for Universities and Colleges Under Beijing Municipality (IDHT20170508), Great Wall Scholars Training Program Project of Beijing Municipality Universities (CIT\&TCD20180323), Beijing Talent Project (2018A35), the Fundamental Research Funds for Beijing Universities of Civil Engineering and Architecture (X18075/X18076/X18124/X18125/X18276) and Scientific Research Foundation of Beijing University of Civil Engineering and Architecture (KYJJ2017033/KYJJ2017008).

\section{Availability of data and materials}

Not applicable.

\section{Competing interests}

The authors declare that they have no competing interests.

\section{Author details}

${ }^{1}$ Beijing Key Laboratory of Functional Materials for Building Structure and Environment Remediation, Beijing University of Civil Engineering and Architecture, Beijing 100044, China. ${ }^{2}$ Beijing Advanced Innovation Center of Future Urban Design, Beijing University of Civil Engineering and Architecture, Beijing 100044, China.

Received: 16 July 2018 Accepted: 27 May 2019

Published online: 04 June 2019

\section{References}

1. Núñez Andrés MA, Buill Pozuelo F. Evolution of the architectural and heritage representation. Landsc Urban Plan. 2009;91:105-12.

2. Pickard R. A comparative review of policy for the protection of the architectural heritage of Europe. Int J Herit Stud. 2002;8:349-63.

3. Houben H, Balderrama AA, Simon S. Our earthen architectural heritage: materials research and conservation. MRS Bull. 2011;29:338-41.

4. Fratini F, Pecchioni E, Rovero L, Tonietti U. The earth in the architecture of the historical centre of Lamezia Terme (Italy): characterization for restoration. Appl Clay Sci. 2011;53:509-16.

5. Quagliarini E, Bondioli F, Goffredo GB, Licciulli A, Munafò P. Self-cleaning materials on architectural heritage: compatibility of photo-induced hydrophilicity of $\mathrm{TiO}_{2}$ coatings on stone surfaces. J Cult Herit. 2013;14:1-7.

6. Friolo KH, Stuart B, Ray A. Characterisation of weathering of Sydney sandstones in heritage buildings. J Cult Herit. 2003;4:211-20.

7. Molina E, Benavente D, Sebastian E, Cultrone G. The influence of rock fabric in the durability of two sandstones used in the Andalusian 
Architectural Heritage (Montoro and Ronda, Spain). Eng Geol. 2015;197:67-81.

8. Daly C. The design of a legacy indicator tool for measuring climate change related impacts on built heritage. Herit Sci. 2016;4:19-31.

9. Adorni E, Coïsson E, Ferretti D. In situ characterization of archaeological adobe bricks. Constr Build Mater. 2013;40:1-9.

10. Graziani L, Quagliarini E, Osimani A, Aquilanti L, Clementi F, Yéprémian C, Lariccia V, Amoroso S, D'Orazio M. Evaluation of inhibitory effect of $\mathrm{TiO}_{2}$ nanocoatings against microalgal growth on clay brick façades under weak UV exposure conditions. Build Environ. 2013;64:38-45.

11. Vítková G, Prokeš L, Novotný K, Pořízka P, Novotný J, Všianský D, Čelko L, Kaiser J. Comparative study on fast classification of brick samples by combination of principal component analysis and linear discriminant analysis using stand-off and table-top laser-induced breakdown spectroscopy. Spectrochim Acta B. 2014;101:191-9.

12. De Bardi M, Hutter H, Schreiner M, Bertoncello R. Potash-lime-silica glass: protection from weathering. Herit Sci. 2015;3:22-31.

13. Van Wersch L, Loisel C, Mathis F, Strivay D, Bully S. Analyses of early medieval stained window glass from the monastery of Baume-LesMessieurs (Jura, France). Archaeometry. 2015;58:930-46.

14. Carmona N, Ortega-Feliu I, Gómez-Tubío B, Villegas MA. Advantages and disadvantages of PIXE/PIGE, XRF and EDX spectrometries applied to archaeometric characterisation of glasses. Mater Charact. 2010;61:257-67.

15. Fernandes P, Vilarigues M, Alves LC, da Silva RC. Stained glasses from Monastery of Batalha: non-destructive characterisation of glasses and glass paintings. J Cult Herit. 2008;9:5-9.

16. Mazzeo R, Cam D, Chiavari G, Fabbri D, Ling H, Prati S. Analytical study of traditional decorative materials and techniques used in Ming Dynasty wooden architecture. The case of the Drum Tower in Xi'an, PR of China. J Cult Herit. 2004;5:273-83.

17. Saito K, Mitsutani T, Imai T, Matsushita Y, Fukushima K. Discriminating the indistinguishable sapwood from heartwood in discolored ancient wood by direct molecular mapping of specific extractives using time-of-flight secondary ion mass spectrometry. Anal Chem. 2008;80:1552-7.

18. Serifaki K, Böke H, Yalçın \$, Ipekoğlu B. Characterization of materials used in the execution of historic oil paintings by XRD, SEM-EDS, TGA and LIBS analysis. Mater Charact. 2009;60:303-11.

19. Rosado T, Gil M, Caldeira AT, Martins MDR, Dias CB, Carvalho L, Mirão J, Candeias AE. Material characterization and biodegradation assessment of mural paintings: renaissance frescoes from Santo Aleixo Church, Southern Portugal. Int J Archit Herit. 2014;8:835-52.

20. Colombini MP, Modugno F, Giacomelli M, Francesconi S. Characterisation of proteinaceous binders and drying oils in wall painting samples by gas chromatography-mass spectrometry. J Chromatogr A. 1999;846:113-24.

21. Torney C, Forster AM, Szadurski EM. Specialist'restoration mortars' for stone elements: a comparison of the physical properties of two stone repair materials. Herit Sci. 2014;2:1-13.

22. Hormes J, Diekamp A, Klysubun W, Bovenkamp GL, Börste N. The characterization of historic mortars: a comparison between powder diffraction and synchrotron radiation based X-ray absorption and X-ray fluorescence spectroscopy. Microchem J. 2016;125:190-5.

23. Wei $G$, Zhang $H$, Wang $H$, Fang S, Zhang B, Yang F. An experimental study on application of sticky rice-lime mortar in conservation of the stone tower in the Xiangji Temple. Constr Build Mater. 2012;28:624-32.

24. Faria P, Henriques F, Rato V. Comparative evaluation of lime mortars for architectural conservation. J Cult Herit. 2008;9:338-46.

25. Ruffolo SA, Comite V, La Russa MF, Belfiore CM, Barca D, Bonazza A, Crisci GM, Pezzino A, Sabbioni C. An analysis of the black crusts from the Seville Cathedral: a challenge to deepen the understanding of the relationships among microstructure, microchemical features and pollution sources. Sci Total Environ. 2015;502:157-66.

26. Böke $H$, Göktürk EH, Caner-Saltık EN, Demirci Ş. Effect of airborne particle on $\mathrm{SO}_{2}$-calcite reaction. Appl Surf Sci. 1999;140:70-82.

27. Herrera LK, Videla HA. Surface analysis and materials characterization for the study of biodeterioration and weathering effects on cultural property. Int Biodeterior Biodegrad. 2009;63:813-22.
28. Fang L, Clausen G, Fanger PO. Impact of temperature and humidity on chemical and sensory emissions from building materials. Indoor Air. 2004;9:193-201.

29. Mimura AMS, Almeida JM, Vaz FAS, de Oliveira MAL, Ferreira CCM, Silva JCJ. Chemical composition monitoring of tropical rainwater during an atypical dry year. Atmos Res. 2016;169:391-9.

30. Lin X, He L, Zhang R, Guo X, Li H. Rainwater in Guangzhou, China: oxidizing properties and physicochemical characteristics. Atmos Pollut Res. 2018. https://doi.org/10.1016/j.apr.2018.08.005.

31. Monte MD, Sabbioni C. Chemical and biological weathering of an historical building: Reggio Emilia Cathedral. Sci Total Environ. 1986;50:165-82.

32. Luque A, De Yuso MM, Cultrone G, Sebastián E. Analysis of the surface of different marbles by X-ray photoelectron spectroscopy (XPS) to evaluate decay by $\mathrm{SO}_{2}$ attack. Environ Earth Sci. 2013;68:833-45.

33. Chiari M, Lucarelli F, Migliori A, Nava S, Valli G, Vecchi R, Garcia-Orellana I, Mazzei F. PIXE analysis of $\mathrm{PM}_{10-2.5}$ and $\mathrm{PM}_{2.5}$ with hourly resolution from Michelozzo's Courtyard in Palazzo Vecchio (Florence, Italy). Nucl Instrum Methods B. 2006;249:552-5.

34. Atzei D, Fantauzzi M, Rossi A, Fermo P, Piazzalunga A, Valli G, Vecchi R. Surface chemical characterization of $\mathrm{PM}_{10}$ samples by XPS. Appl Surf Sci. 2014;307:120-8.

35. Maguregui M, Sarmiento A, Martínez-Arkarazo I, Angulo M, Castro K, Arana G, Etxebarria N, Madariaga JM. Analytical diagnosis methodology to evaluate nitrate impact on historical building materials. Anal Bioanal Chem. 2008;391:1361-70.

36. Charola AE, Pühringer J, Steiger M. Gypsum: a review of its role in the deterioration of building materials. Eng Geol. 2007;52:339-52.

37. Belfiore CM, Barca D, Bonazza A, Comite V, La Russa MF, Pezzino A, Ruffolo SA, Sabbioni C. Application of spectrometric analysis to the identification of pollution sources causing cultural heritage damage. Environ Sci Pollut R. 2013;20:8848-59.

38. Sandrolini F, Franzoni E, Cuppini G, Caggiati L. Materials decay and environmental attack in the Pio Palace at Carpi: a holistic approach for historical architectural surfaces conservation. Build Environ. 2007:42:1966-74.

39. Gulotta D, Bertoldi M, Bortolotto S, Fermo P, Piazzalunga A, Toniolo L. The Angera stone: a challenging conservation issue in the polluted environment of Milan (Italy). Environ Earth Sci. 2013;69:1085-94.

40. Adriaens A. European actions to promote and coordinate the use of analytical techniques for cultural heritage studies. TRAC Trend Anal Chem. 2004;23:583-6.

41. Moropoulou A, Labropoulos KC, Delegou ET, Karoglou M, Bakolas A. Non-destructive techniques as a tool for the protection of built cultural heritage. Constr Build Mater. 2013;48:1222-39.

42. Elsorady DA. Assessment of the compatibility of new uses for heritage buildings: the example of Alexandria National Museum, Alexandria, Egypt. J Cult Herit. 2014;15:511-21.

43. Cardiel BI, Lourdes GC. Multidisciplinary, diachronic methodology for the conservation of archeological remains. Restoration of the Arab baths of the San Francisco Parador Hotel in the grounds of the Alhambra (Granada, Spain). J Cult Herit. 2015;16:623-31.

44. Elia RJ. ICOMOS adopts archaeological heritage charter: text and commentary. J Field Archaeol. 2013;20:97-104.

45. Vornicu N, Bibire C, Murariu E, Ivanov D. Analysis of mural paintings using in situ non-invasive XRF, FTIR spectroscopy and optical microscopy. X-Ray Spectrom. 2013;42:380-7.

46. Thirumalini S, Ravi R, Rajesh M. Experimental investigation on physical and mechanical properties of lime mortar: effect of organic addition. J Cult Herit. 2018;31:97-104.

47. Kramar S, Urosevic M, Pristacz H, Mirtič B. Assessment of limestone deterioration due to salt formation by micro-Raman spectroscopy: application to architectural heritage. J Raman Spectrosc. 2011:41:1441-8.

48. Cardell C, Delalieux F, Roumpopoulos K, Moropoulou A, Auger F, Van Grieken R. Salt-induced decay in calcareous stone monuments and buildings in a marine environment in SW France. Constr Build Mater. 2003:17:165-79.

49. López-Arce P, Garcia-Guinea J, Gracia M, Obis J. Bricks in historical buildings of Toledo City: characterisation and restoration. Mater Charact. 2003:50:59-68. 
50. Vilarigues M, Redol P, Machado A, Rodrigues PA, Alves LC, da Silva $\mathrm{RC}$. Corrosion of 15 th and early 16 th century stained glass from the monastery of Batalha studied with external ion beam. Mater Charact. 2011;62:211-7.

51. Cardell C, Benavente D, Rodríguez-Gordillo J. Weathering of limestone building material by mixed sulfate solutions. Characterization of stone microstructure, reaction products and decay forms. Mater Charact. 2008;59:1371-85.

52. Rodriguez-Navarro C, Doehne E, Sebastian E. How does sodium sulfate crystallize? Implications for the decay and testing of building materials. Cement Concrete Res. 2000;30:1527-34.

53. Gil M, Carvalho ML, Seruya A, Ribeiro I, Queralt I, Candeias AE, Mirão J. Limewashing paintings in Alentejo urban heritage: pigment characterization and differentiation by WDXRF and XRD. Appl Phys A. 2008;90:49-54.

54. Calia A, Lettieri M, Quarta G. Cultural heritage study: microdestructive techniques for detection of clay minerals on the surface of historic buildings. Appl Clay Sci. 2011;53:525-31.

55. Silva AS, CruzT, Paiva MJ, Candeias A, Adriano P, Schiavon N, Mirão JAP. Mineralogical and chemical characterization of historical mortars from military fortifications in Lisbon harbour (Portugal). Environ Earth Sci. 2011;63:1641-50.

56. Theodoridou M, loannou I, Philokyprou M. New evidence of early use of artificial pozzolanic material in mortars. J Archaeol Sci. 2013:40:3263-9.

57. Carasek H, Japiassú P, Cascudo O, Velosa A. Bond between 19th century lime mortars and glazed ceramic tiles. Constr Build Mater. 2014;59:85-98.

58. BartzW, Filar T. Mineralogical characterization of rendering mortars from decorative details of a baroque building in Kożuchów (SW Poland). Mater Charact. 2010;61:105-15.

59. Kramar S, Zalar V, Urosevic M, Körner W, Mauko A, Mirtič B, Lux J, Mladenović A. Mineralogical and microstructural studies of mortars from the bath complex of the Roman villa rustica near Mošnje (Slovenia). Mater Charact. 2011;62:1042-57.

60. Urosevic M, Yebra-Rodríguez A, Sebastián-Pardo E, Cardell C. Black soiling of an architectural limestone during two-year term exposure to urban air in the city of Granada (S Spain). Sci Total Environ. 2012:414:564-75.

61. Bonazza A, Sabbioni C, Ghedini N. Quantitative data on carbon fractions in interpretation of black crusts and soiling on European built heritage. Atmos Environ. 2005:39:2607-18.

62. Vazquez-Calvo C, Alvarez de Buergo M, Fort R, Varas MJ. Characterization of patinas by means of microscopic techniques. Mater Charact. 2007;58:1119-32.

63. Pflugfelder C, Mainusch N, Hammer I, Viöl W. Cleaning of wall paintings and architectural surfaces by plasma. Plasma Process Polym. 2007:4:516-21.

64. Taglieri G, Daniele V, Rosatelli G, Sfarra S, Mascolo MC, Mondelli C. Eco-compatible protective treatments on an Italian historic mortar (XIV century). J Cult Herit. 2017;25:135-41.

65. Falcão L, Araújo MEM. Characterization of Maya Blue pigment in preclassic and classic monumental architecture of the ancient pre-Columbian city of Calakmul (Campeche, Mexico). J Cult Herit. 2011;12:140-8.

66. Kiele E, Lukseniene J, Griguceviciene A, Selskis A, Senvaitiene J, Ramanauskas R, Raudonis R, Kareiva A. Methyl-modified hybrid organic-inorganic coatings for the conservation of copper. J Cult Herit. 2014:15:242-9.

67. Rosato L, Stefanidou M, Milazzo G, Fernandez F, Livreri P, Muratore N, Terranova LM. Study and evaluation of nano-structured cellulose fibers as additive for restoration of historical mortars and plasters. Mater Today. 2017:4:6954-65.

68. Hu K, Bai C, Ma L, Bai K, Liu D, Fan B. A study on the painting techniques and materials of the murals in the Five Northern Provinces' Assembly Hall, Ziyang, China. Herit Sci. 2013:1:18-32.

69. Rodriguez-Navarro C, Ruiz-Agudo E, Ortega-Huertas M, Hansen E. Nanostructure and irreversible colloidal behavior of $\mathrm{Ca}(\mathrm{OH})_{2}$ : implications in cultural heritage conservation. Langmuir. 2005;21:10948-57.

70. Fort González R, Alvarez de Buergo M, Mingarro Martín F, López de Azcona MC. Stone decay in 18th century monuments due to iron corrosion. The Royal Palace, Madrid (Spain). Build Environ. 2004:39:357-64.
71. Xiao Y, Fu X, Gu H, Gao F, Liu S. Properties, characterization, and decay of sticky rice-lime mortars from the Wugang Ming dynasty city wall (China). Mater Charact. 2014:90:164-72.

72. Böke H, Akkurt S, İpekoğlu B, Uğurlu E. Characteristics of brick used as aggregate in historic brick-lime mortars and plasters. Cement Concrete Res. 2006;36:1115-22.

73. Doherty B, Pamplona M, Selvaggi R, Miliani C, Matteini M, Sgamellotti A, Brunetti B. Efficiency and resistance of the artificial oxalate protection treatment on marble against chemical weathering. Appl Surf Sci. 2007:253:4477-84.

74. Sternberg T, Viles H, Cathersides A, Edwards M. Dust particulate absorption by ivy (Hedera helix L.) on historic walls in urban environments. Sci Total Environ. 2010;409:162-8.

75. Lopez-Arce P, Garcia-Guinea J. Weathering traces in ancient bricks from historic buildings. Build Environ. 2005:40:929-41.

76. Kontozovadeutsch V, Cardell C, Urosevic M, Ruizagudo E, Deutsch F, Grieken RV. Characterization of indoor and outdoor atmospheric pollutants impacting architectural monuments: the case of San Jerónimo Monastery (Granada, Spain). Environ Earth Sci. 2011;63:1433-45.

77. Miriello D, Barba L, Blancas J, Bloise A, Cappa M, Cura M, De Angelis D, De Luca R, Pecci A, Taranto M, Yavuz HB, Crisci GM. New compositional data on ancient mortars from Hagia Sophia (Istanbul, Turkey). Archaeol Anthrop Sci. 2017;9:499-514.

78. $\operatorname{Pr}$ G. Fourier transform infrared spectrometry. Science. 1983:222:297-302.

79. Brøns C, Rasmussen KL, Di Crescenzo MM, Stacey R, Lluveras-Tenorio A. Painting the Palace of Apries I: ancient binding media and coatings of the reliefs from the Palace of Apries, Lower Egypt. Herit Sci. 2018;6:6-26.

80. Luo YB, Zhang YJ. Investigation of sticky-rice lime mortar of the Horse Stopped Wall in Jiange. Herit Sci. 2013;1:26-31.

81. Lodi GC, De Ferri L, Pojana G. Spectroscopic characterization of historical building materials: the case study of the Biblioteca Nazionale Marciana (Venice, Italy). J Raman Spectrosc. 2017:49:351-61.

82. Krizova I, Schultz J, Nemec I, Cabala R, Hynek R, Kuckova S. Comparison of analytical tools appropriate for identification of proteinaceous additives in historical mortars. Anal Bioanal Chem. 2018:410:189-200.

83. Zappia G, Sabbioni C, Gobbi G. Non-carbonate carbon content on black and white areas of damaged stone monuments. Atmos Environ. 1993;27:1117-21

84. Carbó MD, Martínez VP, Adelantado JG, Reig FB, Moreno MM. Fourier transform infrared spectroscopy and the analytical study of sculptures and wall decoration. J Mol Struct. 1997:410:559-63.

85. Eastes JW, Salisbury JW. Spectral properties of sulfated limestone and marble: implications for in situ assessment of atmospheric pollution damage to carbonate rock building materials. Appl Spectrosc. 1986:40:954-9.

86. Alessandrini G, Toniolo L, Cariati F, Daminelli G, Polesello S, Pozzi A, Salvi AM. A black paint on the facade of a renaissance building in Bergamo, Italy. Stud Conserv. 1996:41:193-204.

87. Barca D, Belfiore CM, Crisci GM, La Russa MF, Pezzino A, Ruffolo SA. A new methodological approach for the chemical characterization of black crusts on building stones: a case study from the Catania city centre (Sicily, Italy). J Anal Atom Spectrom. 2011;26:1000-11.

88. Ausset P, Bannery F, Monte MD, Lefevre RA. Recording of pre-industrial atmospheric environment by ancient crusts on stone monuments. Atmos Environ. 1998:32:2859-63.

89. Ghedini N, Sabbioni C, Bonazza A, Gobbi G. Chemical-thermal quantitative methodology for carbon speciation in damage layers on building surfaces. Environ Sci Technol. 2006;40:939-44.

90. La Russa MF, Belfiore CM, Comite V, Barca D, Bonazza A, Ruffolo SA, Crisci GM, Pezzino A. Geochemical study of black crusts as a diagnostic tool in cultural heritage. Appl Phys A. 2013:113:1151-62.

91. Barca D, Comite V, Belfiore CM, Bonazza A, La Russa MF, Ruffolo SA, Crisci GM, Pezzino A, Sabbioni C. Impact of air pollution in deterioration of carbonate building materials in Italian urban environments. Appl Geochem. 2014:48:122-31.

92. Bitossi G, Giorgi R, Mauro M, Salvadori B, Dei L. Spectroscopic techniques in cultural heritage conservation: a survey. Appl Spectrosc Rev. 2005; $40: 187-228$

93. Charola AE. Salts in the deterioration of porous materials: an overview. J Am Inst Conserv. 2000:39:327-43. 
94. Shi C, Jiménez AF, Palomo A. New cements for the 21st century: the pursuit of an alternative to Portland cement. Cement Concrete Res. 2011;41:750-63.

95. Lothenbach B, Saout GL, Gallucci E, Scrivener K. Influence of limestone on the hydration of Portland cements. Cement Concrete Res. 2008;38:848-60

96. Tsui N, Flatt RJ, Scherer GW. Crystallization damage by sodium sulfate. J Cult Herit. 2003;4:109-15.

97. Varas-Muriel MJ, Pérez-Monserrat EM, Vázquez-Calvo C, Fort R. Effect of conservation treatments on heritage stone. Characterisation of decay processes in a case study. Constr Build Mater. 2015;95:611-22.

98. Cappitelli F, Toniolo L, Sansonetti A, Gulotta D, Ranalli G, Zanardini E, Sorlini C. Advantages of using microbial technology over traditional chemical technology in removal of black crusts from stone surfaces of historical monuments. Appl Environ Microb. 2007;73:5671-5.

99. Riccardi MP, Duminuco P, Tomasi C, Ferloni P. Thermal, microscopic and $X$-ray diffraction studies on some ancient mortars. Thermochim Acta. 1998;321:207-14

100. Silva DA, Wenk HR, Monteiro PJM. Comparative investigation of mortars from Roman Colosseum and cistern. Thermochim Acta. 2005;438:35-40.

101. Weber J, Gadermayr N, Kozłowski R, Mucha D, Hughes D, Jaglin D, Schwarz W. Microstructure and mineral composition of Roman cements produced at defined calcination conditions. Mater Charact. 2007;58:1217-28.

102. Fang SQ, Zhang $H$, Zhang BJ, Zheng Y. The identification of organic additives in traditional lime mortar. J Cult Herit. 2014;15:144-50.

103. Yang F, Zhang B, Ma Q. Study of sticky rice-lime mortar technology for the restoration of historical masonry construction. Acc Chem Res. 2010;43:936-44

104. Tomasini EP, Cárcamo J, Castellanos Rodríguez DM, Careaga V, Gutiérrez S, Rúa Landa C, Sepúlveda M, Guzman F, Pereira M, Siracusano G, Maier MS. Characterization of pigments and binders in a mural painting from the Andean church of San Andrés de Pachama (northernmost of Chile). Herit Sci. 2018;6:61-73.

105. Costantini I, Castro K, Madariaga JM. Portable and laboratory analytical instruments for the study of materials, techniques and environmental impacts in mediaeval mural paintings. Anal Methods. 2018;10:4854-70

106. Măruţoiu C, Bratu I, Troşan L, Neamtu C, Măruţoiu VC, Pop D, Tănăselia C, Garabagiu S. Scientific investigation of the Imperial Gates belonging to the wooden church from Săcel, Turda County, Romania. Spectrochim Acta A. 2016;152:311-7

107. Lo Monaco A, Mattei E, Pelosi C, Santancini M. The scientific investigation for the study and conservation of the wooden model of S. Maria della Consolazione's church (Todi, Italy). J Cult Herit. 2013;14:537-43.

108. Rao H, Li B, Yang Y, Ma Q, Wang C. Proteomic identification of organic additives in the mortars of ancient Chinese wooden buildings. Anal Methods. 2015:7:143-9.

109. Aulinas M, Garcia-Valles M, Gimeno D, Fernandez-Turiel JL, Ruggieri F, Pugès $M$. Weathering patinas on the medieval (S. XIV) stained glass windows of the Pedralbes Monastery (Barcelona, Spain). Environ Sci Pollut R. 2008;16:443-52.

110. Rodrigues A, Fearn S, Vilarigues M. Historic K-rich silicate glass surface alteration: behaviour of high-silica content matrices. Corros Sci. 2018;145:249-61.

111. Palomar T, Chabas A, Bastidas DM, de la Fuente D, Verney-Carron A. Effect of marine aerosols on the alteration of silicate glasses. J Noncryst Solids. 2017:471:328-37

112. Casadio F, Toniolo L. The analysis of polychrome works of art: 40 years of infrared spectroscopic investigations. J Cult Herit. 2001;2:71-8.

113. Low MJD, Baer NS. Application of infrared Fourier transform spectroscopy to problems in conservation. I. General principles. Stud Conserv. 1977;22:116-28

114. Karr C, Kovach JJ. Far-infrared spectroscopy of minerals and inorganics. Appl Spectrosc. 1969:23:219-23.

115. Prati S, Joseph E, Sciutto G, Mazzeo R. New advances in the application of FTIR microscopy and spectroscopy for the characterization of artistic materials. Acc Chem Res. 2010:43:792-801.

116. Mazzocchin GA, Agnoli F, Mazzocchin S, Colpo I. Analysis of pigments from Roman wall paintings found in Vicenza. Talanta. 2003;61:565-72.
117. Bruni S, Cariati F, Casadio F, Toniolo L. Spectrochemical characterization by micro-FTIR spectroscopy of blue pigments in different polychrome works of art. Vib Spectrosc. 1999;20:15-25.

118. Marras S, Pojana G, Ganzerla R, Marcomini A. Study and characterization of mural paintings from XIX Century in a noble Venetian (Italy) palace. Microchem J. 2010;96:397-405.

119. Bikiaris D, Daniilia S, Sotiropoulou S, Katsimbiri O, Pavlidou E, Moutsatsou AP, Chryssoulakis Y. Ochre-differentiation through micro-Raman and micro-FTIR spectroscopies: application on wall paintings at Meteora and Mount Athos, Greece. Spectrochim Acta A. 2000;56:3-18.

120. Franquelo ML, Duran A, Herrera LK, Haro MCJD, Perez-Rodriguez JL. Comparison between micro-Raman and micro-FTIR spectroscopy techniques for the characterization of pigments from Southern Spain Cultural Heritage. J Mol Struct. 2009;924:404-12.

121. Sotiropoulou S, Papliaka ZE, Vaccari L. Micro FTIR imaging for the investigation of deteriorated organic binders in wall painting stratigraphies of different techniques and periods. Microchem J. 2016;124:559-67.

122. Papliaka ZE, Vaccari L, Zanini F, Sotiropoulou S. Improving FTIR imaging speciation of organic compound residues or their degradation products in wall painting samples, by introducing a new thin section preparation strategy based on cyclododecane pre-treatment. Anal Bioanal Chem. 2015;407:5393-403.

123. Dariz P, Schmid T. Ferruginous phases in 19th century lime and cement mortars: a Raman microspectroscopic study. Mater Charact. 2017:129:9-17.

124. Martínez-Martínez J, Pola A, García-Sánchez L, Reyes Agustin G, Osorio Ocampo LS, Macías Vázquez JL, Robles-Camacho J. Building stones used in the architectural heritage of Morelia (México): quarries location, rock durability and stone compatibility in the monument. Environ Earth Sci. 2018;77:167-83

125. Schmid T, Dariz P. Chemical imaging of historical mortars by Raman microscopy. Constr Build Mater. 2016;114:506-16.

126. Arjonilla P, Domínguez-Vidal A, Torre López MJ, Rubio-Domene R, Ayora-Cañada MJ. In situ Raman spectroscopic study of marble capitals in the Alhambra monumental ensemble. Appl Phys A. 2016:122:1014-22.

127. Svorová Pawełkowicz S, Rohanová D, Svora P. Gothic green glazed tile from Malbork Castle: multi-analytical study. Herit Sci. 2017:5:27-43.

128. Morillas H, Maguregui M, Marcaida I, Trebolazabala J, Salcedo I, Madariaga JM. Characterization of the main colonizer and biogenic pigments present in the red biofilm from La Galea Fortress sandstone by means of microscopic observations and Raman imaging. Microchem J. 2015;121:48-55.

129. Gázquez F, Rull F, Sanz-Arranz A, Medina J, Calaforra JM, de las Heras C, Lasheras JA. In situ Raman characterization of minerals and degradation processes in a variety of cultural and geological heritage sites. Spectrochim Acta A. 2017:172:48-57.

130. Ghirardello M, Mosca S, Marti-Rujas J, Nardo L, Burnstock A, Nevin A, Bondani M, Toniolo L, Valentini G, Comelli D. Time-resolved photoluminescence microscopy combined with $\mathrm{X}$-ray analyses and Raman spectroscopy sheds light on the imperfect synthesis of historical cadmium pigments. Anal Chem. 2018;90:10771-9.

131. Edwards H, Gwyer E, Tait J. Fourier transform Raman analysis of paint fragments from biodeteriorated Renaissance frescoes. J Raman Spectrosc. 1997;28:677-84

132. Edwards H, Rull F, Vandenabeele P, Newton E, Moens L, Medina J, Garcia C. Mediaeval pigments in the monastery of San Baudelio, Spain: a Raman spectroscopic analysis. Appl Spectrosc. 2001;55:71-6.

133. Prieto AC, Martínez O, Souto J, Avella M, Guedes A. Study of a tabernacle with a remarkable architectural structure: in situ examination using Raman spectroscopy. J Raman Spectrosc. 2013;44:1156-62.

134. Won-In K, Thongkam Y, Pongkrapan S, Intarasiri S, Thongleurm C, Kamwanna T, Leelawathanasuk T, Dararutana P. Raman spectroscopic study on archaeological glasses in Thailand: ancient Thai Glass. Spectrochim Acta A. 2011:83:231-5.

135. Pineda P, Robador MD, Perez-Rodriguez JL. Characterization and repair measures of the medieval building materials of a Hispanic-Islamic construction. Constr Build Mater. 2013;41:612-33.

136. Smith DC, Barbet A. A preliminary Raman microscopic exploration of pigments in wall paintings in the Roman Tomb discovered at Kertch, Ukraine, in 1891. J Raman Spectrosc. 1999:30:319-24. 
137. Burgio L, Clark RJH. Library of FT-Raman spectra of pigments, minerals, pigment media and varnishes, and supplement to existing library of Raman spectra of pigments with visible excitation. Spectrochim Acta A 2001;57:1491-521.

138. Seaward M, Edwards H. Biological origin of major chemical disturbances on ecclesiastical architecture studied by Fourier transform Raman spectroscopy. J Raman Spectrosc. 1997;28:691-6.

139. Martínez-Arkarazo I, Sarmiento A, Maguregui M, Castro K, Madariaga JM. Portable Raman monitoring of modern cleaning and consolidation operations of artworks on mineral supports. Anal Bioanal Chem. 2010;397:2717-25

140. Herrmann W, Stöckle M, Sand-Hill M, Hübner U, Herrmann M, Obeid R Wullich B, Loch T, Geisel J. The use of portable Raman spectroscopy to identify conservation treatments applied to heritage stone. Spectrosc Lett. 2012;45:146-50.

141. Pérezalonso M, Castro K, Martinezarkarazo I, Angulo M, Olazabal MA, Madariaga JM. Analysis of bulk and inorganic degradation products of stones, mortars and wall paintings by portable Raman microprobe spectroscopy. Anal Bioanal Chem. 2004;379:42-50.

142. Veneranda M, Irazola M, Díez M, Iturregui A, Aramendia J, Castro K Madariaga JM. Raman spectroscopic study of the degradation of a middle age mural painting: the role of agricultural activities. J Raman Spectrosc. 2015;45:1110-8.

143. Duran A, Perez-Rodriguez $J$, Jimenez de Haro MC, Franquelo ML, Robador MD. Analytical study of Roman and Arabic wall paintings in the Patio De Banderas of Reales Alcazares' Palace using nondestructive XRD/XRF and complementary techniques. J Archaeol Sci. 2011;38:2366-77.

144. Garofano I, Duran A, Perez-Rodriguez JL, Robador MD. Natural earth pigments from Roman and Arabic wall paintings revealed by spectroscopic techniques. Spectrosc Lett. 2011:44:560-5.

145. Ortiz R, Ortiz P, Colao F, Fantoni R, Gómez-Morón MA, Vázquez MA. Laser spectroscopy and imaging applications for the study of cultural heritage murals. Constr Build Mater. 2015;98:35-43.

146. Moussa AMA, Kantiranis N, Voudouris KS, Stratis JA, Ali MF, Christaras $V$. The impact of soluble salts on the deterioration of pharaonic and Coptic wall paintings at Al Qurna, Egypt: mineralogy and chemistry. Archaeometry. 2009;51:292-308.

147. Farriss NM, Miller AG, Chase AF. Late maya mural paintings from Quintana Roo, Mexico. J Field Archaeol. 1975:2:5-10.

148. Gulzar S, Wörle M, Burg JP, Chaudhry MN, Joseph E, Reusser E. Characterization of 17th century Mughal tile glazes from Shahdara complex, Lahore-Pakistan. J Cult Herit. 2013;14:174-9.

149. Zucchiatti A, Prati P, Bouquillon A, Giuntini L, Massi M, Migliori A Cagnana A, Roascio S. Characterisation of early medieval frescoes by $\mu$-PIXE, SEM and Raman spectroscopy. Nucl Instrum Methods B. 2004;219-220:20-5

150. Bayerová T. Buddhist wall paintings at Nako monastery, North India: changing of the technology throughout centuries. Stud Conserv. 2018:63:171-88.

151. Bongiorno V, Campodonico S, Caffara R, Piccardo P, Carnasciali MM. Micro-Raman spectroscopy for the characterization of artistic patinas produced on copper-based alloys. J Raman Spectrosc. 2012;43:1617-22.

152. Sansonetti A, Striova J, Biondelli D, Aliatis I, Rampazzi L. Hidden colours in stuccowork damaged by fire: a multi-analytical investigation for revealing the original decorative pattern. J Cult Herit. 2016;10:1055-60.

153. Wang L, Yang L, Zhou W, Yan J, Guo R. Analysis of the techniques and materials of the coloured paintings in the Renshou Hall in the Summer Palace. Anal Methods. 2015;7:5334-7.

154. Perez-Rodriguez JL, Haro MDCJD, Siguenza B, Martinez-Blanes JM. Green pigments of Roman mural paintings from Seville Alcazar. Appl Clay Sci. 2015;116-117:211-9.

155. Coccato A, Bersani A, Coudray A, Sanyova J, Moens L, Vandenabeele $P$. Raman spectroscopy of green minerals and reaction products with an application in cultural heritage research. J Raman Spectrosc 2016:47:1429-43.

156. Derbyshire A, Withnall R. Pigment analysis of portrait miniatures using Raman microscopy. J Raman Spectrosc. 2015;30:185-8.
157. Francesca O, Danilo B, Di LG, Paolo LP Green earths: vibrational and elemental characterization of glauconites, celadonites and historical pigments. J Raman Spectrosc. 2008;39:1066-73.

158. Corradi A, Leonelli C, Veronesi P, Fabbri B, Macchiarola M, Ruffini A, Boschetti C, Santoro S. Ancient glass deterioration in mosaics of Pompeii. Surf Eng. 2013;21:402-25

159. Andrés MS, de la Roja JM, Baonza VG, Sancho N. Verdigris pigment: a mixture of compounds. Input from Raman spectroscopy. J Raman Spectrosc. 2010;41:1468-76

160. Cruz OL, Bueno AG, Flórez VJM, Sánchez-Navas A. A methodology for timing interventions made on the polychrome decorations of the façade of the Palace of King Peter I, the Royal Alcázar of Seville, Spain. J Cult Herit. 2016;20:573-82.

161. Orecchio S. Microanalytical characterization of decorations in handmade ancient floor tiles using inductively coupled plasma optical emission spectrometry (ICP-OES). Microchem J. 2013;108:137-50.

162. Zhang Y, Wang J, Zhang T. Analysis on mural structures and components of the tombs in Liao Dynasty (A.D. 907-A.D. 1125). Spectrosc Lett. 2015;48:732-40

163. Duce C, Ghezzi L, Onor M, Bonaduce I, Colombini MP, Tine MR, Bramant E. Physico-chemical characterization of protein-pigment interactions in tempera paint reconstructions: casein/cinnabar and albumin/cinnabar. Anal Bioanal Chem. 2012;402:2183-93.

164. Frost RL, Edwards HGM, Duong L, Kloprogge JT, Martens WN. Raman spectroscopic and SEM study of cinnabar from Herod's palace and its likely origin. Analyst. 2002;127:293-6.

165. Lei Z, Wu W, Shang G, Wu Y, Wang J. Study on colored pattern pigments of a royal Taoist Temple beside the Forbidden City (Beijing, China). Vib Spectrosc. 2017;92:234-44.

166. Edwards HGM, Farwell DW, Perez FR, Villar SJ. Spanish mediaeval frescoes at Basconcillos del Tozo: a Fourier transform Raman spectroscopic study. J Raman Spectrosc. 1999;30:307-11.

167. Weijun L. Conservation of architectural paintings at Xiaonan Garden, former residence of Weng family in Changshu. Front Archit Res. 2016:5:91-100

168. Cavaleri T, Buscaglia P, Migliorini S, Nervo M, Piccablotto G, Piccirillo A, Pisani M, Puglisi D, Vaudan D, Zucco M. Pictorial materials database: 1200 combinations of pigments, dyes, binders and varnishes designed as a tool for heritage science and conservation. Appl Phys A. 2017:123:419-34.

169. Appolonia L, Vaudan D, Chatel V, Aceto M, Mirti P. Combined use of FORS, XRF and Raman spectroscopy in the study of mural paintings in the Aosta Valley (Italy). Anal Bioanal Chem. 2009;395:2005-13.

170. Thompson $\mathrm{H}, \mathrm{Cooper} \mathrm{M}$. The use of laser cleaning in the conservation of public copper-alloy monuments in the UK. J Archit Conserv. 2010;16:7-24.

171. Sansonetti A, Striova J, Biondelli D, Castellucci EM. Colored grounds of gilt stucco surfaces as analyzed by a combined microscopic, spectroscopic and elemental analytical approach. Anal Bioanal Chem. 2010;397:2667-76

172. Sáez-Pérez MP, Rodríguez-Gordillo J, Durán-Suárez JA. Synthetic white pigments (white titanium and white zinc) in different binding media. Influence of environmental agents. Constr Build Mater. 2016:114:151-61.

173. Zafiropulos V, Balas C, Manousaki A, Marakis Y, Maravelakikalaitzaki P, Melesanaki K, Pouli P, Stratoudaki T, Klein S, Hildenhagen J. Yellowing effect and discoloration of pigments: experimental and theoretical studies. J Cult Herit. 2003;4:249-56.

174. Bianchin S, Casellato U, Favaro M, Vigato PA, Colombini MP, Gautier G. Physico-chemical and analytical studies of the mural paintings at Kariye Museum of Istanbul. J Cult Herit. 2008:9:179-83.

175. Ion R-M, Turcanu-Caruțiu D, Fierăscu R-C, Fierăscu I, Bunghez I-R, lon M-L, Teodorescu S, Vasilievici G, Rădițoiu V. Caoxite-hydroxyapatite composition as consolidating material for the chalk stone from BasarabiMurfatlar churches ensemble. Appl Surf Sci. 2015:358:612-8.

176. Palomar T, Díaz Hidalgo RJ, Vilarigues M. Pigments, vinegar, and blood: interpretation and reproduction of glassy materials from the medieval manuscript H-490. Int J Appl Glass Sci. 2018;9:555-64.

177. Berrie BH, Strumfels Y. Change is permanent: thoughts on the fading of cochineal-based watercolor pigments. Herit Sci. 2017;5:30-9. 
178. Schabbach LM, Marinoski DL, Güths S, Bernardin AM, Fredel MC. Pigmented glazed ceramic roof tiles in Brazil: thermal and optical properties related to solar reflectance index. Sol Energy. 2018;159:113-24.

179. Gherardi F, Colombo A, D'Arienzo M, Di Credico B, Goidanich S, Morazzoni F, Simonutti R, Toniolo L. Efficient self-cleaning treatments for built heritage based on highly photo-active and well-dispersible $\mathrm{TiO}_{2}$ nanocrystals. Microchem J. 2016;126:54-62.

180. La Russa MF, Rovella N, Alvarez de Buergo M, Belfiore CM, Pezzino A, Crisci GM, Ruffolo SA. Nano-TiO 2 coatings for cultural heritage protection: the role of the binder on hydrophobic and self-cleaning efficacy. Prog Ogr Coat. 2016;91:1-8.

181. Meulebroeck W, Wouters H, Nys K, Thienpont H. Authenticity screening of stained glass windows using optical spectroscopy. Sci Rep. 2016;6:37726-36.

182. Ceglia A, Nuyts G, Meulebroeck W, Cagno S, Silvestri A, Zoleo A, Nys K, Janssens $\mathrm{K}$, Thienpont $\mathrm{H}$, Terryn $\mathrm{H}$. Iron speciation in soda-lime-silica glass: a comparison of XANES and UV-vis-NIR spectroscopy. J Anal Atom Spectrom. 2015;30:1552-61.

183. Vilarigues M, Fernandes P, Alves LC, Silva RCD. Stained glasses under the nuclear microprobe: a window into history. Nucl Instrum Methods B. 2009;267:2260-4.

184. Dei L, Baglioni P, Sarti G, Ferroni E. Aging effects on ammonium carbonate/acetone solutions and cleaning of works of art. Stud Conserv. 1996:41:9-18.

185. Rodriguez-Navarro C, Ruiz-Agudo E, Burgos-Cara A, Elert K, Hansen EF. Crystallization and colloidal stabilization of $\mathrm{Ca}(\mathrm{OH})_{2}$ in the presence of nopal juice (Opuntia ficus indica): implications in architectural heritage conservation. Langmuir. 2017;33:10936-50.

186. Edreira MC, Feliu MJ, Fernández-Lorenzo C, Martín J. Spectroscopic study of egyptian blue mixed with other pigments. Helv Chim Acta. 2003:86:29-49.

187. Edreira MC, Feliu MJ, Fernández-Lorenzo C, Martín J. Roman wall paintings characterization from Cripta del Museo and Alcazaba in Mérida (Spain): Chromatic, energy dispersive $\mathrm{X}$-ray flurescence spectroscopic, $X$-ray diffraction and Fourier transform infrared spectroscopic analysis. Anal Chim Acta. 2001:434:331-45.

188. Edreira MC, Feliu MJ, Fernández-Lorenzo C, Martín J. Spectroscopic analysis of roman wall paintings from Casa del Mitreo in Emerita Augusta, Mérida, Spain. Talanta. 2003;59:1117-39.

189. Feliu MJ, Edreira MC, Martin J. Application of physical-chemical analytical techniques in the study of ancient ceramics. Anal Chim Acta. 2004:502:241-50.

190. Sotiropoulou S, Danilia S, Miliani C, Rosi F, Cartechini L, PapanikolaBakirtzis D. Microanalytical investigation of degradation issues in Byzantine wall paintings. Appl Phys A. 2008;92:143-50.

191. Veneranda M, Fdez-Ortiz de Vallejuelo S, Prieto-Taboada N, Maguregui M, Marcaida I, Morillas H, Martellone A, de Nigris B, Osanna M, Castro K, Madariaga JM. In-situ multi-analytical characterization of original and decay materials from unique wall mirrors in the House of Gilded Cupids, Pompeii. Herit Sci. 2018;6:40-51.

192. Gaona I, Lucena P, Moros J, Fortes FJ, Guirado S, Serrano J, Laserna JJ. Evaluating the use of standoff LIBS in architectural heritage: surveying the Cathedral of Málaga. J Anal Atom Spectrom. 2013;28:810-20.

193. Senesi GS, Campanella B, Grifoni E, Legnaioli S, Lorenzetti G, Pagnotta S, Poggialini F, Palleschi V, De Pascale O. Elemental and mineralogical imaging of a weathered limestone rock by double-pulse micro-laserinduced breakdown spectroscopy. Spectrochim Acta B. 2018;143:91-7.

194. Toschi F, Paladini A, Colosi F, Cafarelli P, Valentini V, Falconieri M, Gagliardi S, Santoro P. A multi-technique approach for the characterization of Roman mural paintings. Appl Surf Sci. 2013;284:291-6.

195. Maravelaki-Kalaitzaki P, Anglos D, Kilikoglou V, Zafiropulos V. Compositional characterization of encrustation on marble with laser induced breakdown spectroscopy. Spectrochim Acta B. 2001;56:887-903.

196. Morillas H, García-Florentino C, Marcaida I, Maguregui M, Arana G, Silva LFO, Madariaga JM. In-situ analytical study of bricks exposed to marine environment using hand-held X-ray fluorescence spectrometry and related laboratory techniques. Spectrochim Acta B. 2018;146:28-35.

197. Syvilay D, Texier A, Arles A, Gratuze B, Wilkie-Chancellier N, Martinez L, Serfaty S, Detalle V. Trace elements quantification of lead based roof sheets of historical monuments by laser induced breakdown spectroscopy. Spectrochim Acta B. 2014;103-104:34-42.
198. Brysbaert A, Melessanaki K, Anglos D. Pigment analysis in Bronze Age Aegean and Eastern Mediterranean painted plaster by laser-induced breakdown spectroscopy (LIBS). J Archaeol Sci. 2006;33:1095-104.

199. Filippakis SE, Perdikatsis B, Paradellis T. An analysis of blue pigments from the Greek Bronze Age. Stud Conserv. 1976;21:143-53.

200. Hradil D, Grygar T, Hradilová J, Bezdička P. Clay and iron oxide pigments in the history of painting. Appl Clay Sci. 2003;22:223-36.

201. Anglos D. Laser-induced break-down spectroscopy in art and archaeology. Appl Spectrosc. 2001;55:186-205.

202. Caneve L, Diamanti A, Grimaldi F, Palleschi G, Spizzichino V, Valentini F. Analysis of fresco by laser induced breakdown spectroscopy. Spectrochim Acta B. 2010;65:702-6.

203. Klein S, Stratoudaki T, Zafiropulos V, Hildenhagen J, Dickmann K, Lehmkuhl T. Laser-induced breakdown spectroscopy for on-line control of laser cleaning of sandstone and stained glass. Appl Phys A. 1999:69:441-4.

204. Vandenabeele P. Raman spectroscopy in art and archaeology. J Raman Spectrosc. 2004;35:607-9.

205. Trusso S. Laser induced breakdown spectroscopy for the analysis of archaeological dyes from Licata (Sicily). Radiat Effects Defects Solids. 2008;163:535-43.

206. Syvilay D, Texier A, Arles A, Gratuze B, Wilkie-Chancellier N, Martinez $L$, Serfaty S, Detalle V. Trace element quantification of lead based roof sheets of historical monuments by laser induced breakdown spectroscopy. Spectrochim Acta B. 2015;103:34-42.

207. Ramil A, López AJ, Yáñez A. Application of artificial neural networks for the rapid classification of archaeological ceramics by means of laser induced breakdown spectroscopy (LIBS). Appl Phys A. 2008;92:197-202.

208. Spizzichino V, Fantoni R. Laser induced breakdown spectroscopy in archeometry: a review of its application and future perspectives. Spectrochim Acta B. 2014:99:201-9.

209. Moropoulou A, Bakolas A, Anagnostopoulou S. Composite materials in ancient structures. Cement Concrete Comp. 2005;27:295-300.

210. Lanas J, Alvarez-Galindo Jl. Masonry repair lime-based mortars: factors affecting the mechanical behavior. Cement Concrete Res. 2003:33:1867-76

211. Moropoulou A, Bakolas A, Bisbikou K. Characterization of ancient, byzantine and later historic mortars by thermal and $\mathrm{X}$-ray diffraction techniques. Thermochim Acta. 1995;269-270:779-95.

212. Moropoulou A, Bakolas A, Aggelakopoulou E. The effects of limestone characteristics and calcination temperature to the reactivity of the quicklime. Cement Concrete Res. 2001;31:633-9.

213. Sanjurjo Sánchez J, Alves CAS, Vidal Romaní JR, Fernández Mosquera D. Origin of gypsum-rich coatings on historic buildings. Water Air Soil Pollut. 2009;204:53-68.

214. Sanjurjo Sánchez J, Vidal Romaní JR, Fernández Mosquera D, Alves CA. Study of origin and composition of coatings in a monument built with granitic rocks, by SEM, XRD, XRF and DTA-TGA. X-Ray Spectrom. 2008:37:346-54.

215. Ghedini N, Sabbioni C, Pantani M. Thermal analysis in cultural heritage safeguard: an application. Thermochim Acta. 2003:406:105-13.

216. Riontino C, Sabbioni C, Ghedini N, Zappiaa G, Gobbi G, Favoni O. Evaluation of atmospheric deposition on historic buildings by combined thermal analysis and combustion techniques. Thermochim Acta. 1998:321:215-22.

217. Ozga I, Bonazza A, Bernardi E, Tittarelli F, Favoni O, Ghedini N, Morselli L, Sabbioni C. Diagnosis of surface damage induced by air pollution on 20th-century concrete buildings. Atmos Environ. 2011;45:4986-95.

218. Bakolas A, Biscontin G, Contardi V, Franceschi E, Moropoulou A, Palazzi $D$, Zendri E. Thermoanalytical research on traditional mortars in venice. Thermochim Acta. 1995;269-270:817-28.

219. Velosa AL, Veiga R, Coroado J, Ferreira VM, Rocha F. Characterization of ancient pozzolanic mortars from Roman times to the 19th century: compatibility issues of new mortars with substrates and ancient mortars. Berlin: Springer; 2010.

220. Schueremans L, Cizer Ö, Janssens E, Serré G, Balen KV. Characterization of repair mortars for the assessment of their compatibility in restoration projects: research and practice. Constr Build Mater. 2011;25:4338-50.

221. Moropoulou A, Bakolas A, Bisbikou K. Investigation of the technology of historic mortars. J Cult Herit. 2000;1:45-58. 
222. Özkaya ÖA, Böke H. Properties of Roman bricks and mortars used in Serapis temple in the city of Pergamon. Mater Charact. 2009;60:995-1000.

223. Zeng Y, Zhang B, Liang X. A case study and mechanism investigation of typical mortars used on ancient architecture in China. Thermochim Acta. 2008:473:1-6.

224. Sabbioni C, Bonazza A, Zappia G. Damage on hydraulic mortars: the Venice Arsenal. J Cult Herit. 2002;3:83-8.

225. Elert K, Rodriguez-Navarro C, Pardo ES, Hansen E, Cazalla O. Lime mortars for the conservation of historic buildings. Stud Conserv. 2002;47:62-75.

226. Bultrini G, Fragala I, Ingo GM, Lanza G. Minero-petrographic, thermal and microchemical investigation of historical mortars used in Catania (Sicily) during the XVII century A.D. Appl Phys A. 2006;83:529-36.

227. Maravelaki-Kalaitzaki P, Bakolas A, Moropoulou A. Physico-chemical study of Cretan ancient mortars. Cement Concrete Res. 2003;33:651-61.

228. Chadwick AV, Berko A, Schofield EJ, Jones AM, Mosselmans JFW, Smith AD. Application of microfocus X-Ray beams from synchrotrons in heritage conservation. Int J Archit Herit. 2012;6:228-58.

229. Franzini $M$, Leoni L, Lezzerini M. A procedure for determining the chemical composition of binder and aggregate in ancient mortars: its application to mortars from some medieval buildings in Pisa. J Cult Herit. 2000;1:365-73.

230. Zedef V, Kocak K, Doyen A, Ozsen H, Kekec B. Effect of salt crystallization on stones of historical buildings and monuments, Konya, Central Turkey. Build Environ. 2007;42:1453-7.

231. Colao F, Fantoni R, Ortiz P, Vazquez MA, Martin JM, Ortiz R, Idris N. Quarry identification of historical building materials by means of laser induced breakdown spectroscopy, X-ray fluorescence and chemometric analysis. Spectrochim Acta B. 2010;65:688-94.

232. Götze J, Siedel H. A complex investigation of building sandstones from Saxony (Germany). Mater Charact. 2007;58:1082-94.

233. Gianoncelli A, Castaing J, Ortega L, Dooryhée E, Salomon J, Walter P, Hodeau JL, Bordet P. A portable instrument for in situ determination of the chemical and phase compositions of cultural heritage objects. X-Ray Spectrom. 2010;37:418-23.

234. Madariaga JM, Maguregui M, Knuutinen U, Castro K, Martinez-Arkarazo I, Giakoumaki A, Pitarch A. In situ analysis with portable Raman and EDXRF spectrometers for the diagnosis of the formation of efflorescence on walls and wall paintings of the Insula IX 3 (Pompeii, Italy). J Raman Spectrosc. 2015;45:1059-67.

235. Aquilia E, Barone G, Crupi V, Longo F, Majolino D, Mazzoleni P, Venuti V. Multi-technique characterization of ancient findings from Gela (Sicily, Italy). J Anal Atom Spectrom. 2011;26:977-83.

236. Gómez-Laserna O, Arrizabalaga I, Prieto-Taboada N, Olazabal MÁ, Arana G, Madariaga JM. In situ DRIFT, Raman, and XRF implementation in a multianalytical methodology to diagnose the impact suffered by built heritage in urban atmospheres. Anal Bioanal Chem. 2015;407:5635-47.

237. Creagh DC. The characterization of artefacts of cultural heritage significance using physical techniques. Radiat Phys Chem. 2005;74:426-42.

238. Mounier A, Le Bourdon G, Aupetit C, Belin C, Servant L, Lazare S. Hyperspectral imaging, spectrofluorimetry, FORS and XRF for the noninvasive study of medieval miniatures materials. Herit Sci. 2014:2:24-36.

239. Figueiredo MO, Silva TP, Veiga JP. Analysis of degradation phenomena in ancient, traditional and improved building materials of historical monuments. Appl Phys A. 2008;92:151-4.

240. Herrera LK, Cotte M, Haro MCJD, Duran A, Justo A, Perez-Rodriguez JL. Characterization of iron oxide-based pigments by synchrotron-based micro X-ray diffraction. Appl Clay Sci. 2008;42:57-62.

241. Cnudde V, Silversmit G, Boone M, Dewanckele J, Samber BD, Schoonjans T, Loo DV, Witte YD, Elburg M, Vincze L. Multi-disciplinary characterisation of a sandstone surface crust. Sci Total Environ. 2009;407:5417-27.

242. Madariaga JM. Analytical chemistry in the field of cultural heritage. Anal Methods. 2015;7:4848-76.

243. Xu L, Ma X, Zhang B, Zhang Q, Zhao P. Multi-analytical studies of the lime mortars from the Yanxi Hall in the Yangxin Palace of the Palace Museum (Beijing). Archaeometry. 2018;1:1-18.

244. Cizer Ö, Ruiz-Agudo E, Rodriguez-Navarro C. Kinetic effect of carbonic anhydrase enzyme on the carbonation reaction of lime mortar. Int J Archit Herit. 2018;12:779-89.
245. Aloiz E, Douglas JG, Nagel A. Painted plaster and glazed brick fragments from Achaemenid Pasargadae and Persepolis, Iran. Herit Sci. 2016:4:3-13.

246. Shu CX, Cantisani E, Fratini F, Rasmussen KL, Rovero L, Stipo G, Vettori S. China's brick history and conservation: laboratory results of Shanghai samples from 19th to 20th century. Constr Build Mater. 2017;151:789-800.

247. Gherardi F, Gulotta D, Goidanich S, Colombo A, Toniolo L. On-site monitoring of the performance of innovative treatments for marble conservation in architectural heritage. Herit Sci. 2017;5:4-19.

248. Molina E, Rueda-Quero L, Benavente D, Burgos-Cara A, Ruiz-Agudo E, Cultrone G. Gypsum crust as a source of calcium for the consolidation of carbonate stones using a calcium phosphate-based consolidant. Constr Build Mater. 2017;143:298-311.

249. Ercoli L, Rizzo G, Algozzini G. Petrography and decay of a marly limestone in the cloister of a medieval cathedral in Sicily. Environ Geol. 2004;46:414-20.

250. Warscheid T, Braams J. Biodeterioration of stone: a review. Int Biodeterior Biodegrad. 2000;46:343-68.

251. Ghedini N, Gobbi G, Sabbioni C, Zappia G. Determination of elemental and organic carbon on damaged stone monuments. Atmos Environ. 2000;34:4383-91.

252. Corvo F, Reyes J, Valdes C, Villaseñor F, Cuesta O, Aguilar D, Quintana P. Influence of air pollution and humidity on limestone materials degradation in historical buildings located in cities under tropical coastal climates. Water Air Soil Pollut. 2010;205:359-75.

253. Lombillo I, Thomas C, Villegas L, Fernández-Álvarez JP, NorambuenaContreras J. Mechanical characterization of rubble stone masonry walls using non and minor destructive tests. Constr Build Mater. 2013;43:266-77.

254. Ostrooumov M. A Raman, IR and XRD analysis of the deterioration on historical monuments: case study from Mexico. Spectrochim Acta A. 2009;73:498-504.

255. Ventolà L, Vendrell M, Giraldez P, Merino L. Traditional organic additives improve lime mortars: new old materials for restoration and building natural stone fabrics. Constr Build Mater. 2011;25:3313-8.

256. Pedrazzani R, Alessandri I, Bontempi E, Cappitelli F, Cianci M, Pantos E, Toniolo L, Depero LE. Study of sulphation of Candoglia marble by means of micro X-ray diffraction experiments. Appl Phys A. 2006:83:689-94.

257. Grousset S, Kergourlay F, Neff D, Foy E, Gallias JL, Reguer S, Noumowe A, Dillmann P. In situ monitoring of corrosion processes by coupled micro-XRF/micro-XRD mapping to understand the degradation mechanisms of reinforcing bars in hydraulic binders from historic monuments. J Anal Atom Spectrom. 2015;30:721-9.

258. Coccato A, Moens L, Vandenabeele P. On the stability of mediaeval inorganic pigments: a literature review of the effect of climate, material selection, biological activity, analysis and conservation treatments. Herit Sci. 2017;5:12-37.

259. Fermo P, Cappelletti G, Cozzi N, Padeletti G, Kaciulis S, Brucale M, Merlini M. Hydrophobizing coatings for cultural heritage. A detailed study of resin/stone surface interaction. Appl Phys A. 2014;116:341-8.

260. Rowland $\mathrm{CH}$, Abdulsattar $\mathrm{AH}$. Equilibriums for magnesia wet scrubbing of gases containing sulfur dioxide. Environ Sci Technol. 1978;12:1158-62.

261. Liu Y, Bisson TM, Yang $H, X u$ Z. Recent developments in novel sorbents for flue gas clean up. Fuel Process Technol. 2010;91:1175-97.

262. Przepiórski J, Czyżewski A, Kapica J, Moszyński D, Grzmil B, Tryba B, Mozia S, Morawski AW. Low temperature removal of $\mathrm{SO}_{2}$ traces from air by MgO-loaded porous carbons. Chem Eng J. 2012;191:147-53.

263. Zhu T, Chen J, Hui R, Gong L, Zhang W, Zhang Y. Spectroscopic characterization of the architectural painting from the Cizhong Catholic Church of Yunnan Province, China. Anal Lett. 2013;46:2253-64.

264. Oscarson DW, Huang PM, Defosse C, Herbillon A. Oxidative power of $\mathrm{Mn}(\mathrm{IV})$ and $\mathrm{Fe}(\mathrm{III})$ oxides with respect to $\mathrm{As}(\mathrm{III})$ in terrestrial and aquatic environments. Nature. 1981;291:50-1.

265. Maria SA, Fausto L, Andrea M, Pia SM, Laurenzi TM. XPS characterization of (copper-based) coloured stains formed on limestone surfaces of outdoor Roman monuments. Chem Cent J. 2012;6:1-13. 
266. Badía-Romano L, Rubín J, Bartolomé F, Magén C, Bartolomé J, Varnakov SN, Ovchinnikov SG, Rubio-Zuazo J, Castro GR. Morphology of the asymmetric iron-silicon interfaces. J Alloy Compd. 2015;627:136-45

267. Bakolas A, Bertoncello R, Biscontin G, Glisenti A, Moropoulou A, Zendri ETE. Chemico-physical interactions among the constituents of historical walls in Venice. MRS Proc. 1995;352:771-7.

268. Gilham RJJ, Spencer SJ, Butterfield D, Seah MP, Quincey PG. On the applicability of XPS for quantitative total organic and elemental carbon analysis of airborne particulate matter. Atmos Environ. 2008;42:3888-91.

269. Atzei D, Rossi A. Quantitative surface analysis of urban airborne particles by X-ray photoelectron spectroscopy. Ann Chim. 2004;94:123-33.

270. Fermo P, Turrion RG, Rosa M, Omegna A. A new approach to assess the chemical composition of powder deposits damaging the stone surfaces of historical monuments. Environ Sci Pollut R. 2015;22:1-9.

271. Rehr JJ, Ankudinov AL. Progress in the theory and interpretation of XANES. Coordin Chem Rev. 2005;249:131-40.

272. Walter P, Variola A, Zomer F. A new high quality X-ray source for cultural heritage. CR Phys. 2009;10:676-90.

273. Lytle FW. The EXAFS family tree: a personal history of the development of extended X-ray absorption fine structure. I Synchrotron Radiat. 1999:6:123-34.

274. Marco JF, Gancedo JR, Gracia M, Gautier UL, Rios E, Berry FJ. Characterization of the nickel cobaltite, $\mathrm{NiCO}_{2} \mathrm{O}_{4}$, prepared by several methods: an XRD, XANES, EXAFS, and XPS study. J Solid State Chem. 2000;153:74-81.

275. Janssens K, NolfWD, Snickt GVD, Vincze L, Vekemans B, Terzano R, Brenker FE. Recent trends in quantitative aspects of microscopic X-ray fluorescence analysis. TRAC Trend Anal Chem. 2010;29:464-78.

276. Bertrand L, Robinet L, Thoury M, Janssens K, Cohen SX, Schöder S. Cultural heritage and archaeology materials studied by synchrotron spectroscopy and imaging. Appl Phys A. 2012:106:377-96.

277. Cotte M, Metrich N, Moscato A, Gratziu C, Bertagnini A. Blackening of pompeian cinnabar paintings: X-ray microspectroscopy analysis. Anal Chem. 2006;78:7484-92.

278. Quartieri S, Triscari M, Sabatino G, Boscherini F, Sani A. Fe and Mn K-edge XANES study of ancient Roman glasses. Eur J Mineral. 2002;14:749-56.

279. Farges F, Chalmin E, Vignaud C, Pallotfrossard I, Susini J, Bargar J, Menu M. Archeological applications of XAFS: prehistorical paintings and medieval glasses. Phys Scripta. 2006;2005:885-7.

280. Farges F, Etcheverry MP, Scheidegger A, Grolimund D. Speciation and weathering of copper in "copper red ruby" medieval flashed glasses from the Tours cathedral (XIII century). Appl Geochem. 2006;21:1715-31.

281. Cotte M, Susini J, Dik J, Janssens K. Synchrotron-based X-ray absorption spectroscopy for art conservation: looking back and looking forward. Acc Chem Res. 2010:43:705-14.

282. Cotte M, Susini J, Solé VA, Taniguchi Y, Chillida J, Checroun E, Walter P. Applications of synchrotron-based micro-imaging techniques to the chemical analysis of ancient paintings. J Anal Atom Spectrom. 2008:23:820-8.

283. Walker RA, Wilson K, Lee AF, Woodford J, Grassian VH, Baltrusaitis J, Rubasinghege G, Cibin G, Dent A. Preservation of York Minster historic limestone by hydrophobic surface coatings. Sci Rep. 2012;2:880-5

284. Hormes J, Xiao Q, Hu Y, Bläuer C, Diekamp A, Goll J, Bovenkamp GL. Mortar samples from the Abbey of Saint John at Müstair: a combined spatially resolved X-ray fluorescence and X-ray absorption (XANES) study. J Anal Atom Spectrom. 2015;30:702-6.

285. Monnier J, Réguer S, Vantelon D, Dillmann P, Neff D, Guillot I. X-rays absorption study on medieval corrosion layers for the understanding of very long-term indoor atmospheric iron corrosion. Appl Phys A. 2010;99:399-406.

286. Monnier J, Legrand L, Bellot-Gurlet L, Foy E, Reguer S, Rocca E, Dillmann P, Neff D, Mirambet F, Perrin S, Guillot I. Study of archaeological artefacts to refine the model of iron long-term indoor atmospheric corrosion. J Nucl Mater. 2008:379:105-11.

287. Monnier J, Vantelon D, Reguer S, Dillmann P. X-ray absorption spectroscopy study of the various forms of phosphorus in ancient iron samples. J Anal Atom Spectrom. 2011;26:885-91.
288. Stuart BH, Thomas PS. Pigment characterisation in Australian rock art: a review of modern instrumental methods of analysis. Herit Sci. 2017:5:10-6.

289. Morillas H, Maguregui M, Bastante J, Huallparimachi G, Marcaida I, García-Florentino C, Astete F, Madariaga JM. Characterization of the Inkaterra rock shelter paintings exposed to tropical climate (Machupicchu, Peru). Microchem J. 2018:137:422-8.

290. Coutinho ML, Veiga JP, Alves LC, Mirão J, Dias L, Lima AM, Muralha VS, Macedo MF. Characterization of the glaze and in-glaze pigments of the nineteenth-century relief tiles from the Pena National Palace, Sintra, Portugal. Appl Phys A. 2016;122:696-706.

291. Neri E, Biron I, Verità M. New insights into Byzantine glass technology from loose mosaic tesserae from Hierapolis (Turkey): PIXE/PIGE and EPMA analyses. Archaeol Anthrop Sci. 2018;10:1751-68.

292. Coutinho I, Medici T, Alves LC, Gratuze B, Vilarigues M. Provenance studies of 18th century potassium-rich archaeological glass from Portugal. $J$ Archaeol Sci Rep. 2017;13:185-98.

293. Lindroos A, Ranta H, Heinemeier J, Lill JO. 14C chronology of the oldest Scandinavian church in use. An AMS/PIXE study of lime lump carbonate in the mortar. Nucl Instrum Methods B. 2014:331:220-4.

294. Garofano I, Robador MD, Duran A. Materials characteristics of Roman and Arabic mortars and stuccoes from the Patio De Banderas in the real Alcazar of Seville (Spain). Archaeometry. 2013;56:541-61.

295. Swann CP, Mcgovern PE, Fleming SJ. Recent applications of PIXE spectrometry in archaeology part II observations on early glassmaking in the Near East. Nucl Instrum Methods B. 1993;75:445-9.

296. Wedepohl KH, Simon K, Kronz A. Data on 61 chemical elements for the characterization of three major glass compositions in Late Antiquity and the Middle Ages. Archaeometry. 2011;53:81-102.

297. Roascio S, Zucchiatti A, Prati P, Cagnana A. Study of the pigments in medieval polychrome architectural elements of "Veneto-Byzantine" style. J Cult Herit. 2002;3:289-97.

298. Absil J, Garnir HP, Strivay D, Oger C, Weber G. Study of color centers induced by PIXE irradiation. Nucl Instrum Methods B. 2002;198:90-7.

299. Enguita O, Calderón T, Fernández MT. Damage induced by proton irradiation in carbonate based natural painting pigments. Nucl Instrum Methods B. 2004;219:53-6.

300. Nava S, Becherini F, Bernardi A, Bonazza A, Chiari M, García-Orellana I, Lucarelli F, Ludwig N, Migliori A, Sabbioni C, Udisti R, Valli G, Vecchi R. An integrated approach to assess air pollution threats to cultural heritage in a semi-confined environment: the case study of Michelozzo's Courtyard in Florence (Italy). Sci Total Environ. 2010;408:1403-13.

301. Camuffo D, Brimblecombe P, Van GR, Busse HJ, Sturaro G, Valentino A, Bernardi A, Blades N, Shooter D, De BL. Indoor air quality at the Correr Museum, Venice, Italy. Sci Total Environ. 1999;236:135-52.

302. Sabbioni C, Zappia G. Atmospheric-derived element tracers on damaged stone. Sci Total Environ. 1992;126:35-48.

303. Costa TG, Richter FA, Castro ET, Gonçalves S, Spudeit DA, Micke GA. Elemental identification of blue paintings traces present in historic cemeteries in the São Martinho region, southern Brazil. J Mol Struct. 2018;1155:434-42.

304. Farkas O, Siegesmund S, Licha T, Török Á. Geochemical and mineralogical composition of black weathering crusts on limestones from seven different European countries. Environ Earth Sci. 2018;77:211-31.

305. La Russa MF, Fermo P, Comite V, Belfiore CM, Barca D, Cerioni A, De Santis M, Barbagallo LF, Ricca M, Ruffolo SA. The Oceanus statue of the Fontana di Trevi (Rome): the analysis of black crust as a tool to investigate the urban air pollution and its impact on the stone degradation. Sci Total Environ. 2017;593-594:297-309.

306. Arjonilla P, Domínguez-Vidal A, Correa-Gómez E, Rubio-Domene R, Lluveras-Tenorio A, Ayora-Cañada MJ, Colombini MP. Characterization of organic materials in the decoration of ornamental structures in the Alhambra monumental ensemble using gas-chromatography/mass spectrometry (GC/MS). Microchem J. 2018;140:14-23.

307. Degano I, Tognotti P, Kunzelman D, Modugno F. HPLC-DAD and HPLCESI-Q-TOF characterisation of early 20th century lake and organic pigments from Lefranc archives. Herit Sci. 2017;5:7-22. 
308. Martínez-Arkarazo I, Angulo M, Bartolomé L, Etxebarria N, Olazabal MA, Madariaga JM. An integrated analytical approach to diagnose the conservation state of building materials of a palace house in the metropolitan Bilbao (Basque Country, North of Spain). Anal Chim Acta. 2007:584:350-9.

309. Colombini MP, Andreotti A, Bonaduce I, Modugno F, Ribechini E. Analytical strategies for characterizing organic paint media using gas chromatography/mass spectrometry. Acc Chem Res. 2010;43:715-27.

310. Bonaduce I, Colombini MP. Gas chromatography/mass spectrometry for the characterization of organic materials in frescoes of the Momumental Cemetery of Pisa (Italy). Rapid Commun Mass Spectrom. 2003;17:2523-7.

311. Samide MJ, Liggett MC, Mill J, Smith GD. Relating volatiles analysis by GC-MS to oddy test performance for determining the suitability of museum construction materials. Herit Sci. 2018;6:47-57.

312. Lluveras A, Bonaduce I, Andreotti A, Colombini MP. GC/MS analytical procedure for the characterization of glycerolipids, natural waxes, terpenoid resins, proteinaceous and polysaccharide materials in the same paint microsample avoiding interferences from inorganic media. Anal Chem. 2010;82:376-86.

313. Lluveras-Tenorio A, Mazurek J, Restivo A, Colombini MP, Bonaduce I. Analysis of plant gums and saccharide materials in paint samples: comparison of GC-MS analytical procedures and databases. Chem Cent J. 2012;6:1-16.

314. Gautier G, Colombini MP. GC-MS identification of proteins in wall painting samples: a fast clean-up procedure to remove copper-based pigment interferences. Talanta. 2007;73:95-102.

315. Bonaduce I, Cito M, Colombini MP. The development of a gas chromatographic-mass spectrometric analytical procedure for the determination of lipids, proteins and resins in the same paint microsample avoiding interferences from inorganic media. J Chromatogr A. 2009;1216:5931-9.

316. Colombini MP, Modugno F. Characterisation of proteinaceous binders in artistic paintings by chromatographic techniques. J Sep Sci. 2004:27:147-60

317. Hynek R, Kuckova S, Hradilova J, Kodicek M. Matrix-assisted laser desorption/ionization time-of-flight mass spectrometry as a tool for fast identification of protein binders in color layers of paintings. Rapid Commun Mass Spectom. 2004;18:1896-900.

318. Kuckova S, Crhova M, Vankova L, Hnizda A, Hynek R, Kodicek M. Towards proteomic analysis of milk proteins in historical building materials. Int J Mass Spectrom. 2009;284:42-6.

319. Szostek B, Orska-Gawrys J, Surowiec I, Trojanowicz M. Investigation of natural dyes occurring in historical Coptic textiles by high-performance liquid chromatography with UV-Vis and mass spectrometric detection. J Chromatogr A. 2003:1012:179-92.

320. And XZ, Laursen RA. Development of mild extraction methods for the analysis of natural dyes in textiles of historical interest using LC-diode array detector-MS. Anal Chem. 2005;77:2022-5.

321. Pawlak K, Puchalska M, Miszczak A, Rosłoniec E, Jarosz M. Blue natural organic dyestuffs-from textile dyeing to mural painting. Separation and characterization of coloring matters present in elderberry, logwood and indigo. J Mass Spectrom. 2006:41:613-22.

322. Rosenberg E. Characterisation of historical organic dyestuffs by liquid chromatography-mass spectrometry. Anal Bioanal Chem. 2008;391:33-57

323. Lee JS, Kim DH, Liu KH, Oh TK, Lee CH. Identification of flavonoids using liquid chromatography with electrospray ionization and ion trap tandem mass spectrometry with an MS/MS library. Rapid Commun Mass Spectom. 2005;19:3539-48

324. Ostrowski SG, Bell CTV, Winograd N, Ewing AG. Mass spectrometric imaging of highly curved membranes during tetrahymena mating. Science. 2004;305:71-3.

325. Altelaar AFM, Minnen JV, Jiménez CR, Heeren RMA, Piersma SR, Chem A. Direct molecular imaging of Lymnaea stagnalis nervous tissue at subcellular spatial resolution by mass spectrometry. Anal Chem. 2005;77:735-41.

326. Hughes MK, Milsom SJ, Leggett PA. Sapwood estimates in the interpretation of tree-ring dates. J Archaeol Sci. 1981;8:381-90.

\section{Publisher's Note}

Springer Nature remains neutral with regard to jurisdictional claims in published maps and institutional affiliations.

\section{Submit your manuscript to a SpringerOpen ${ }^{\circ}$ journal and benefit from:}

- Convenient online submission

- Rigorous peer review

- Open access: articles freely available online

- High visibility within the field

Retaining the copyright to your article

Submit your next manuscript at springeropen.com 